Fabricio Rodrigues Lapolli

\title{
The South Atlantic Current Revisited: Description and Mesoscale Dynamics
}

Thesis submitted to the Instituto Oceanográfico of Universidade of São Paulo in partial fullfillment of the requirements for the degree of Master of Sciences, Oceanography Program, Physical Oceanography area.

Advisor: Prof. Dr. Ilson Carlos Almeida da

Silveira

Co-Advisor: Prof. Dr. Paulo Henrique Rezende Calil 


\section{Universidade de São Paulo INSTITUTO OCEANOGRÁFICO}

\section{The South Atlantic Current Revisited: Description and Mesoscale Dynamics}

by

Fabrício Rodrigues Lapolli

\section{Versão Corrigida}

Thesis submitted to the Instituto Oceanográfico of Universidade of São Paulo in partial fullfillment of the requirements for the degree of Master of Sciences, Oceanography Program, Physical Oceanography area.

Evaluated in

Prof. Dr.

Prof. Dr.

Prof. Dr. 


\section{Acknowledgements}

I would to express my great appreciation to my advisor Professor Ilson C. A. da Silveira. His insatiable hunger for knowledge and perfection allowed me to gather an invaluable experience and skill from these two years of $\mathrm{MsC}$ at the Instituto Oceanografico of Universidade of Sao Paulo. Although he not always agreed, but always supported my final decisions.

I would also like to offer my special thanks to my coadvisor Professor Paulo H. R. Calil from the Instituto de Oceanografia (IO) of Universidade Federal do Rio Grande (FURG), whose help not only allowed me to achieve the MsC program, but also perfected my critical thinking as a way to draw better conclusions on my recent scientific career. His blunt, yet clear advisement was, in a way, reflected on this work.

I am also particularly grateful for the assistance given by Prossefor Pedro Peixoto of Instituto de Matematica e Estatistica (IME) of USP. His advanced mathematical knowledge helped me develop the model given in this dissertation. There is not a doubt that without his help this model would not have achieve my expectations. I also hope we are able to maintain future work relationship.

I also wish to acknowledge the help provided by Professor Wandrey Watanabe, Master lury Souza, Vadim Harlamov, Dante Napolitano, Master Dalton Sasaki, that not only provided me with sanity checks, but also indubitably were part of the work performed in this dissertation. Their knowledge upon various subjects also gave me a sense humility.

I express my gratitude aswell to my classmates and coleagues, Felipe Vilela, Pedro Walfir Souza Filho, Caique Dias Luko, Caue Zimberger Lazaneo, Laura Sobral Verona, Marina Noro, and Paula Birocchi. These friends surely helped me to relief the stress by also sharing their most stressfull moments in the academia. So I feel as we traverse alongside these moments.

My also deep thanks to the professors who broaden my skills through their lectures: Professor Olga Sato, Professor Belmiro Castro, and Professor Paulo Polito. Their hard working 
lectures and pursuit for a better quality education is something that I will ever hold true.

I would also like to thank my newly made friends from São Paulo: Renato Guimarães, Mateus Cortezi, Matheus Chuqui, Giulia Campos, and Pedro Marone were part of my memories while experiencing this new universe called São Paulo. To them I hold my most heartfelt thank you.

Lastly, I would like to thank the following projects and companies. The Coordenação de Aperfeiçoamento Pessoal de Nível Superior (CAPES) for funding my research in one of the state-of-the-art latin american universities and also the project Rede de Estudos da Corrente do Brasil na Margem Continental Sudeste-Sul (REMARSUL), that provided our laboratory the necessary infracstructure for this work to be possible. 


\title{
List of Abbreviations
}

\author{
ACC Antarctic Circumpolar Current \\ ACR Agulhas Current Retroflection \\ AzC Azores Current \\ AAIW Antarctic Intermediate Water \\ AMOC Atlantic Meridional Overturning Circulation \\ BC Brazil Current \\ BeC Benguela Current \\ BMC Brazil-Malvinas Confluence \\ BSAF Brazil-Benguela Subtropical Front \\ CaC Canary Current \\ MC Malvinas Current \\ MOC Meridional Overturning Circulation \\ NAC North Atlantic Current \\ NASG North Atlantic Subtropical Gyre \\ PtC Portugal Current \\ SAC South Atlantic Current \\ SAF Subantarctic Front \\ SEC South Equatorial Current \\ STF Subtropical Front \\ SASG South Atlantic Subtropical Gyre \\ StHC Saint Helena Current
}




\section{List of Symbols}

\begin{tabular}{|c|c|c|}
\hline$x$ & zonal distance coordinate & $\mathrm{m}$ \\
\hline$y$ & meridional distance coordinate & $\mathrm{m}$ \\
\hline$z$ & vertical distance coordinate & $\mathrm{m}$ \\
\hline$u$ & zonal velocity & $\mathrm{m} \mathrm{s}^{-1}$ \\
\hline$u_{r}$ & zonal reference velocity & $\mathrm{ms}^{-1}$ \\
\hline$U$ & zonal basic state velocity & $\mathrm{m} \mathrm{s}^{-1}$ \\
\hline$f_{0}$ & mean Coriolis paramater & $\mathrm{s}^{-1}$ \\
\hline$k$ & zonal wavenumber & $\mathrm{m}^{-1}$ \\
\hline$N$ & Brünt Väisälä Frequency & $\mathrm{s}^{-1}$ \\
\hline$c$ & phase speed of the unstable waves & $\mathrm{ms}^{-1}$ \\
\hline$T_{v}$ & volume transport & Sv \\
\hline$g$ & acceleration of Gravity & $\mathrm{ms}^{-2}$ \\
\hline$p$ & pressure & $\mathrm{m}$ \\
\hline$S_{n}$ & normal strain component & $\mathbf{s}^{-1}$ \\
\hline$S_{s}$ & shear strain component & $\mathbf{s}^{-1}$ \\
\hline$Q_{y}$ & meridional gradient of basic state potential vorticity & $\mathrm{m}^{-1} \mathrm{~s}^{-1}$ \\
\hline$T$ & potential temperature referenced at the surface & ${ }^{\circ} \mathrm{C}$ \\
\hline$S$ & salinity & psu \\
\hline$\Phi$ & modal vertical structure of the unstable waves & $\mathrm{m}$ \\
\hline$\delta$ & specific volume anomaly & $\mathrm{m}$ \\
\hline$\psi$ & geostrophic streamfunction & $\mathrm{m}^{2} \mathrm{~s}^{-1}$ \\
\hline$\eta$ & sea surface height & $\mathrm{m}$ \\
\hline$\omega$ & relative Vorticity & $\mathbf{s}^{-1}$ \\
\hline$\beta$ & Rossby parameter & $\mathrm{m}^{-1} \mathrm{~s}^{-1}$ \\
\hline
\end{tabular}


$\sigma_{0}$ potential density anomaly referenced at the surface $\mathrm{kgm}^{-3}$ 


\section{List of Figures}

1.1 Annual average mass transport streamfunction for the total Sverdrup transport computed from the COADS surface meteorological fields. From Mayer and Weisberg (1993). . . . . . . . . . . . . . . . . .

1.2 Schematic representarion of the Atlantic Ocean upper level with emphasis of the north and south subtropical gyres in salmon color. Abbreviations are used for the East Iceland (EIC), Irminger (IC), West Greenland (WGC), and Antilles (AC) Currents and the Caribbean Countercurrent (CCC). Other abbreviations refer to fronts: JMF: Jan Mayen Front, NCF: Norwegian Current Front, IFF: Iceland - Faroe Front, SAF: Subarctic Front, AF: Azores Front, ABF: Angola - Benguela Front, BCF: Brazil Current Front, STF: Subtropical Front, SAF: Subantarctic Front, PF: Polar Front, CWB/WGB: Continental Water Boundary/Weddell Gyre Boundary. From Tomczak and Godfrey (2013). . . . . . . .

1.3 Schematic path of the NAC and adjacent stationary eddies. The arrows indicate probable pathways and directions of loss from the NAC to the surrounding waters. The dashed line in the north indicates an additional meander (or partially attached eddy) that appears in some of the deeper float trajectories. The thin lines indicate the 200-, 2000-, and 4000-m isobaths; FC is Flemish Cap. From Rossby (1996). . . . . . . . . . . . . . . . . . . . . .

1.4 Illustration of the oceanic fronts in the Subtropical South Atlantic: STF represents the Subtropical Front; SAF, the Subantarctic Front; PF, the Polar Front; BCF, the Brazil Current Front. Adapted from Stramma and Peterson (1990). .

1.5 Vertical Section from R/V Atlantis II at $45^{\circ} \mathrm{W}$ of the zonal geostrophic velocity in $\mathrm{cm} \mathrm{s}^{-1}$. The unshaded velocity band correspond to the SAC. From Stramma and Peterson (1990). 
1.6 Illustration of the Antarctic Intermediate Water (AAIW) transport and circulation in Sv. The shaded region represents the $3000 \mathrm{~m}$ isobath. Adapted from Schmid et al. (2000) . . . . . . . . . . . . . . . . . . . . 8

1.7 Surface annual mean field of the horizontal absolute geostrophic velocity ( $\mathrm{m}$ $\mathbf{s}^{-1}$ ) in the Atlantic Ocean computed by the nonlinear $\beta$-spiral method. From Juliano and Alves (2007). . . . . . . . . . . . . . . . . . . .

1.8 Vertical distribution along a meridional section at $35^{\circ} \mathrm{W}$ of annual mean eastward absolute velocity (contour interval is $0.005 \mathrm{~m} \mathrm{~s}-1$, and the eastward positive values are shaded). From Juliano and Alves (2007).

1.9 Vertical distribution along a meridional section at $17.5^{\circ} \mathrm{W}$ of annual mean eastward absolute velocity (contour interval is $0.005 \mathrm{~m} \mathrm{~s}-1$, and the eastward positive values are shaded). From Juliano and Alves (2007). . . . . . . . . 10

1.10 Vertical distribution along a meridional section at $5 \mathrm{~W}$ of annual mean eastward absolute velocity (contour interval is $0.005 \mathrm{~m} \mathrm{~s}-1$, and the eastward positive values are shaded). From Juliano and Alves (2007). . . . . . . . . . 11

1.11 Illustration of Total Volume transport for the first $1000 \mathrm{dbar}$ in Sv. Red arrow indicates Brazil Current (BC) Water; Blue Arrow, Malvinas Current (MC) Water; Green Arrow, Agulhas Current (AC) Water; Light blue arrow, combination of AC and MC. Adapted from Rodrigues et al. (2010). . . . . . . . . . . . . 1

2.1 Region of Study with etopo data plotted on background. . . . . . . . . . . . . 15

4.1 Surface temperature (1), salinity (2) and $\sigma_{0}(2)$ for WOA (A), ARMOR3D (B). . 26

4.2 WOA-ARMOR3D difference fields of temperature $(A)$, salinity $(B)$ and density

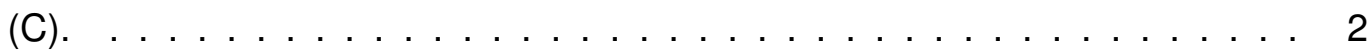

4.3 Spatial average and standard deviation (upper panels) and histogram (lower pannels) of temperature (left panels), salinity (middle panels), and density (right panels) for WOA and ARMOR3D. . . . . . . . . . . . . . . . . 29

4.4 Surface gradient of temperature (1), salinity (2) and density (3) for WOA (A) and ARMOR3D (B)

4.5 Surface geostrophic velocity (vectors) and the streamfunction field (red curves) of WOA $(\mathrm{A}), \mathrm{ARMOR} 3 \mathrm{D}(\mathrm{B})$ and $\mathrm{AVISO}(\mathrm{C})$. Isolines are the streamfunction. 
4.6 Location of the core of the SAC (red), ACCn (green), and ACCs (blue) for WOA (A1) and ARMOR3D (A2), and respective TS profile (bottom panel) for WOA (solid lines) and ARMOR3D (dashed lines). Red isolines represent the streamfunction.

4.7 Water correlation for the WOA dataset for the temperature (A), salinity $(B)$ and density $(C)$ variables. The isolines represent the streamfunction parameter. Isolines represent the streamfunction.

4.8 Water correlation for the ARMOR3D dataset for the temperature $(A)$, salinity $(B)$ and density $(C)$ variables. The isolines represent the streamfunction parameter. Isolines represent the streamfunction. . . . . . . . . . . . . 36

4.9 AVISO Windrose geostrophic current time series for SAC at $40^{\circ} \mathrm{W}, 30^{\circ} \mathrm{W}$, $20^{\circ} \mathrm{W}, 10^{\circ} \mathrm{W}, 0^{\circ}, 10^{\circ} \mathrm{E}$. Isolines represent the streamfunction. . . . . . . . 38

4.10 AVISO Windrose geostrophic current time series for $\mathrm{StHC}$ at $40^{\circ} \mathrm{W}, 30^{\circ} \mathrm{W}$, $20^{\circ} \mathrm{W}, 10^{\circ} \mathrm{W}, 0^{\circ}, 10^{\circ} \mathrm{E}$. Isolines represent the streamfunction. . . . . . . . 39

4.11 AVISO Windrose geostrophic current time series for the northern and southern branch of the $\mathrm{StHC}$ at $13^{\circ} \mathrm{E}$. Isolines represent the streamfunction. . . . 40

4.12 Vertical section of WOA (left) and ARMOR3D (right) for $40^{\circ} \mathrm{W} . \ldots \ldots 1$

4.13 Vertical section of WOA (left) and ARMOR3D (right) for $20^{\circ} \mathrm{W} . \quad \ldots \ldots$

4.14 Vertical section of WOA (left) and ARMOR3D (right) for $10^{\circ} \mathrm{W} . \ldots \ldots$

4.15 Vertical section of WOA (left) and ARMOR3D (right) for $10^{\circ} \mathrm{E} . \ldots . . . . . .44$

4.16 Schematic representation of the flow pattern and accompanying volume transport values for the upper 3000 dbar in the SASG southern border: WOA (upper panel) and AMOR3D (lower panel). . . . . . . . . . . . . . . . . . . 46

5.1 AVISO mean total (A) and eddy (B) Kinectic Energy. Isolines represent the streamfunction.

5.2 Okubo-Weiss Standard Deviation from sea surface anomaly of AVISO. Isolines represent the streamfunction.

5.3 Mean Kinetic Energy (MKE) and Mean Eddy Kinetic Energy (MEKE) monthly climatology. Red line indicates MEKE, while blue line indicates the MKE . . . 50

5.4 Same as Figure 5.3, but for the sections between $30^{\circ} \mathrm{W}$ and $0^{\circ}$. . . . . . 51 
5.5 (upper panel) Growth rate and (lower pannel) phase speed of the local most unstable vorticity wave obtained via baroclinic instability analysis. Streamlines of the main flow are plotted over the linear model results. . . . . . . . . . . . 54

5.6 Baroclinically and Barotropically $(A / B)$ unstable bidimensional jets with the Brünt-Väisälä and Ambient Potential Vorticity profile (1/2). The red lines are jet velocity in $\mathrm{cms}^{-1} \ldots \ldots \ldots \ldots$. . . . . . . . . . . . . 5 5

5.7 Instability results of the uni/bidimensional model for the phase speed $(A)$ and growth rate (B) for the barotropic (1) and baroclinic (2) instability results. . . . 58

5.8 Sectional profile of $u$ and contour levels of $N^{2}$ (top). . . . . . . . . . . . 60

5.9 Model instability results (phase speed and growth rate). The shadowed region represents the domain not analysed . . . . . . . . . . . . . . 61

5.10 Period calculated from the model results for each longitude section. The shadowed region represents the domain not analysed . . . . . . . . . . . . . . 63

5.11 Velocity vertical structure estimated from model for each section for the fastest growth rate. . . . . . . . . . . . . . . . . . . . . . . . . 6 64

B.1 Model grid for the discretized model. The red lines and points represent the boundaries of the model. 


\section{List of Tables}

4.1 Spatial average and stantard deviation of the difference between the data sets (Figure 4.2) and the spatial fields of WOA and ARMOR3D . . . . . . . . . . 28

4.2 RMS calculated between each of the data sets. . . . . . . . . . . . . 33

5.1 Jet parameters for the validation cases of the baroclinically and barotropically unstable wave. . . . . . . . . . . . . . . . . . . 56

5.2 Detailed results for growth rate $(\mathrm{GR})$, phase speed $\left(\mathrm{c}_{r}\right)$, wavenumber $(\mathrm{k})$ and period of the fastest growing wave for each longitude analysed. . . . . . . . 65

5.3 Detailed results of the height, width, core depth and maximum speed of the perturbation velocity structure. 


\section{Contents}

Acknowledgements

List of Figures $\quad$ vi

List of Tables $\quad x$

Abstract $\quad$ xiv

Resumo xvi

1 Introduction 1

1.1 Subtropical Gyres in the Atlantic Ocean . . . . . . . . . . . . . . 1

1.2 The SAC Description . . . . . . . . . . . . . . . . . 5

1.3 Scientific Questions and Hypotheses . . . . . . . . . . . . . . . . . . . . 12

1.4 Objectives . . . . . . . . . . . . . . . . . . . . . . . . . . . 13

1.4 .1 General Objective . . . . . . . . . . . . . . . . . . . . 13

1.4 .2 Specific Objectives . . . . . . . . . . . . . . . . . . . . 13

2 Study area and Data Sets $\quad 14$

2.1 The Study Area . . . . . . . . . . . . . . . . . . . . . . . . . . . . . 14

2.2 Data Sets . . . . . . . . . . . . . . . . . . . . . . . . 15

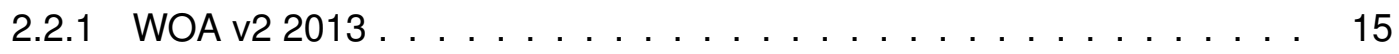

2.2 .2 AVISO . . . . . . . . . . . . . . . . . . . . 16

2.2 .3 ARMOR3D . . . . . . . . . . . . . . . . . 16

3 Basic Methodology 18

3.1 Methods of Hydrographic Data Analysis . . . . . . . . . . . . . . . . 18

3.1 .1 Dynamic Method . . . . . . . . . . . . . . . . . . . . . 18 
3.1.2 Relative geostrophic velocities from ARMOR3D . . . . . . . . . . . . 19

3.1 .3 T-S- $\sigma_{0}$ correlation analysis . . . . . . . . . . . . . . . . . 19

3.1 .4 Geostrophic velocities from AVISO . . . . . . . . . . . . . . . . . . . 20

3.1 .5 Basic Statistics . . . . . . . . . . . . . . . . . . . 20

3.2 Linear Instability Analysis . . . . . . . . . . . . . . . . . . . . . . 20

3.2.1 Sectional Mixed Instability Model . . . . . . . . . . . . . . . . . . 20

3.2.2 Local Baroclinic Instability Model . . . . . . . . . . . . . . . . . . . 22

3.3 Analysis of Energetics . . . . . . . . . . . . . . . . . . . . 23

4 The SAC System Description 25

4.1 Intercomparison between WOA, ARMOR3D and AVISO data sets . . . . . 25

4.1 .1 The surface hydrographic fields . . . . . . . . . . . . . . . . 25

4.1.2 Surface Geostrophic Velocities and Streamfunction . . . . . . . . . . 31

$4.2 \mathrm{TS} \sigma_{0}$ Correlation Maps . . . . . . . . . . . . . . . . . . . . . 33

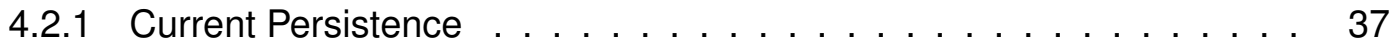

4.2.2 Velocity Vertical Structure and Volume Transports . . . . . . . . . . . 40

4.2 .3 Synthesis . . . . . . . . . . . . . . . . . . . . . . . . . 44

5 The SAC System Mesoscale Dynamics $\quad 47$

5.1 Energetics . . . . . . . . . . . . . . . . . . . 47

5.1 .1 Anual Climatological Energetics . . . . . . . . . . . . . 47

5.1 .2 Monthly climatological Energetics . . . . . . . . . . . . . . . . . 49

5.1 .3 Synthesis . . . . . . . . . . . . . . . . . . . 52

5.2 Linear Instability Analysis . . . . . . . . . . . . . . . . . . . . 52

5.2 .1 Local Baroclinic Analysis . . . . . . . . . . . . . . . . . 53

5.2 .2 Seccional Mixed Instability Analysis . . . . . . . . . . . . . . . 54

Model Validation . . . . . . . . . . . . . . . . . . . . . 55

Model Application to Selected Longitudes . . . . . . . . . . . . . 56

5.2 .3 Discussion and Synthesis . . . . . . . . . . . . . . . . . 63

6 Conclusions $\quad 67$

A The Partial Differential Instability Equation 70 
B Numerical Differentiation of the Instability PDE Equation

B.1 Discretization . . . . . . . . . . . . . . . . . . . . . 73

B.1.1 Boundary Conditions . . . . . . . . . . . . . . . . . 73

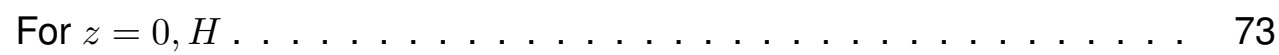

For $y=0, W(i=0, N) \ldots \ldots \ldots \ldots \ldots \ldots \ldots \ldots$

B.1.2 The Main Equation . . . . . . . . . . . . . . . . . . . . . . 74

Discretizing for different $i$ 's and $j$ 's . . . . . . . . . . . . 75 


\section{Abstract}

Oceanic Gyres are the most conspicuous features in the Earth's ocean. They are ubiquitous to each basin and hemisphere. In the Atlantic Ocean, there is an uncanny symmetry between the North and South Atlantic Subtropical Gyres. Focusing on their poleward limits, we can think of them as virtually perfect analogues. However, while the North Atlantic Current has been extensively studied, the South Atlantic Current (SAC) still has been very little investigated and its knowledge presents crucial gaps on understanding it ocean's mesoscale variability and climate. Very little studies attempted so far to describe the SAC characteristics in terms of water mass properties and volume transports. In addition, there is the presence of recently described Saint Helen Current (StHC), which can be considered as the South Atlantic analogue of the Azores Current. The StHC has its formation tied with the Brazil Current $(B C)$ retroflection. The SAC, on the other hand, is originated at the Brazil-Malvinas Confluence (BMC), and flows crossing zonally the Atlantic Basin. However, the presence of the northern branch of Antarctic Circumpolar Current (ACCn) (without an analogue in the northern hemisphere) brought a few additional challenges to studying the SAC. The ACCn can be thought as the Malvinas Current (MC) Extension, which exits the BMC region via the southern flank of the Zapíola Rise. In this work, we revisit the descriptive oceanography of the SAC system with newly developed climatologies (WOA13 and ARMOR3D) and seek to unravel the pattern associated with the current in the Southern limb of the region. Recent literature mentions that there is an important interplay between this three zonal jets as the cross the South Atlantic. However, only kinematics arguments were used to pinpoint this interplay so far. Hence, we opted to employ a statistical correlation method involving temperature, salinity and density vertical profiles (and consequently, T-S curves as well). We also computed volume transport values for the whole zonal domain across the South 
Atlantic Subtropical Gyre southern limb. In particular, at the longitude that it reaches the Mid-Atlantic Ridge, the major portion of the SAC veers south and merge almost completely with the ACCn. Its smaller northern the StHC. Near the eastern ocean border of the South Atlantic Ocean, the SAC-ACCn as well as a portion of the StHC traverse into the Indian Ocean. The combined analysis of geostrophic streamfunction fields and the temperaturedensity correlation diagrams do not show sufficient evidence for the StHC being an independent current, and not a branch of the SAC. Since there is also no study regarding the dynamics of the SAC we also constructed a linear QG instability model aiming to evaluate the current system mesoscale activity. We then analyzed the mesoscale activity of the SAC, and discovered that SAC is unstable throughout the whole path domain towards Africa. This instabilities, however, are found to be not as vigorous as the ACC. We also identify a shift in mesoscale vorticity wave regime as the SAC crosses the Mid-Atlantic Ridge. We found it to be less unstable than at the western side. We, however, could not identify the type of instabilities associated with the current. Therefore, we propose as sequential future work to further pursue investigation on the mesoscale dynamics of the ACCn-SAC-StHC system.

Keywords: Subtropical Gyre, Saint Helena Current, South Atlantic Current, Antarctic Circumpolar Current, Description, Dynamics, Mesoscale, AVISO, WOA, ARMOR3D. 


\section{Resumo}

Os Giros Oceânicos são os aspectos mais notáveis dos oceano. Eles são ubíquos em todos os hemisférios e bacias oceânicas. No Atlântico, por exemplo, existe uma clara simetria entre os giros subtropicais do Atlântico norte e sul. Nos seus limites mais polar, podemos pensar neles como análogos perfeitos. Entretanto, enquanto a Corrente do Atlântico Norte foi extensamente estudado, a Corrente do Atlântico Sul ainda tem sido muito pouco investigada deixando lacunas cruciais no conhecimento no entendimento do clima e variabilidade de mesoscala nos oceanos. Pouquíssimos estudos foram realizados até agora a fim de descrever a CAS e suas características nos tópicos relacionados às propriedades das massas de água transporte de voluma. Ademais, há a presença de um corrente recentemente descrita, cunhada de Corrente de Santa Helena (CStH) que pode considerada, tal qual a Corrente do Atlântico Sul, uma análoga da Corrente dos Açores. A CStH possui sua formação atrelada à Corrente do Brasil (CB). A CAS, por sua vez, origina-se na confluência Brasil-Malvinas e escoa atravessando zonalmente a bacia do Atlântico. Entretanto, a presença do ramo norte da Corrente Circumpolar Antártica (CCAn) (sem um análogo no hemisfério norte) trouxe desafios adicionais ao estudo da CAS. A CCAn pode ser pensada como uma extensão da Corrente das Malvinas (CM), a qual sai da região da confluência via o flanco sul da Elevação de Zapiola. Nesse trabalho, revisitamo a oceanografia descritiva do sistema CAS com novas climatologias desenvolvidas (WOA13 e ARMOR3D) e procuramos desvendar o padrão associado à corrente no membro sul da região. Estudos recentes apontam uma importante interação entre os três jatos zonais enquanto atravessam o Atlântico Sul. Somente argumentos cinemáticos, entretanto, foram utilizados para identificar essa interação. Consequentemente, optamos em empregar um método de correlação 
estatística envolvendo perfis verticais de temperatura, salinidade e densidade(e, logo, curvas T-S). Nós também calculamos o transporte de volume para todo o domínio zonal através do ramo sul do Giro Subtropical do Atlântico Norte. Em particular, na longitude que alcança a Cadeia Meso-Atlântica, a maior porção da CAS desvia-se para o sul e dilui-se quanse que por completo à CCAn. Próxima à borda este do Oceano Atlântico Sul, tanto a CAS-CCAn como uma parte da CStH atravessam em direção ao Oceano Índico. A análise combinada dos campos de função de corrente geostróficos e pelos diagramas de correlação de temperatura-densidade não mostra evidências suficientes para que a CStH seja considerada uma corrente independente e não um ramo da CAS. Além disso, já que não há estudos relacionados a dinâmica da CAS, nós tambémconstruímos um modelo de instabilidade QG a fim de avaliar a atividade de mesoscala do sistema de correntes. Analisamos essa atividade da CAS e descobrimos que ela é instável durante todo o seu percurso em direção à África. Essas instabilidades, entretanto, não são tão vigorosas quanto aquelas da CCA. Também identidicamos mudanças no regime de ondas das vorticidades de mesoscala no cruzamento da CAS com a cadeia meso-oceânica. Descobrimos que a corrente é menos instável ao lado leste da cadeia. Não podemos, contudo, identificar os tipos de instabilidades associada à corrente. Por conseguinte, propomos trabalhos futuros que irão auxiliar à investigação da dinâmica de mesoscala do sistema CCAn-CAS-CStH.

Palavras-chave: Giro Subtropical, Corrente de Santa Helena, Corrente do Atlântico Sul, Corrente Circumpolar Antártica, Descrição, Dinâmica, Mesoscala, AVISO, WOA, ARMOR3D. 


\section{Chapter 1}

\section{Introduction}

\subsection{Subtropical Gyres in the Atlantic Ocean}

Certainly, the most conspicuous basin-wide features of the world ocean are the gyres. These large-scale eddies are ubiquitous to each basin and hemisphere and can be tropical, equatorial, subtropical or subpolar. Their vertical extension is about $1000 \mathrm{~m}$, which coincides with the the base of the permanent pycnocline.

The gyre dynamics was unraveled by a series of seminal articles from the late 40's and early 50's of the XIX Century (Sverdrup, 1947; Stommel, 1948; Munk, 1950). The gyres are primarily forced by large-scale winds, or more specifically, by the wind stress curl. The zero curl bands, which extends zonally throughout the ocean basins, delimit the gyre meridional extension. Most of the gyre domain is forced directly by the wind, while the northern and southern borders consist of free geostrophic currents (Sverdrup, 1947). The exception is the gyre western boundary, which present narrow, stronger currents explained by continuity and by the east-west angular velocity of the near-spherical Planet Earth (Stommel, 1948).

The so-called Sverdrup theory allow us to compute the locked, meridionally-organized gyre cells merely from meteorological data centers, which excludes the western boundary currents. Of course, no other forcing than winds is considered in this calculation. Figure 1.1 exihibits the pattern observed in the Atlantic Ocean, focusing in the northern hemisphere. It is clear that the largest cell is the North Atlantic Subtropical Gyre.

However, the thermohaline component of the ocean circulation introduces a richer and stratified vertical structure to the ocean gyres and, therefore, allows the gyre cells to exchange mass with the neighboring ones. Therefore, we can restate the affirmation in the 


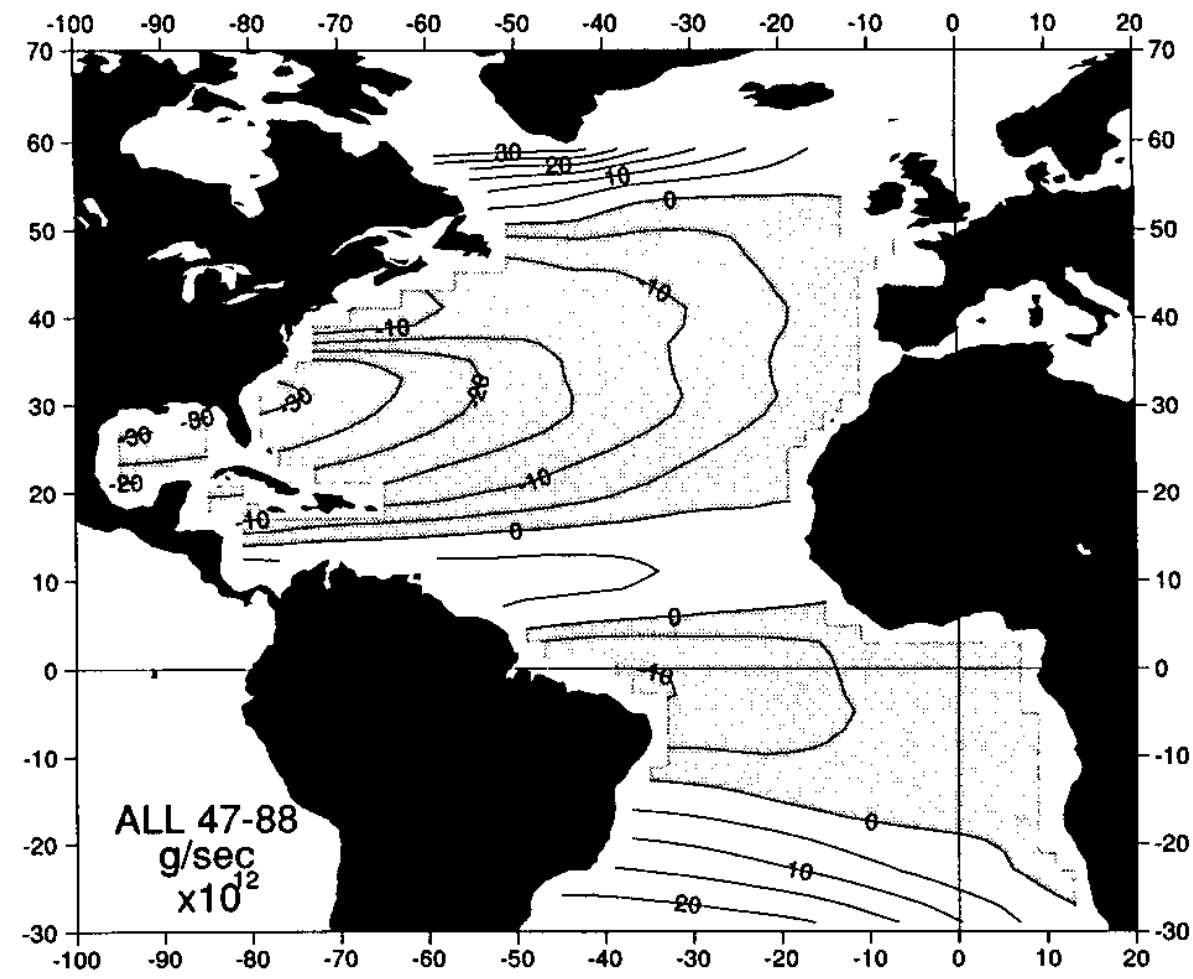

FIGURE 1.1: Annual average mass transport streamfunction for the total Sverdrup transport computed from the COADS surface meteorological fields. From Mayer and Weisberg (1993).

first paragraph in more complete form: the ocean gyres are primarily mechanically forced by winds and modified by the meridional overturning circulation (MOC).

The observed structure of the subtropical gyres of the Atlantic Ocean is sketched in Figure 1.2. The North Atlantic Subtropical Gyre is formed by North Equatorial Current (NEC) in the south, the Gulf Stream in the western boundary, the North Atlantic Current (NAC) and the Azores Current $(\mathrm{AzC})$ in the north and, the Portugal Current $(\mathrm{PtC})$ and the Canary Current $(\mathrm{CaC})$ closing the gyre in the eastern boundary. In the South Atlantic, the anticyclonic subtropical gyre is traditionally considered as composed by the South Atlantic Current (SAC) in the south, the Benguela Current $(\mathrm{BeC})$ in the east, the South Equatorial Current (SEC) in the north and, the Brazil Current (BC) bordering the western boundary. 


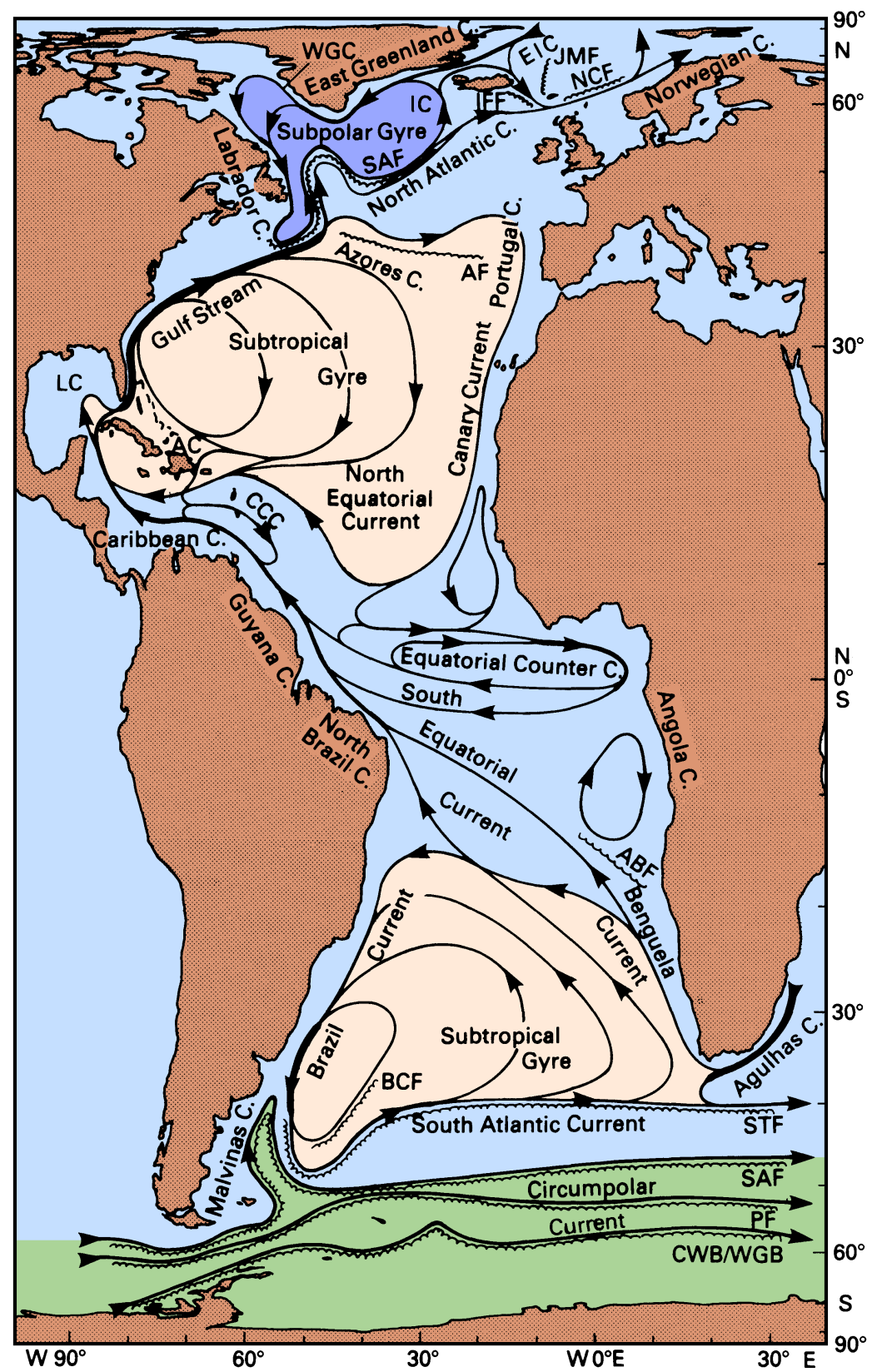

FIGURE 1.2: Schematic representarion of the Atlantic Ocean upper level with emphasis of the north and south subtropical gyres in salmon color. Abbreviations are used for the East Iceland (EIC), Irminger (IC), West Greenland (WGC), and Antilles (AC) Currents and the Caribbean Countercurrent (CCC). Other abbreviations refer to fronts: JMF: Jan Mayen Front, NCF: Norwegian Current Front, IFF: Iceland - Faroe Front, SAF: Subarctic Front, AF: Azores Front, ABF: Angola - Benguela Front, BCF: Brazil Current Front, STF: Subtropical Front, SAF: Subantarctic Front, PF: Polar Front, CWB/WGB: Continental Water Boundary/Weddell Gyre Boundary. From Tomczak and Godfrey (2013). 
Focusing on the poleward limit of the subtropical gyres in the Atlantic, we might think the NAC and SAC as perfect analogues for the North and South Atlantic Subtropical Gyres (NASG and SASG), respectively. But, is this assessment correct? The NAC has already been extensively studied in both its characteristics and dynamics (Mann, 1967; Richardson, 1983; Krauss, 1986; Bower and von Appen, 2008). The recent review presented by Talley (2011) indicates that only a minor part of the NAC veers south to feed the CaC directly. About a third of its transport forms the PtC, which adds (does not add) volume to the $\mathrm{CaC}$ during the boreal spring-summer (autumn-winter). The other two thirds flows to the Nordic Seas. It is the AzC which primarily feeds the NEC.

The dynamics of the NAC is characterized by strong topographic control, which leads to finite amplitude meandering and a trifurcation of the NAC jet downstream. Mesoscale stationary eddies (Figure 1.3) are related to the Newfoundland Rise, Newfoundland Seamounts and the Flemming Cap (Krauss, 1986; Rossby, 1996). The southnermost eddy is a permanent anticyclonic feature discovered by Mann (1967), known as the Mann Eddy, while the others seem to be recurrent and persistent only for months at a time.

On the other hand, few articles have attempted so far to describe the SAC characteristics in terms of water mass properties and volume transports. Juliano and Alves (2007) challenged the traditional SASG pattern presented in Figure 1.2. These authors suggested there is also an analogue to the $\mathrm{AzC}$ in the South Atlantic and named it the Saint Helena Current $(\mathrm{StHC})$. For the dynamical investigation of the SAC, the literature was also found to be scarce. In the next section, we present a review on the descriptive oceanography of the SAC and discuss the contradictions among the works. 


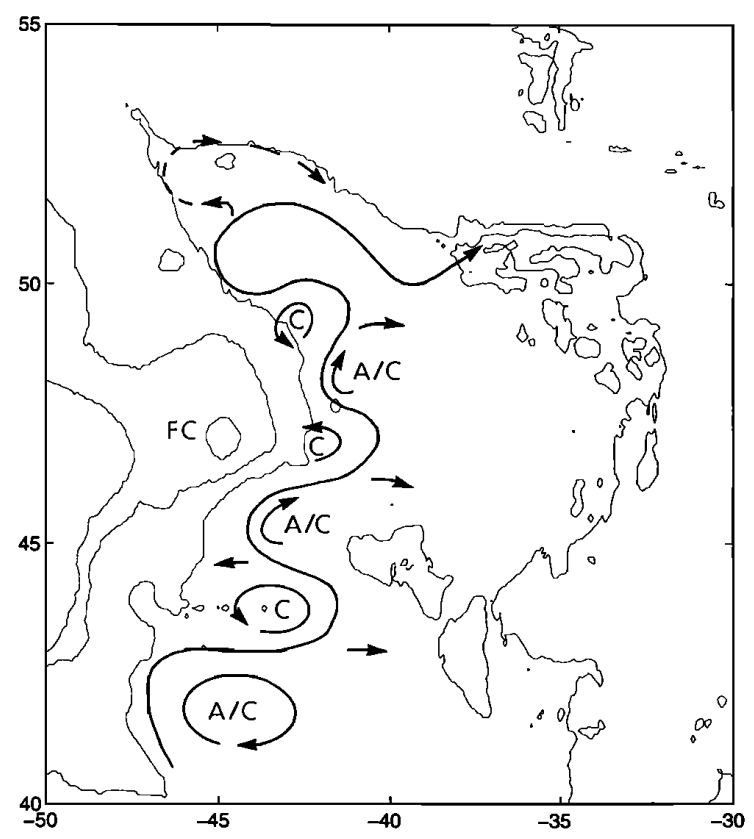

FIGURE 1.3: Schematic path of the NAC and adjacent stationary eddies. The arrows indicate probable pathways and directions of loss from the NAC to the surrounding waters. The dashed line in the north indicates an additional meander (or partially attached eddy) that appears in some of the deeper float trajectories. The thin lines indicate the 200-, 2000-, and 4000-m isobaths; FC is Flemish Cap. From Rossby (1996).

\subsection{The SAC Description}

The original description of the SAC was made by Stramma and Peterson (1990) based on in situ hydrographic data from a collection of historical surveys. They described the current as being closely associated with the Subtropical Front (STF), a meridional temperature discontinuity which separates the SASG from the Antarctic Circunpolar Current (ACC) (Fig. 1.4).

At the formation longitude $\left(45^{\circ} \mathrm{W}\right)$, they evaluated a maximum velocity of $\approx 0.1 \mathrm{~ms}^{-1}$ and a transport $14.1 \mathrm{~Sv}\left(1 \mathrm{~Sv}=10^{6} \mathrm{~m}^{3} \mathrm{~s}^{-1}\right.$, Fig. 1.5). The authors justified the weakness of the SAC as being caused by the presence of a strong salinity gradient acting in opposition to the distribution of temperature, and therefore, attenuating the thermal wind as well as rich mesoscale activity.

The former authors obtained the largest transport value of the SAC at $30^{\circ} \mathrm{W}: 29-37$ Sv. They also identified at the same longitude a inflection of the STF southward which 


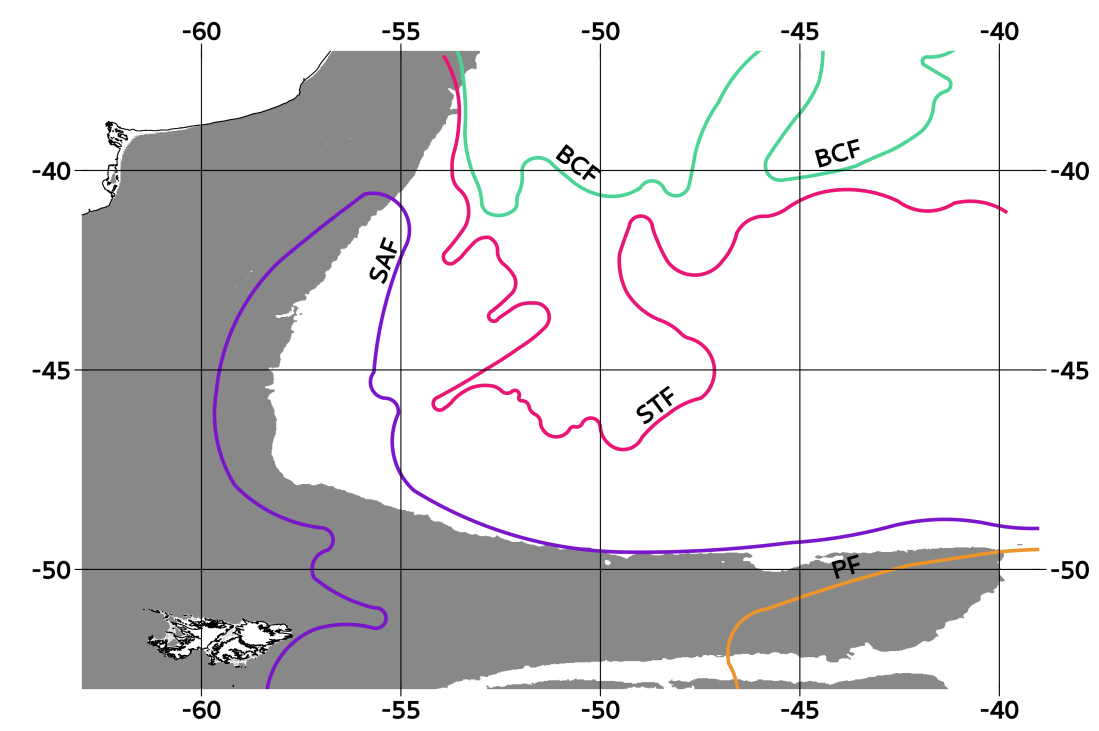

FIGURE 1.4: Illustration of the oceanic fronts in the Subtropical South Atlantic: STF represents the Subtropical Front; SAF, the Subantarctic Front; PF, the Polar Front; BCF, the Brazil Current Front. Adapted from Stramma and Peterson (1990).

was not followed by the SAC. Stramma and Peterson (1990) argued that shallow southward extension of subtropical water overrode subantarctic surface water, but most of the baroclinic structure of the STF remained north. They also identified what seemed to be a weaker branch around $200 \mathrm{~km}$ further north of the main current.

At the eastern side of the Mid-Atlantic Ridge (MAC) $\left(0^{\circ}\right)$, the current is narrower and the most of the transport is found south of STF reaching values of $8 \mathrm{~Sv}$, while the surface front has around $9 \mathrm{~Sv}$. Therefore, the total transport was calculated as being $17 \mathrm{~Sv}$. Stramma and Peterson (1990) then concluded that part of the transport of the SAC turns north to feed the $\mathrm{BeC}$.

Later, Gordon et al. (1992) studied the eastern side of Atlantic Ocean also through hydrographic data willing to understand the communication between the waters from this ocean basin to the Indian Ocean. They identified the Brazil-Benguela Subtropical Front (BSAF), around $5^{\circ} \mathrm{W}$. They stated that the band between this front and the Subantarctic Front (SAF) marked the SAC presence.

According the aforementioned authors, the SAC transports $12 \mathrm{~Sv}$ of thermocline water, and about $6 \mathrm{~Sv}$ of this transport turns to the $\mathrm{BeC}$, whilst the rest continues to flow eastward, passing into the Indian Ocean. SAC carries the same transport for the lower thermocline, 


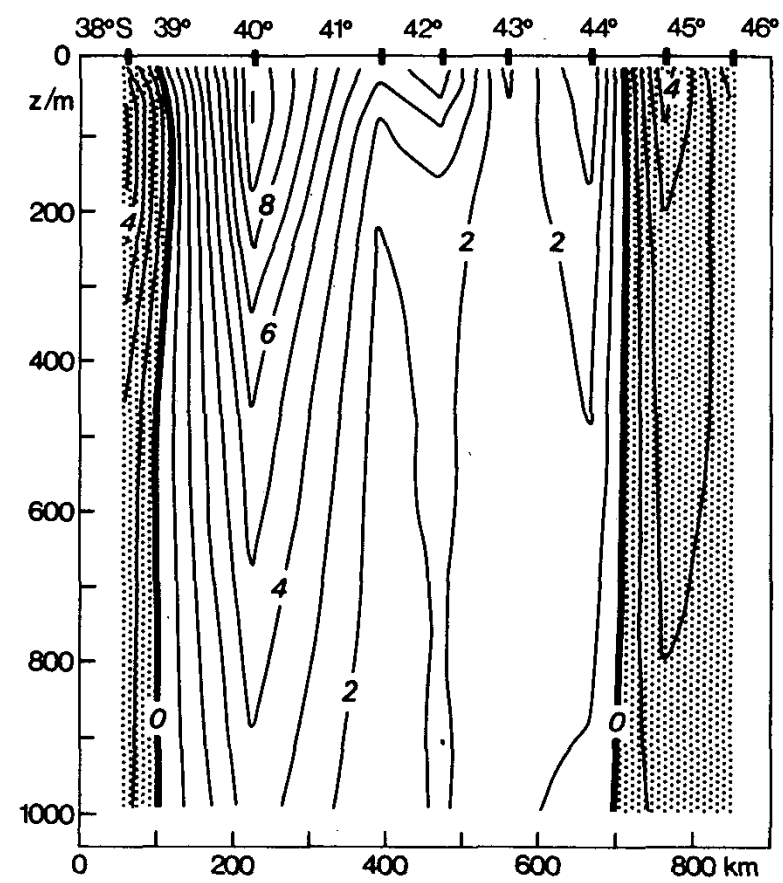

FIGURE 1.5: Vertical Section from R/V Atlantis II at $45^{\circ} \mathrm{W}$ of the zonal geostrophic velocity in $\mathrm{cm} \mathrm{s}^{-1}$. The unshaded velocity band correspond to the SAC. From Stramma and Peterson (1990).

Antarctic Intermediate Water (AAIW). It is likely, however, that most of the AAIW originated in the Pacific Ocean with some contribution of the BC. Approximately $4 \mathrm{~Sv}$ of this transport turns to $\mathrm{BeC}$, whilst the rest (8 Sv) flows into the Indian Ocean. The authors also argue that the transport patterns of the SAC and its role in the interocean exchange has an impact at the global thermocline circulation.

In contrast, the study by Schmid et al. (2000) identified a transport ranging from 6 Sv to $26 \mathrm{~Sv}$ of AAIW in the SAC (Fig. 1.6). The highest value (26 Sv) was found adjacent to the western boundary. They also reported a significantly decrease of $19 \mathrm{~Sv}$ between $52^{\circ}$ $\mathrm{W}-41^{\circ} \mathrm{W}$. The SAC transport is reduced at lower rates while the current flows eastward. The authors found values ranging from $19 \mathrm{~Sv}\left(38^{\circ} \mathrm{W}\right)$ to $16 \mathrm{~Sv}\left(30^{\circ} \mathrm{W}\right)$ and $6 \mathrm{~Sv}\left(1^{\circ} \mathrm{E}\right)$. This faster transport drop, as the authors suggested, may be caused by mesoscale variability in the region, while the slower drop rates between $38^{\circ} \mathrm{W}$ and $30^{\circ} \mathrm{W}$ could be result of the exchange of waters between SASG and the ACC. They supported this hypothesis by the fact the trajectories of the floaters suggest an interaction between ACC and SAC. This interaction seems more evident near $20^{\circ} \mathrm{W}$ where both currents seem to merge as one.

The more recent study conducted by Juliano and Alves (2007) employed the $\beta$-spiral 


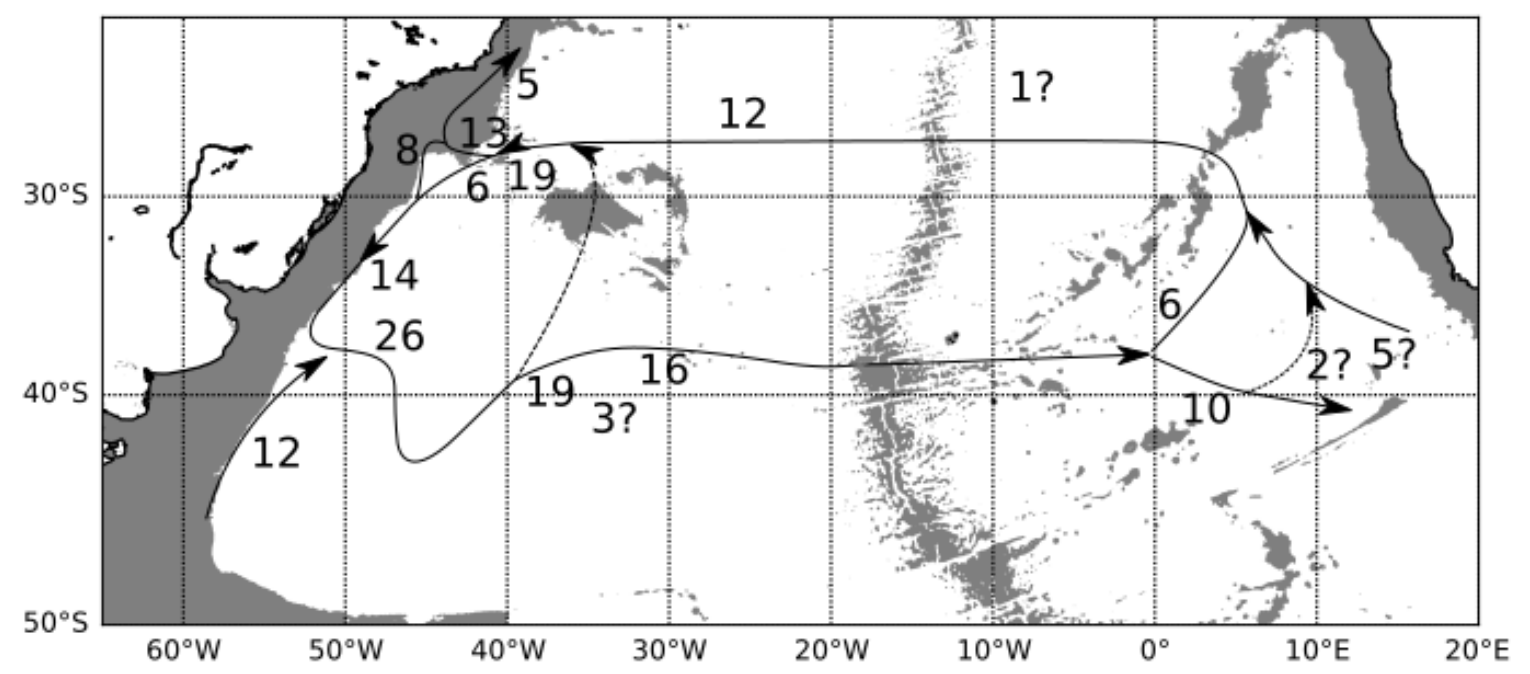

FIGURE 1.6: Illustration of the Antarctic Intermediate Water (AAIW) transport and circulation in Sv. The shaded region represents the $3000 \mathrm{~m}$ isobath. Adapted from Schmid et al. (2000)

method in its linear and nonlinear versions using a T-S climatology built from hydrographic data gathered from three different data distributions centers (NODC, GTSPP and WOCE's). With the absolute geostrophic velocity maps, they claimed to have discovered a new current, the StHC. The authors chose the South Atlantic island name in analogy with the $\mathrm{AzC}$ in the NASG (see Figure 1.7).

The authors interpreted as the StHC is formed due to the northern retroflection of the Brazil-Malvinas Confluence (BMC) and as flowing eastward paralleling the SAC at $35^{\circ} \mathrm{W}$, $33^{\circ} \mathrm{S}$ (Figure 1.8). At about $20^{\circ} \mathrm{W}$, they also identified the interaction between the southern edge of the SAC with norther part of the ACC. This meridional, very broad jet in Figure 1.9 makes the distinction between the ACC and the SAC rather difficult if only velocity patterns are examined. As a matter of fact, both Stramma and Peterson (1990) and Schmid et al. (2000) argued that it is actually the displacement of the STF that caused an interaction between these latter two currents.

At $5^{\circ} \mathrm{W}$, however,Juliano and Alves (2007) detected a slight northward displacement of the SAC core and gets closer to the StHC (Figure 1.8). This current pattern is in agreement with Stramma and Peterson (1990)'s findings. From the Greenwhich Meridian to $10^{\circ} \mathrm{E}$ (Figure 1.10), the intensified StHC moves slightly in southeast direction, and past $10^{\circ} \mathrm{E}$, it deflects northwestward merging with the $\mathrm{BeC}$. As previously said, the $\mathrm{StHC}$ is the main 


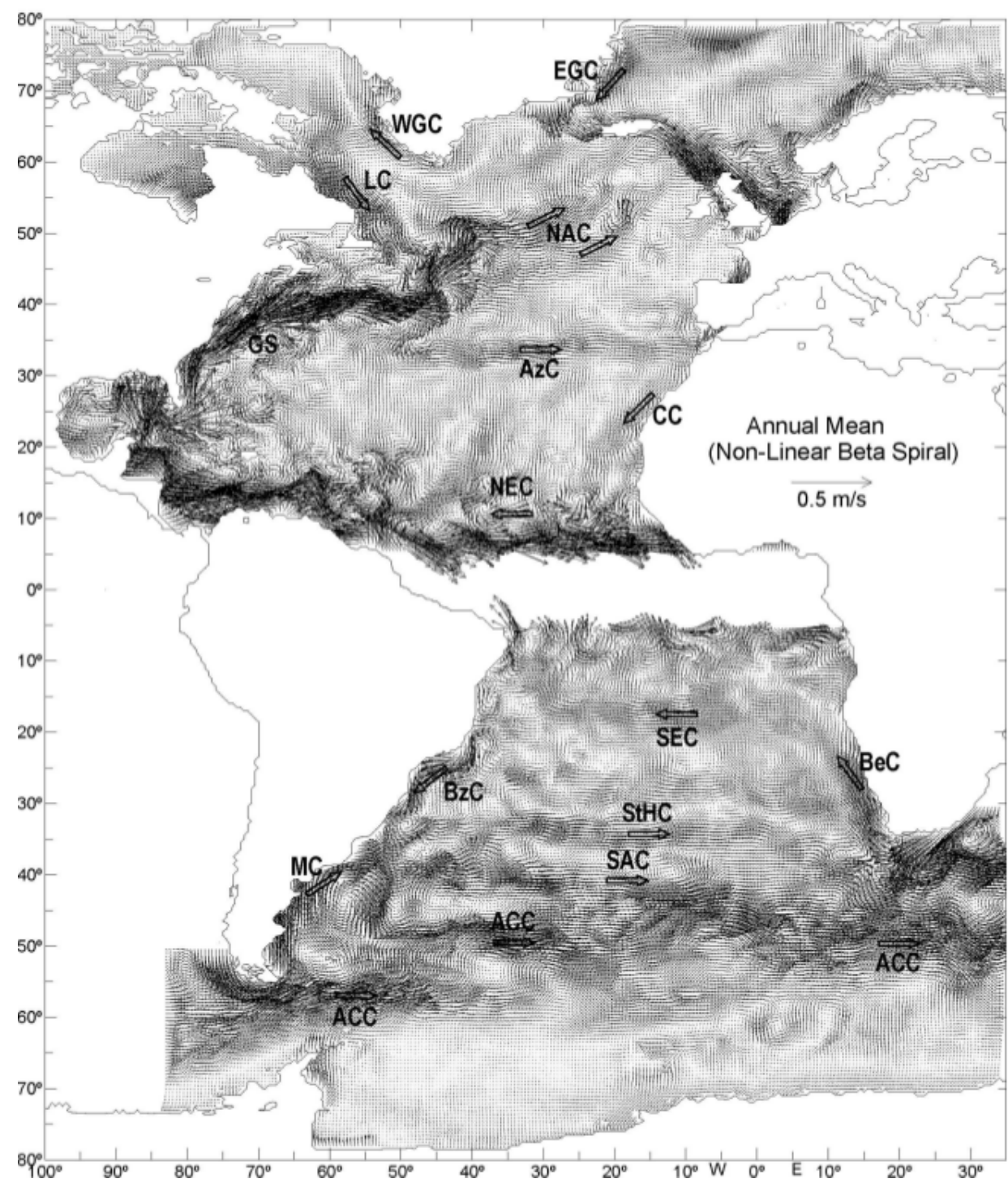

FIGURE 1.7: Surface annual mean field of the horizontal absolute geostrophic velocity $\left(\mathrm{m} \mathrm{s}^{-1}\right)$ in the Atlantic Ocean computed by the nonlinear $\beta$-spiral method. From Juliano and Alves (2007).

feeder of $\mathrm{BeC}$ with other relevant source being volume flux leaking from the Agulhas Current Retroflection (AgCR). Richardson (2007) studied the influence of the Agulhas Rings into the Atlantic Ocean, and he found that the water transported from Indian Ocean by Agulhas Rings into the South Atlantic might cause a split in the SAC around $5^{\circ} \mathrm{E}$.

Rodrigues et al. (2010) employed the Gravest Empiral Mode (GEM) technique on a quasi-isobaric subsurface float data set to obtain total (i.e., barotropic+baroclinic) mass transports in SASG poleward limb. They estimated a total SAC transport of $50 \mathrm{~Sv}$ at $30^{\circ} \mathrm{W}$. Some $10.3 \mathrm{~Sv}$ of those $50 \mathrm{~Sv}$ come from BC, while the rest from MC. In that region Stramma 


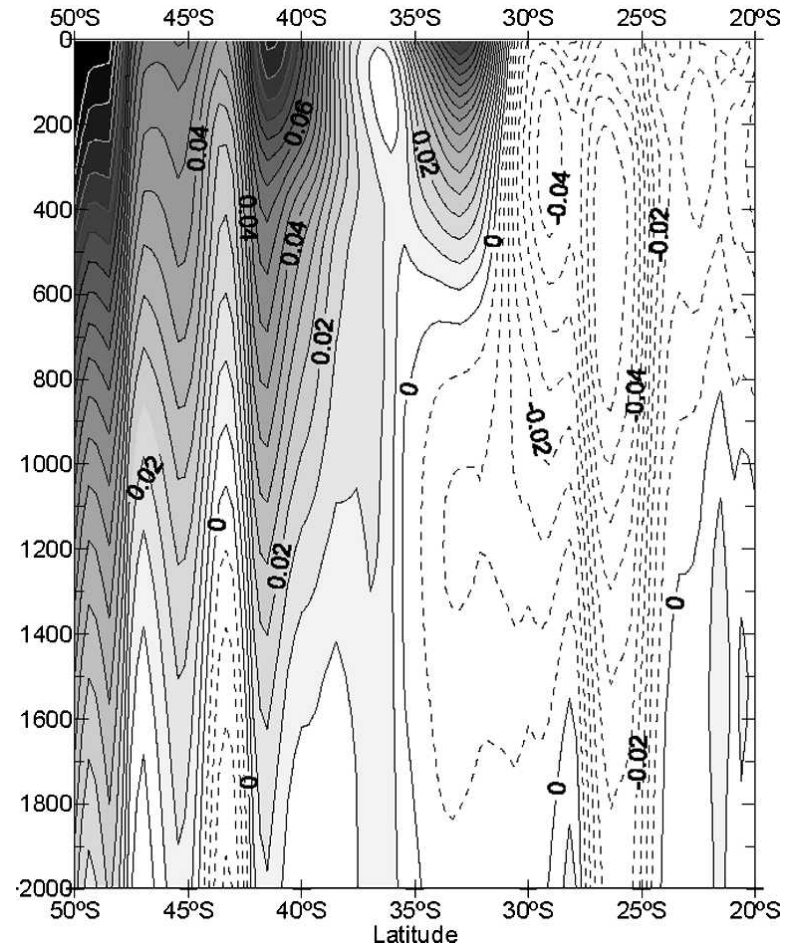

FIGURE 1.8: Vertical distribution along a meridional section at $35^{\circ} \mathrm{W}$ of annual mean eastward absolute velocity (contour interval is $0.005 \mathrm{~m} \mathrm{~s}-1$, and the eastward positive values are shaded). From Juliano and Alves (2007).

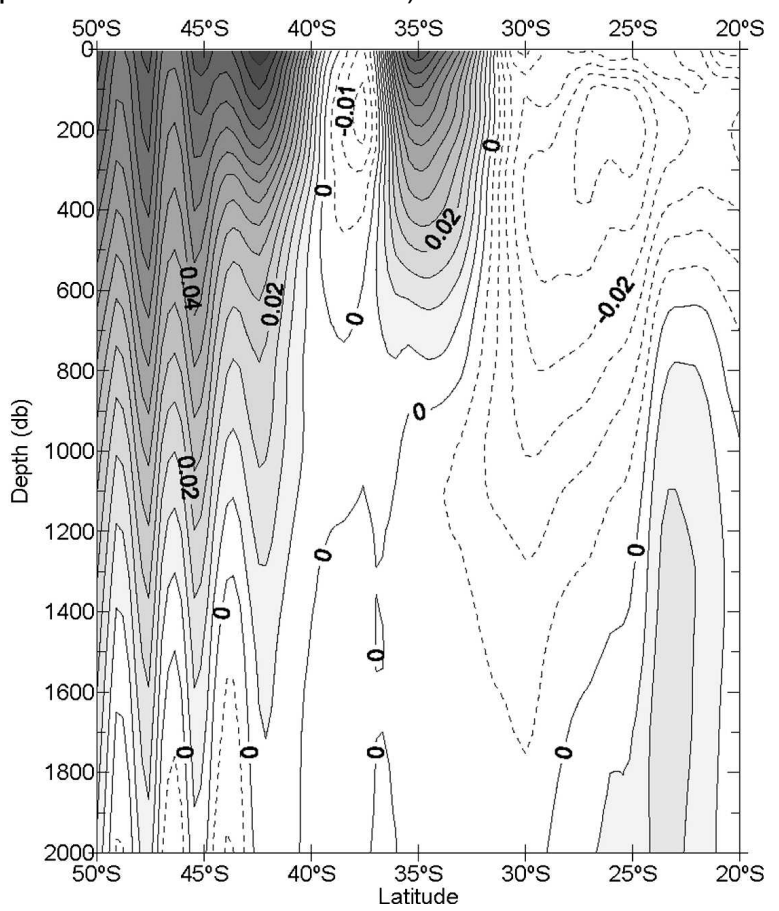

FIGURE 1.9: Vertical distribution along a meridional section at $17.5^{\circ} \mathrm{W}$ of annual mean eastward absolute velocity (contour interval is $0.005 \mathrm{~m} \mathrm{~s}-1$, and the eastward positive values are shaded). From Juliano and Alves (2007). 


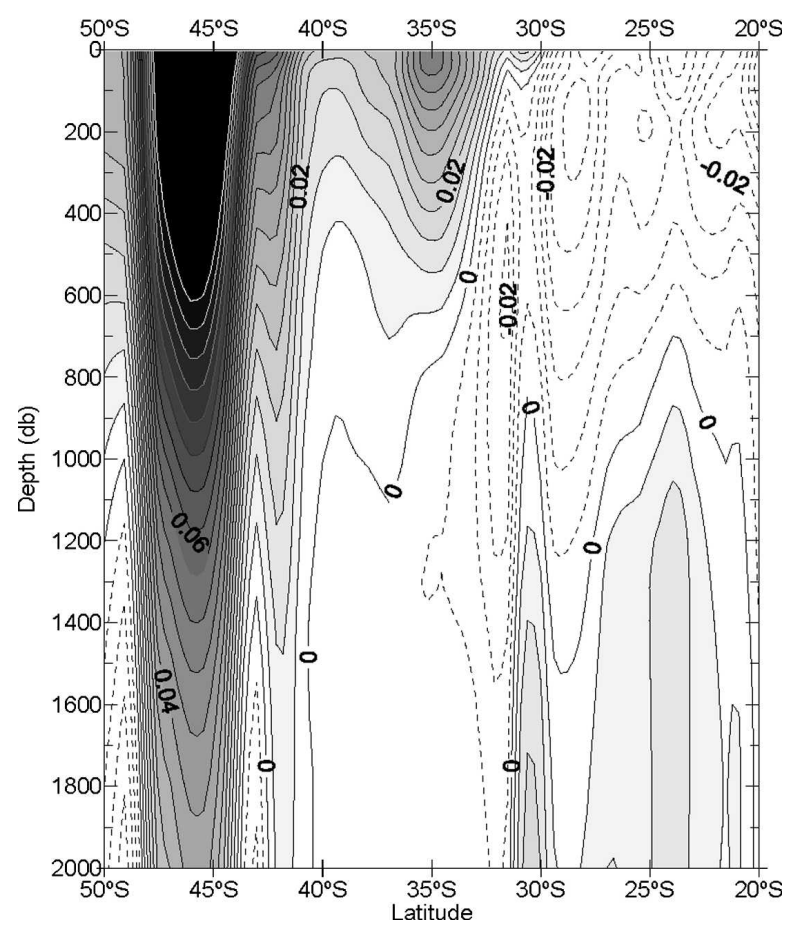

FIGURE 1.10: Vertical distribution along a meridional section at $5 \mathrm{~W}$ of annual mean eastward absolute velocity (contour interval is $0.005 \mathrm{~m} \mathrm{~s}-1$, and the eastward positive values are shaded). From Juliano and Alves (2007).

and Peterson (1990) calculated a transport between 30-37 Sv. Across the $0^{\circ}$ meridian, the SAC also carried the same $50 \mathrm{~Sv}$ of transport. Since no change was found between $30^{\circ} \mathrm{W}$ and $0^{\circ}$ meridian, they concluded, therefore, that there was no evidence for recirculation.

In agreement with Richardson (2007), Rodrigues et al. (2010) also found the split at around $7^{\circ} \mathrm{W}$ (Fig. 1.11). They suggested that the reason why earlier studies were not able to identify this splitting was because of their consideration of baroclinic flow only, which, from their results, was not visible in their baroclinic component, and therefore these studies regarded an eastward weakening of the current. Neither Richardson (2007) nor Rodrigues et al. (2010) cited or referenced the work of Juliano and Alves (2007), since the three articles entered the review process in their journals at a very close date.

Rodrigues et al. (2010) also found, from their results, that of the $39.7 \mathrm{~Sv}$ of the SAC coming from the MC only $8.7 \mathrm{~Sv}$ contribute to the northern branch of the current. The southern branch either rejoins ACC or flows into the AgCR. Some $4 \mathrm{~Sv}$ of these $8.7 \mathrm{~Sv}$ interact also with the $\mathrm{AgCR}$, while the remaining flow, along with the $10.3 \mathrm{~Sv}$ of the $\mathrm{BC}$ water and 8.5 Sv of the $\mathrm{AgC}$ to feed the $\mathrm{BeC}$ (Fig. 1.11). 


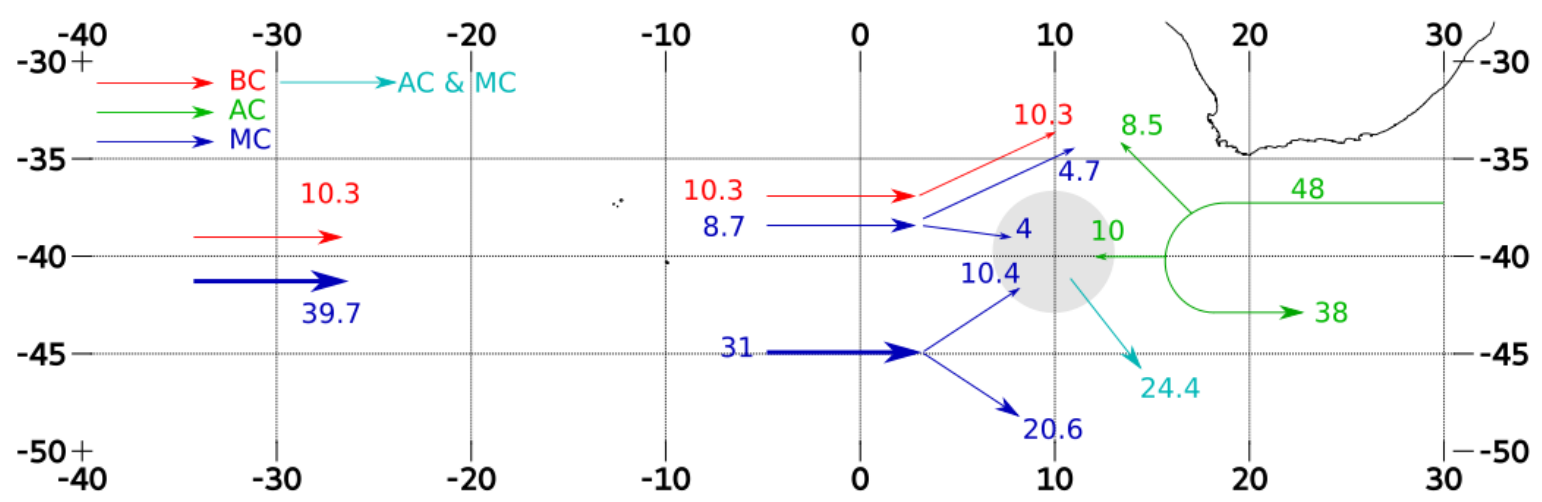

FIGURE 1.11: Illustration of Total Volume transport for the first 1000 dbar in Sv. Red arrow indicates Brazil Current (BC) Water; Blue Arrow, Malvinas Current (MC) Water; Green Arrow, Agulhas Current (AC) Water; Light blue arrow, combination of AC and MC. Adapted from Rodrigues et al. (2010).

\subsection{Scientific Questions and Hypotheses}

A few ambiguities arise from the literature review presented in the previous section regarding the SAC. One of those is the actual presence of the StHC as an independent current and not as a branch of the SAC. Another deals with the assertments of most of the reviewed works regarding the water masses transported by the zonal jets without presenting the T-S characteristics of the StHC-SAC-ACC system. Therefore, we formulate the following scientific questions to address those unresolved issues:

1. Is the StHC indeed an independent current fed by the first retroflection of the $B C$ as claimed by Juliano and Alves (2007) or part of the SAC split into two branches around $7^{\circ} \mathrm{W}$, as reported by Rodrigues et al. (2010)?

2. Does the water mass composition allow the differentiation between the SAC and the ACC as well as the indentification of they longitude they merge to exit the Atlantic Ocean basin?

3. What is the role of the StHC in SASG?

4. Is the SAC current unstable throughout its flow path and does the MAC acts a stabilizer to the SASG southern limb current system?

In order to attempt to answer these questions, we formulate two hypotheses which will be guide the current work. The first hypothesis deals with the descriptive aspects of the 
StHC-SAC-ACC system, while the latter aims to target the yet unexplored dynamics of the current system.

\section{Hypothesis \# 1}

The SAC-StHC with the same T-S signature travel zonally along SASG southern limb and close the subtropical gyre.

\section{Hypothesis \# 2}

The SAC system undergoes through important zonal changes in their jet configurations as they cross the South Atlantic basin, which in turn yields different patterns of mesoscale activity.

\subsection{Objectives}

\subsubsection{General Objective}

The main objective of the current work is to revisit the description of the StHC-SAC-ACC system with newly available data sets as well investigate the instability processes which give rise to the mesoscale variability in the SASG southern border.

\subsubsection{Specific Objectives}

- To identify the geostrophic current patterns between $30^{\circ} \mathrm{S}$ and $60^{\circ} \mathrm{S}$ using the new T-S climatologies available;

- To spatial variations of the climatology of the StHC, SAC and ACC through their water masses structure correlation;

- To construct a climatological volume transport charts using the new climatologies and compare with historical information;

- To identify the SAC-StHC current intensity and direction variability through daily data;

- To evaluate the SAC stability through a quasi-geostrophic, meridionally-oriented sectional, linear model. 


\section{Chapter 2}

\section{Study area and Data Sets}

\subsection{The Study Area}

The study area is comprised between $65^{\circ} \mathrm{S}-30^{\circ} \mathrm{S}$ of latitude, and $70^{\circ} \mathrm{W}-23^{\circ} \mathrm{E}$ of longitude (Figure 2.1). Away from the western and eastern continental margins, two main topographic emerge from the abyssal plain: the Zapiola Rise and the MAC. The former is a quasi-circular, $250 \mathrm{~km}$-radius topographic feature, which height exceeds $1300 \mathrm{~m}$ with a sediment cover of thicker than $3000 \mathrm{~mm}$ (Weijer et al., 2015). The Zapiola Rise occupies the southwestern corner of the Argentine Basin and plays a crucial role in separating most of the MC from the BC extension flows (Talley, 2011). The more barotropic flow of the MC extension is diverted to the south contouring the rise and, as seen in Chapter 1, originates the so-called northern branch of the ACC centered at about $50^{\circ} \mathrm{S}$ (Talley, 2011; Tomczak and Godfrey, 2013). The Zapiola Rise itself is characterized by a permanent barotropic anticyclonic circulation, which dynamics was unraveled by the Dewar (1998); Miranda et al. (1999). The MAC within the study area presents a northwest-southeast orientation and rises more than $2000 \mathrm{~m}$ from the ocean floor. 


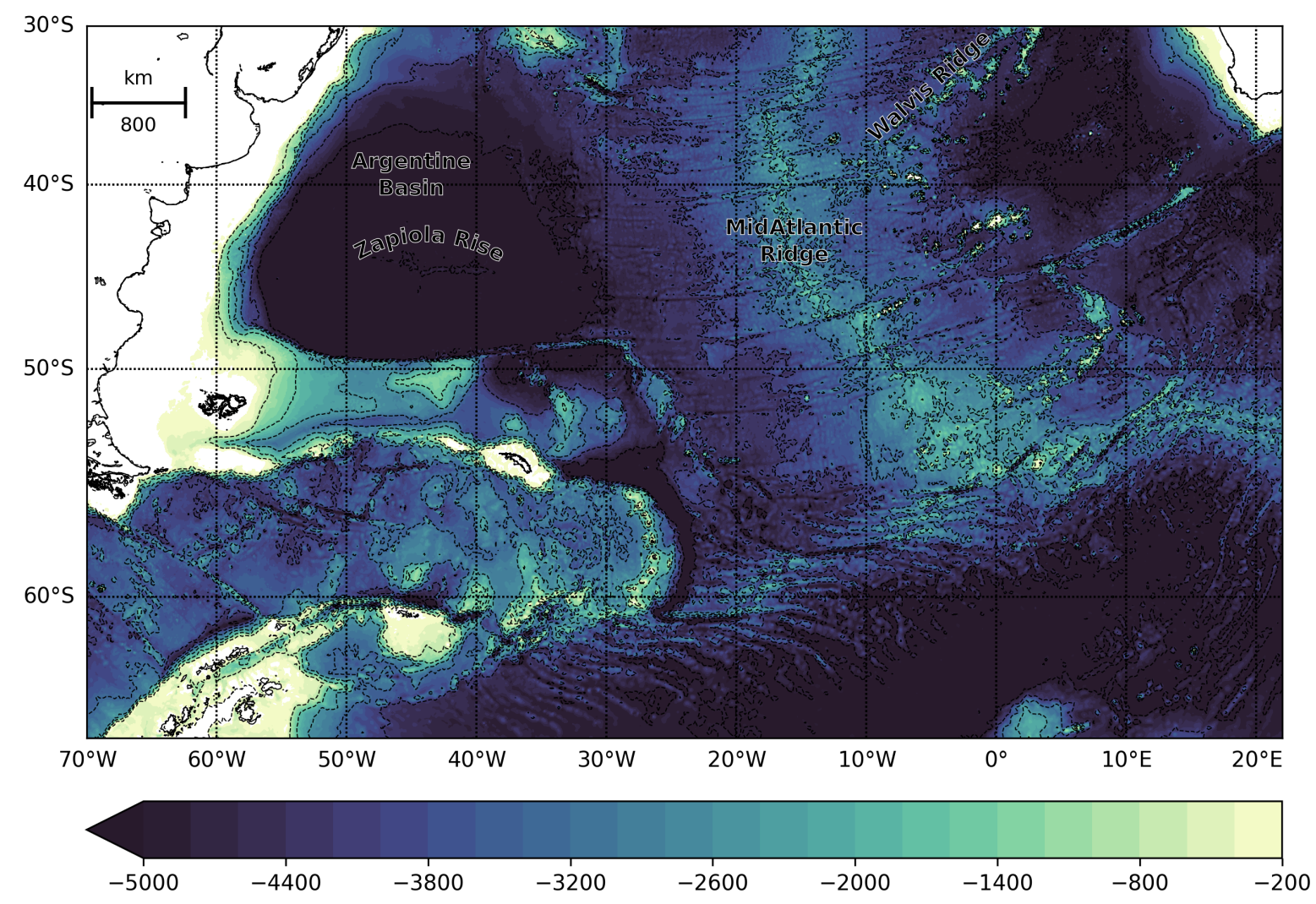

FIGURE 2.1: Region of Study with etopo data plotted on background.

\subsection{Data Sets}

In this investigation we employ different hydrographic climatologies as well as altimetric data to build the large scale patterns of ocean circulationin the southern border of South Atlantic Subtropical Gyre. Particularly for World Ocean Atlas (WOA) v2 2013 distributed by United States Oceanographic Data Center (NODC), Archiving, Validation and Interpretation of Satellite Oceanographic Data (AVISO) distributed by the French Center of Spatial Study (CNES), and ARMOR3D distributed by the French Operational Oceanography Mercator Project.

\subsubsection{WOA v2 2013}

WOA is a set of objectively analysed $1 / 4^{\circ}$ grid (climatological fields of in-situ temperature and salinity, among other properties) with 101 vertical levels. According to Boyer et al. (2013), the TS data have multiple source of measurements: CTDs, Nansen Bottle data, 
MBTs, XBTs, predecessor of profilling floats, ARGO floats, moored buoy data, and drifting buoy data.

\subsubsection{AVISO}

The so-called AVISO products produced by CLS Space Oceanography Division are derived from the SSALTO/Duacs processing integrating data from: HY-2A, Saral/AltiKa, Cryosat-2, OSTM/Jason-2, Jason-1, Topex/Poseidon, Envisat, GFO, ERS-1\&2. This data set extends from 1993 to 2016 . It is provided daily maps of absolute dynamic topographic (ADT) data at a $1 / 4^{\circ}$ grid.

The ADT maps result on the sum of the daily sea level anomaly (SLA) maps and the mean dynamic topography (MDT). The last MDT released is the CNES-CLS13 combined gravimetric satellite data (2 years of GOCE, 7 years of GRACE), and 20 years of altimetry and in-situ data (hydrologic and drifters data).

\subsubsection{ARMOR3D}

The ARMOR3D data utilizes accurate but sparse in-situ T-S data merged with high resolution altimeter and SST data to reconstruct global, instantaneous, 3D thermohaline and geostrophic velocity fields (Larnicol et al., 2006; Mulet et al., 2012; Guinehut et al., 2012). According to Larnicol et al. (2006), the ARMOR3D geostrophic velocity fields are constructed through 3 steps:

1. The SLA and SST satellite observations are projected onto the vertical via a multiple linear regression method and using covariances deduced from historical observations. This leads to synthetic fields;

2. The synthetic fields and all available in-situ T/S profiles are combined through an optimal interpolation method. This leads to the ARMOR3D T/S combined fields;

3. The thermal wind equation with a reference level at the surface is used to combine geostrophic current fields from satellite altimetry with ARMOR3D T/S fields and thus 
to generate the global 3D geostrophic current and geopotential height fields.

The TS and geostrophic velocity data sets are provided weekly since 1993. The vertical resolution consists of 33 levels, while the horizontal resolution is a $1 / 4^{\circ}$. 


\section{Chapter 3}

\section{Basic Methodology}

The methods to be presented in this chapter are separated in two sections. In the first section, we present the methods and techniques used to describe the StHC-SAC-ACC system (or hereafter SAC system) regarding its T-S characteristics, its sectional vertical distributions and volume transport across the Atlantic Ocean. In the second section, we show the tools employed to study the current system dynamics, especially in regards to its mesoscale activity, and energy fluxes.

\subsection{Methods of Hydrographic Data Analysis}

\subsubsection{Dynamic Method}

Base on the classical dynamic method we can infer the geostrophic velocity as:

$$
u(p)=u_{r}-\frac{1}{f_{0}} \int_{p}^{p_{r}} \frac{\partial \delta}{\partial y} d p^{\prime}
$$

where $u_{r}$ is the reference velocity from a known isobaric level, $f_{0}$ is the Coriolis parameter, $p\left(p_{r}\right)$ is the (reference) pressure level, $\delta$ is the specific volume anomaly, and $y$ is the meridional distance coordinate. The reference pressure is usually chosen as the level where there is a null velocity.

WOA was used to make this estimate from its geopotential anomaly calculated from the climatological data offered. A fixed level of no motion was chosen to be approximately $3000 \mathrm{dbar}$ (hence, $u_{r}$ is set 0 ), which is in agreement with Stramma and Peterson (1990)'s original description of the SAC. The surface geostrophic currents (relative to $3000 \mathrm{dbar}$ ) 
are then compared to surface currents estimated from the AVISO (Archiving, Validation and Interpretation of Satellite Oceanographic Data) altimetry-derived sea surface height.

The transport values for SAC system in the region were calculated by the height gradients and compared with the literature, using the following equation:

$$
\begin{array}{r}
T=\iint_{R} u d y d z, \\
R=\left\{(y, z) \in \mathbb{R}^{2}: Y_{0} \leq y \leq Y_{1} ; H_{0} \leq z \leq 0\right\}
\end{array}
$$

where $u\left(\mathrm{~ms}^{-1}\right)$ is the zonal velocity; $R$ is the region being integrated; $Y_{0} / Y_{1}$ is the south/north most limit of the current; $H_{0}$ is the reference depth chosen for integrating.

\subsubsection{Relative geostrophic velocities from ARMOR3D}

For the ARMOR3D, the geostrophic velocity components were also referenced at the $3000 \mathrm{dbar}$ as a way to remove the statistical artifacts produce by its vertical extrapolation. This data set, first published in 2012, combines sparse in situ temperature and salinity profile data with satellite altimetry and sea surface temperature data to provide a high spatial and temporal resolution of 3-D temperature, salinity and absolute geostrophic velocity fields. The ARMOR3D velocity fields are referenced at the surface by the AVISO dataset. We, however, observed that probably due to less available TS data to compute the climatology the imposition of the AVISO geostrophic velocities yields to very unrealistic barotropic component in all zonal jets under investigation in this work. Therefore, in order to avoid this issue and to allow direct comparison with the WOA geostrophic velocity relative to $3000 \mathrm{dbar}$, we opt to compute the ARMOR3D geostrophic field relative to this isobaric level.

\subsubsection{T-S- $\sigma_{0}$ correlation analysis}

From the potential temperature $(T)$, salinity $(S)$, and density ${ }^{1}$ vertical profiles we performed the Pearson Correlation Coefficient at the origin site of $\mathrm{SAC}\left(40^{\circ} \mathrm{S}, 40^{\circ} \mathrm{W}\right.$.)

\footnotetext{
${ }^{1}$ We treat as density in fact the deviation of the potential density referenced at the surface as $\sigma_{0}$ from the reference value of $1000 \mathrm{~kg} \mathrm{~m}^{-3}$. Mathematically we express it as $\sigma_{0}=\rho_{T}(T, S, 0)-1000$.
} 


$$
r=\frac{\sum_{i=1}^{n}\left(x_{i}-\bar{x}\right)\left(y_{i}-\bar{y}\right)}{\left[\sum_{i=1}^{n}\left(x_{i}-\bar{x}\right)^{2}\right]^{1 / 2}\left[\sum_{i=1}^{n}\left(y_{i}-\bar{y}\right)^{2}\right]^{1 / 2}}
$$

where $x_{i}, y_{i}$ are the sample value at specific depth, and $\bar{x}$ and $\bar{y}$ are the sample mean.

\subsubsection{Geostrophic velocities from AVISO}

From the downloadable Absolute Dynamic Topography $(\eta)$ fields from the whole time series, we computed the average and inferred the geostrophic velocities as being

$$
\begin{gathered}
u=-\frac{g}{f_{0}} \frac{\partial \eta}{\partial y} \\
v=\frac{g}{f_{0}} \frac{\partial \eta}{\partial x} .
\end{gathered}
$$

Since the definition of the streamfunction is: $u=-\partial \psi / \partial y$ and $v=\partial \psi / \partial x$, we can infer it as

$$
\psi=\frac{g}{f_{0}} \eta
$$

\subsubsection{Basic Statistics}

As auxiliary analysis methods to perform the intercomparison between the data sets, we employ first and second statistical momenta and tests of normality, such as the t-student test. Correlation coeficients and normalized roo mean square errors (rms) are used as figures of statistical merit to compare two fields of the same oceanographic quantity Pinardi and Robinson (1987). The normalized rms is given by:

$$
R M S=\sqrt{\frac{<\left(g_{1}-g_{2}\right)^{2}>}{<g_{2}^{2}>}}
$$

\subsection{Linear Instability Analysis}

\subsubsection{Sectional Mixed Instability Model}

In order to evaluate the linear instability properties of the StHC-SAC-ACC system, we follow Kontoyiannis (1997) and construct a quasi-geostrophic (QG) model of a flat-bottomed, 
stratified ocean on a $\beta$-plane centered at the latitude of the SAC core (see A for algebraic details). The model solves the Chaney-Stern equation for meridional sections which encompass the latitude range of interest $\left(30^{\circ} \mathrm{S}-60^{\circ} \mathrm{S}\right)$ and applied for different longitudes. We chose the meridians for the model application based upon the results of the jet patterns obtained in the analyses described in the previous section. The longitudes $40^{\circ} \mathrm{W}, 20^{\circ} \mathrm{W}, 10^{\circ} \mathrm{W}$, and $10^{\circ} \mathrm{E}$ revelead to be the appropriate choices.

The QG potential vorticity equation given in terms of the geostrophic pressure is

$$
\left(\partial_{t}+U \partial_{x}\right)\left\{\nabla^{2} p^{\prime}+\partial_{z}\left[\left(\frac{f_{0}}{N}\right)^{2} p_{z}^{\prime}\right]\right\}+p_{x}^{\prime} Q_{y}=0
$$

where $U$ is the basic state zonal velocity, $p^{\prime}$ is the pressure deviation relative to its basic state $P, N$ is the Brünt-Väisälä (or stratification) frequency, and $Q_{y}$ is the meridional gradient of the basic potential vorticity $Q$ defined by

$$
Q_{y}=\beta-U_{y y}+\partial_{z}\left[\left(\frac{f_{0}}{N}\right)^{2} U_{z}\right]
$$

The Eq. 3.7 is solved considering rigid lids at the surface and bottom, as well as imposing an idealized zonal channel to restrain the unstable waves to noninfinite wavelengths. Hence, the boundary conditions are

$$
\begin{cases}w=0 & z=0, H \\ v=0 & y=0, W .\end{cases}
$$

where $y=0, W$ represent the meridional limits of the channel.

We reach the traditional Charney-Stern instability equation for mixed instabilities by assuming a solution to Equation 3.7 in the form of

$$
p^{\prime}(x, y, z, t)=\operatorname{Re}\left[\Phi_{n}(y, z) e^{i k\left(x-c_{n} t\right)}\right]
$$

where $P h i$ is the $n$th complex meridional-vertical structure eigenfuction associated with the $n$th complex eigenvalue $c_{n}$, which denotes the complex phase speed of the pressure pertubations. 
Hence, the well-known eigenvalue problem to be solved is

$$
(U-c)\left\{\Phi_{y y}-k^{2} \Phi+\left[\left(\frac{f_{0}}{N}\right)^{2} \Phi_{z}\right]_{z}\right\}+Q_{y} \Phi=0
$$

subject to the boundary conditions

$$
\left\{\begin{array}{l}
(U-c) \Phi_{z}=U_{z} \Phi \quad z=0, H \\
\Phi=0 \quad y=0, W
\end{array}\right.
$$

The eigenvalue problem 3.11 written in its canonical form is simply

$$
(\mathbf{A}-\mathbf{I} \tilde{c}) \tilde{\Phi}=0 .
$$

The method chosen for solving Equation 3.13 is finite difference method. The reader is refered to Appendix B for the detailed discretization of Equation 3.11. The model provides us the real phase speed, the growth rate, as wells the pressure perturbation spatial configuration of the unstable modes.

We limit our calculations to a maximum wavenumber value of $0.1 \mathrm{~km}^{-1}$ which corresponds to five times of the inverse of the average radius of deformation of the area, which is in agreement with the QG theory (Tulloch et al., 2011).

\subsubsection{Local Baroclinic Instability Model}

Solving the local instability poblem for the whole region provides an interesting view of the differences of linear instability properties. This kind of study was conducted by Tulloch et al. (2011), as well as Gill et al. (1974), Johns (1988), Rocha et al. (2014).

The local instability focus on the potential vorticity reduced by the stretching and $\beta y$ terms. Therefore, only vertical shear instability is solved. The local instability model equations can be writtern by neglecting the relative vorticity gradient in Equation 3.8, which in turn becomes:

$$
Q_{y}^{(L)}=\beta-\frac{\partial}{\partial z}\left[\left(\frac{f_{0}}{N}\right)^{2} U_{z}\right]
$$


While the governing conservation equation is still Equation 3.7, its boundary conditions is reduced to:

$$
w=0 \quad z=0, H
$$

The solution proposed, therefore, is similar to Equation 3.10, but with the eigenfunction depending only on the $z$ axis. The Charney-Stern equation written for the local model, then becomes:

$$
(U-c)\left\{-k^{2} \Phi+\frac{\partial}{\partial z}\left[\left(\frac{f_{0}}{N}\right)^{2} U_{z}\right]\right\}+Q_{y}^{(L)} \Phi=0 .
$$

As presented in the seccional model, we consider here only the zonal velocity. Other authors (such as Smith (2007) and Tulloch et al. (2011)) have included both velocity components. We then acknowledge that our results will likely represent an underestimation of the real growth rates. We again should state we opted for that in order to allow direct comparison with the seccional model.

\subsection{Analysis of Energetics}

To analyse the dynamical field of the SAC System we calculated for the AVISO data set (which is the only data that provides daily outputs) the Mean Kinectic Energy (MKE)

$$
M K E=\frac{1}{2}<u^{2}+v^{2}>
$$

Its eddy fields were also computed as the Mean Eddy Kinectic Energy (MEKE)

$$
M E K E=\frac{1}{2}\left(<u^{\prime 2}>+<v^{\prime 2}>\right)
$$

For both of these physical quantities, we also computed the monthly climatological field for each six sections of interest $\left(40^{\circ} \mathrm{W}, 30^{\circ} \mathrm{W}, 20^{\circ} \mathrm{W}, 10^{\circ} \mathrm{W}, 0^{\circ}, 10^{\circ} \mathrm{E}\right)$. MKE and MEKE are expressed in this text in terms of energy per unit of mass $\left(\mathrm{m}^{2} \mathrm{~s}^{-2}\right)$. The maps of MEKE presented were low-pass filtered to remove any variability longer than 120 days in order to assure that we will examine only mesoscale variation. 
Finally, we present the standard deviation of the Okubo-Weiss field, which is defined as

$$
W=S_{n}^{2}+S_{s}^{2}-\omega^{2}
$$

where $S_{n}=\partial u / \partial x-\partial v / \partial y$ and $S_{s}=\partial v / \partial x+\partial u / \partial y$ are the normal and shear components of strain, and $\omega=\partial v / \partial x-\partial u / \partial y$ is the relative vorticity. Although we miss the leading dominant term of the equation by taking its standard deviation, we are interested in seeing the main field variability of vortices. 


\section{Chapter 4}

\section{The SAC System Description}

\subsection{Intercomparison between WOA, ARMOR3D and AVISO data sets}

In order to analyse and employ the three datasets interchangeably, we opt to intercompare the three datasets focusing solely on the surface fields. Of course, the intercomparison of T-S- $\sigma_{0}$ fields will consist only of analysis of the WOA and the ARMOR3D sets. The surface velocity ones will encompass the three datasets used in this work.

\subsubsection{The surface hydrographic fields}

The comparison between the datasets began with WOA and ARMOR3D temperature, salinity, and density profile (Figure 4.1). From both datasets, it is visible the presence of a dense, cold-fresh water tongue coming from the $\mathrm{MC}$ and conflicting with the less dense and warmer-saltier water from BC (Figure 4.1 A1; A2; B1; B2). Both datasets also show the fresh water bulb coming from La Plata River at the South America continental margin.

The largest differences between the datasets, however, arise near the BMC. At the northern/southern branch $\left(39^{\circ} \mathrm{S} / 49^{\circ} \mathrm{S}\right)$, ARMOR3D/WOA results in a denser water (Figure 4.2.C). Even though ARMOR3D results in warmer water in both branches (Figure 4.2.A), WOA results in a slightly more saline water at the southern branch (Figure 4.2.B). The density, however, does not change excessively between data sets. The average deviation of ARMOR3D and WOA are $4.521 \times 10^{-2} \pm 0.181 \mathrm{~kg} \mathrm{~m}^{-3}$ and $4.994 \times 10^{-2} \pm 0.1474 \mathrm{~kg} \mathrm{~m}^{-3}$, respectively. 

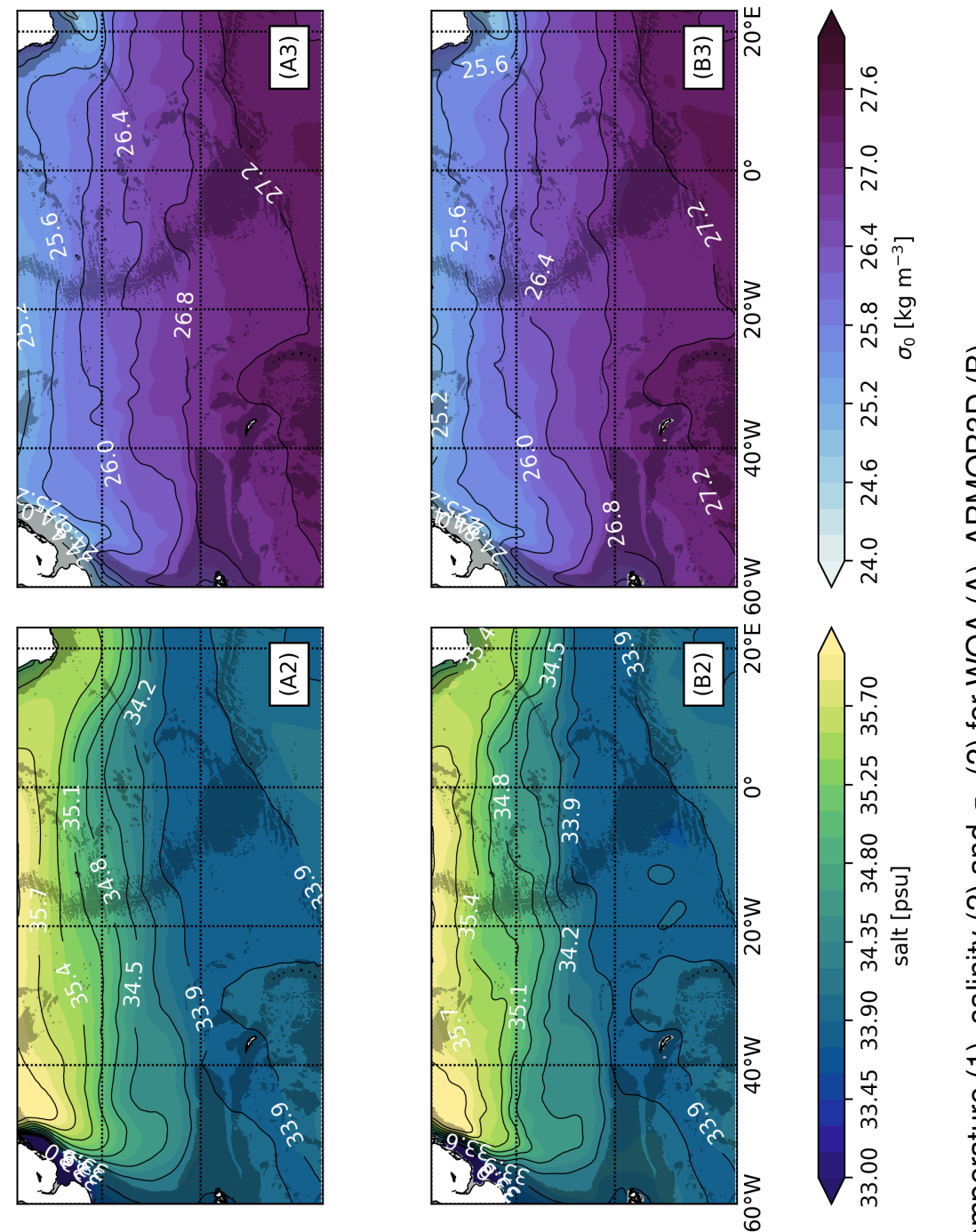

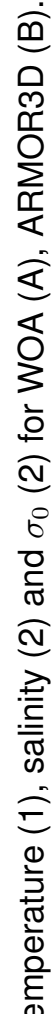
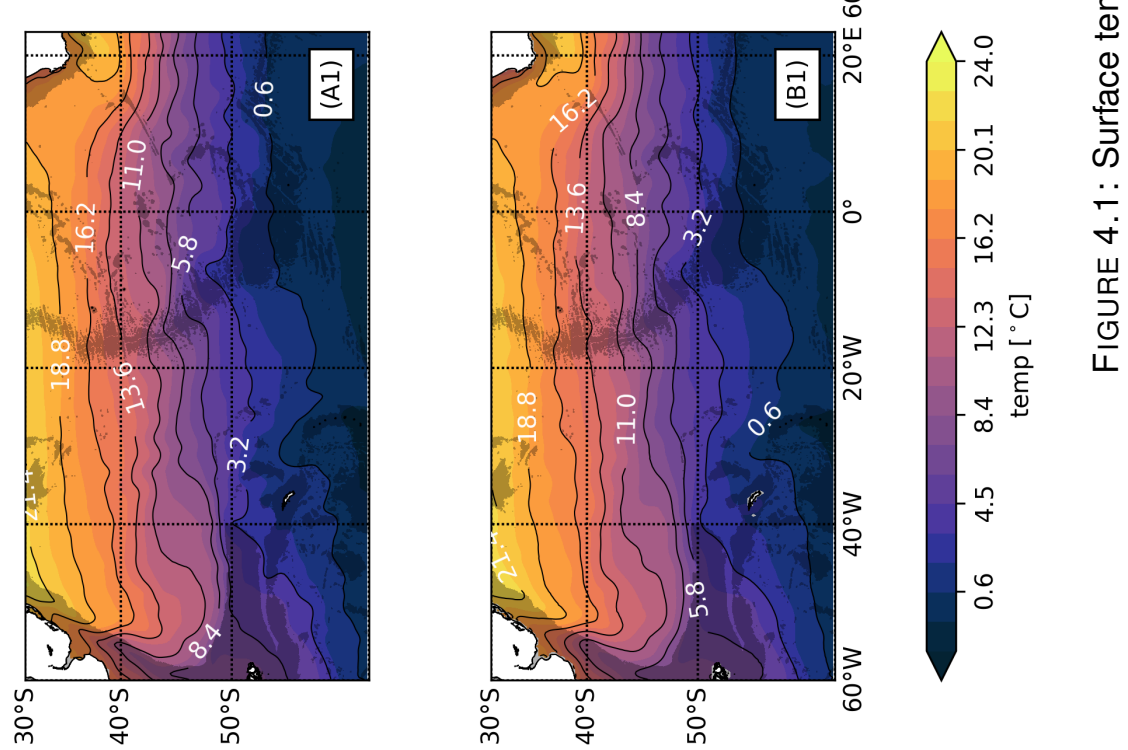
Although ARMOR3D estimate an approximately $2^{\circ} \mathrm{C}$ warmer temperature at the South American shelf (which is the region of the largest temperature difference of the datasets), most of the temperature of the region is slightly overstimated by WOA at a maximum of $1^{\circ} \mathrm{C}$. Although the average temperature difference is not discrepant, each data set exceeds the temperature in an average of $0.201 \pm 0.211^{\circ} \mathrm{C}$ and $0.209 \pm 0.163^{\circ} \mathrm{C}$ for ARMOR3D and WOA, respectively.
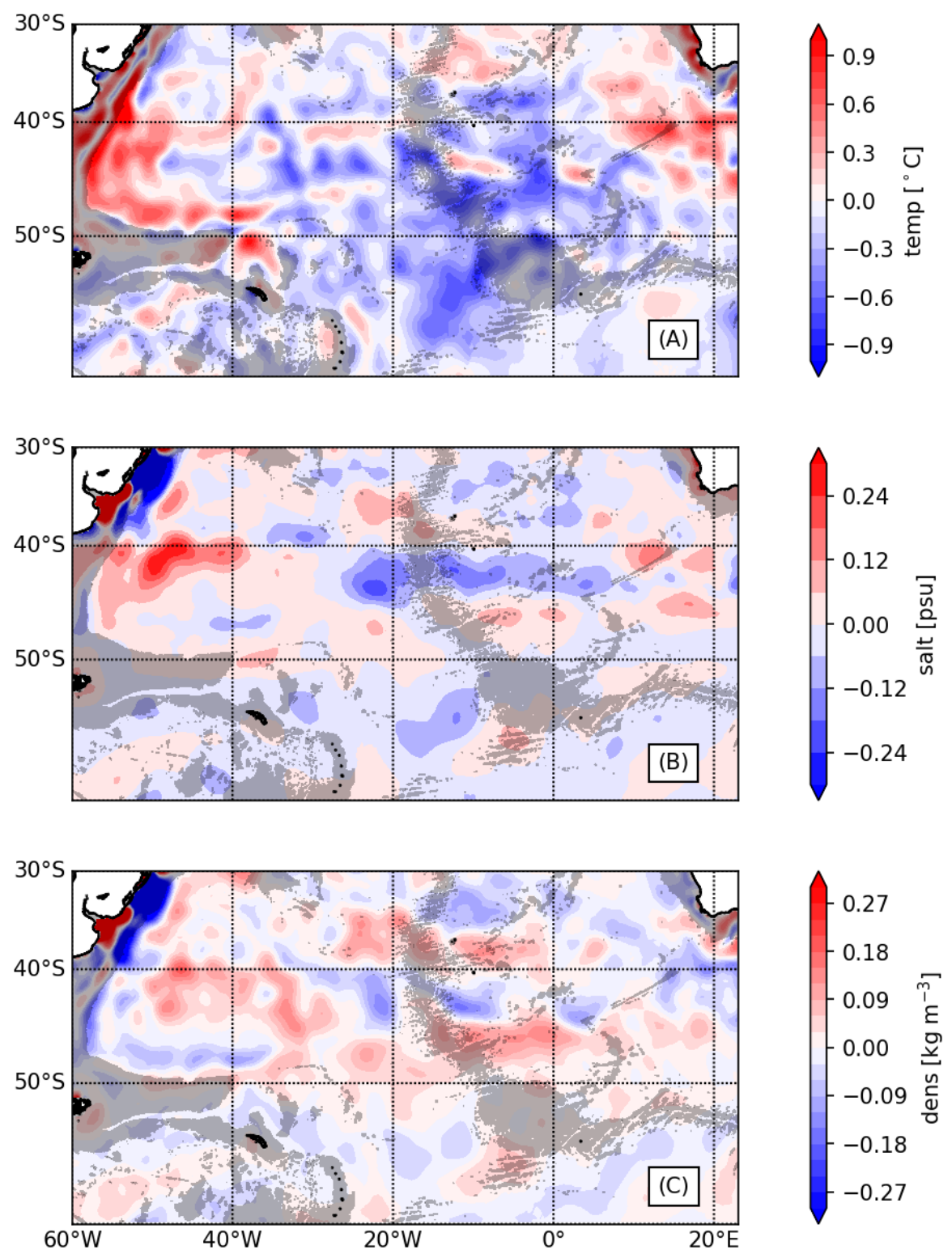

FIGURE 4.2: WOA-ARMOR3D difference fields of temperature (A), salinity (B) and density $(\mathrm{C})$. 
For the salinity differences, WOA shows at $42^{\circ} \mathrm{S}$ as small bulb extending eastward through the midoceanic ridge. However, the largest discrepancy in this property happens close to the La Plata River where there are higher salinity levels in the ARMOR3D by a maximum of 10.480 psu and at some parts in the WOA data with a maximum of 4.155 psu. Despite these differences, the average difference of $5.213 \times 10^{-2} \pm 0.252 \mathrm{psu}$ and $5.603 \times 10^{-2} \pm 0.179$ psu for ARMOR3D and WOA, respectively, can be considered small for the study region.

The overall spatial average and standard deviation, which can be seen in Table 4.1, imply that both datasets agree and the largest differences found are localized in regions away from the study region. This can be futher confirmed by the spatial average and standard deviation of the fields themselves (Table 4.1 and Figure 4.3.A) which shows that for the temperature, salinity, and density the difference are in the range of $0.5 \%, 0.05 \%$, and $0.05 \%$, respectively. The field histograms of the data sets (Figure 4.3.B) also seem to mostly agree between themselves.

TABLE 4.1: Spatial average and stantard deviation of the difference between the data sets (Figure 4.2) and the spatial fields of WOA and ARMOR3D.

\begin{tabular}{c|ccc}
\hline & Difference between data sets & ARMOR3D & WOA \\
\hline Temperature $\left({ }^{\circ} \mathrm{C}\right)$ & $-7.311 \times 10^{-2} \pm 0.264$ & $9.272 \pm 7.124$ & $9.221 \pm 7.202$ \\
& & & \\
Salinity (psu) & $-1.046 \times 10^{-2} \pm 0.220$ & $34.504 \pm 0.797$ & $34.485 \pm 0.813$ \\
& & & \\
$\sigma_{0}\left(\mathrm{~kg} \mathrm{~m}^{-3}\right)$ & $2.513 \times 10^{-3} \pm 0.172$ & $26.410 \pm 0.750$ & $26.397 \pm 0.791$ \\
\hline
\end{tabular}

From a zonal gradient perspective of density (Figure 4.4.A3 and Figure 4.4.B3), it can be seen a similar pattern of steep gradients between both data sets. Two steep gradients are found at the BMC, which are likely to be the STF and SAF; at the BeC and the La Plata river there is algo a significant gradient result, and, finally, a wide zonal band gradient extending from northwest region to the $\mathrm{BeC}$. This feature might likely be associated with StHC. But again, a few differences may be denoted between the data sets.

At the BMC, WOA seems to result a stronger surface density gradient in what seems to be the northern and southern branch of the confluence, despite the southern branch being leaner than ARMOR3D. It is also apparent at the mid oceanic ridge, around $10^{\circ} \mathrm{W}, 45^{\circ} \mathrm{S}$, a more pronounced gradient from WOA. 

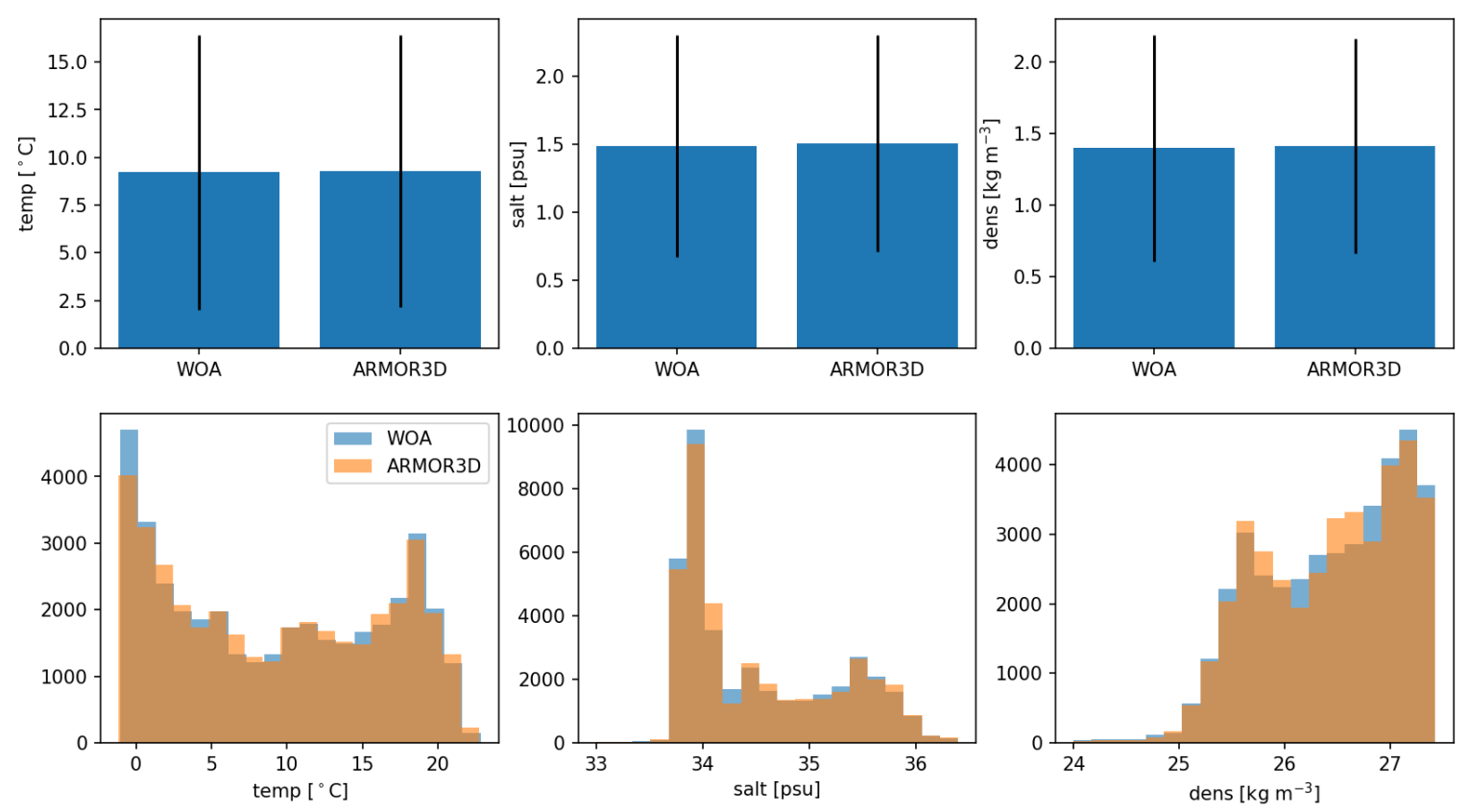

FIGURE 4.3: Spatial average and standard deviation (upper panels) and histogram (lower pannels) of temperature (left panels), salinity (middle panels), and density (right panels) for WOA and ARMOR3D.

Analysing the temperature gradient (Figure 4.4.A1 and Figure 4.4.B1), we observer that the stronger density gradient at the southern branch of the BMC and at the mid-oceanic ridge are probably justified by the temperature gradient of WOA being much steeper than the ARMOR3D results. However, from the salinity gradient (Figure 4.4.A2 and Figure 4.4.B2), ARMOR3D in general seems to show higher values than WOA, specially at the northern branch of BMC extending zonally through the SA ocean.

From the literature, the range of isotherms used to define the STF and SAF structures is approximately $11.5^{\circ} \mathrm{C}-18.5^{\circ} \mathrm{C}$ and $4^{\circ} \mathrm{C}-8^{\circ} \mathrm{C}$, respectively. As these fronts present robust seasonal temperature variations, for instance the winter and the summer values are $11.5^{\circ}$ C- $15.5^{\circ} \mathrm{C}$ and $14.5^{\circ}-18.5^{\circ} \mathrm{C}$, respectively Stramma and Peterson (1990); Stramma (1992); Belkin and Gordon (1996). To produce an annual climatology map for the fronts only by using isotherms patterns can be misleading, therefore, we add the temperature gradient maps to detect the bands at which those fronts occur on a mean climatological sense. 

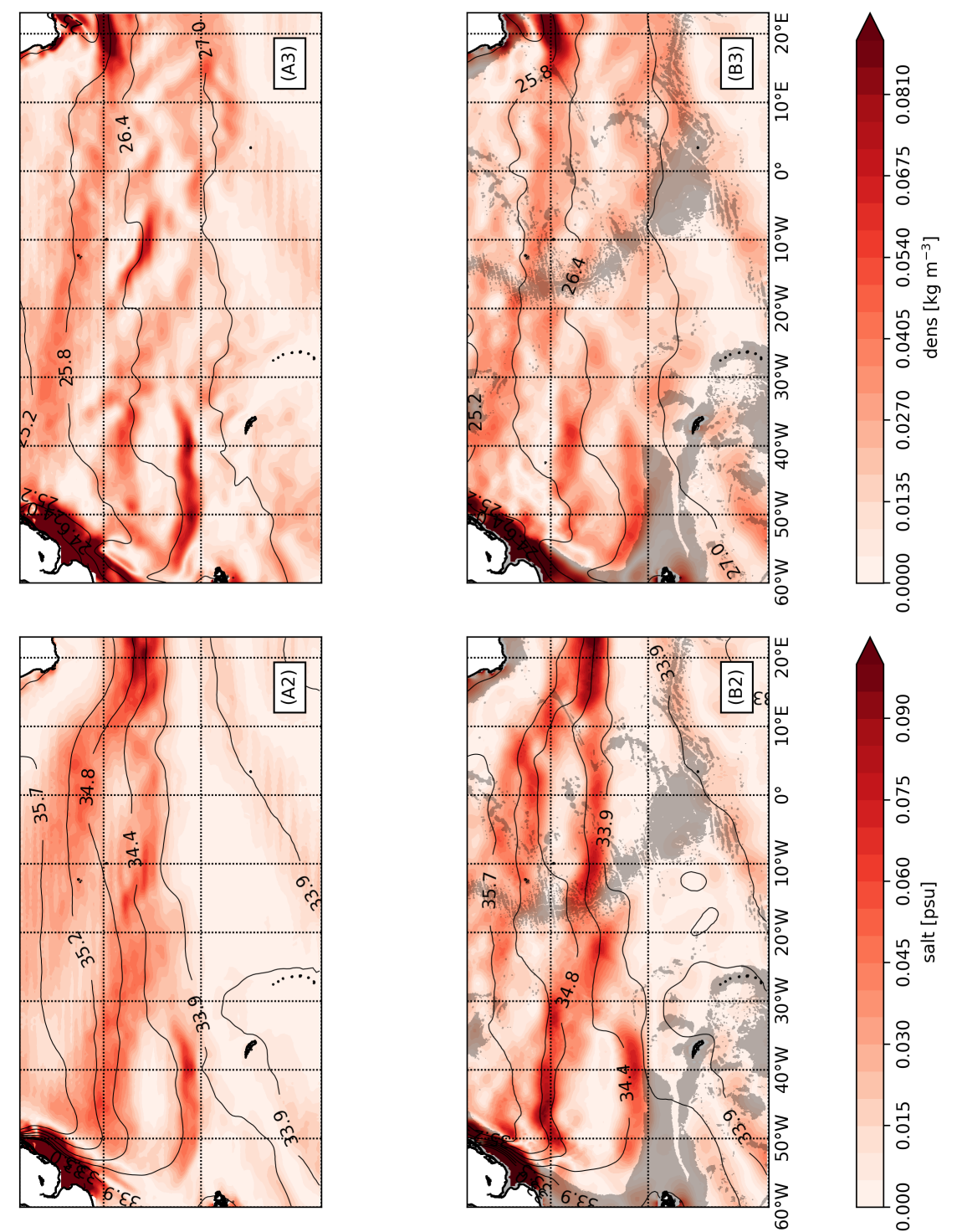

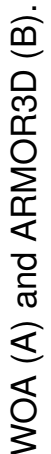

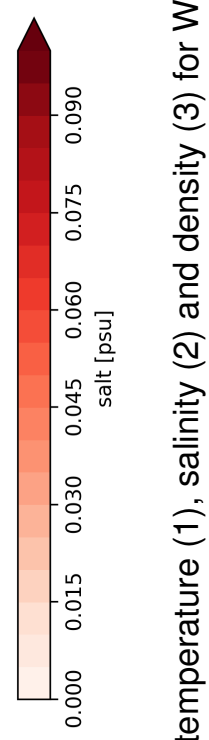
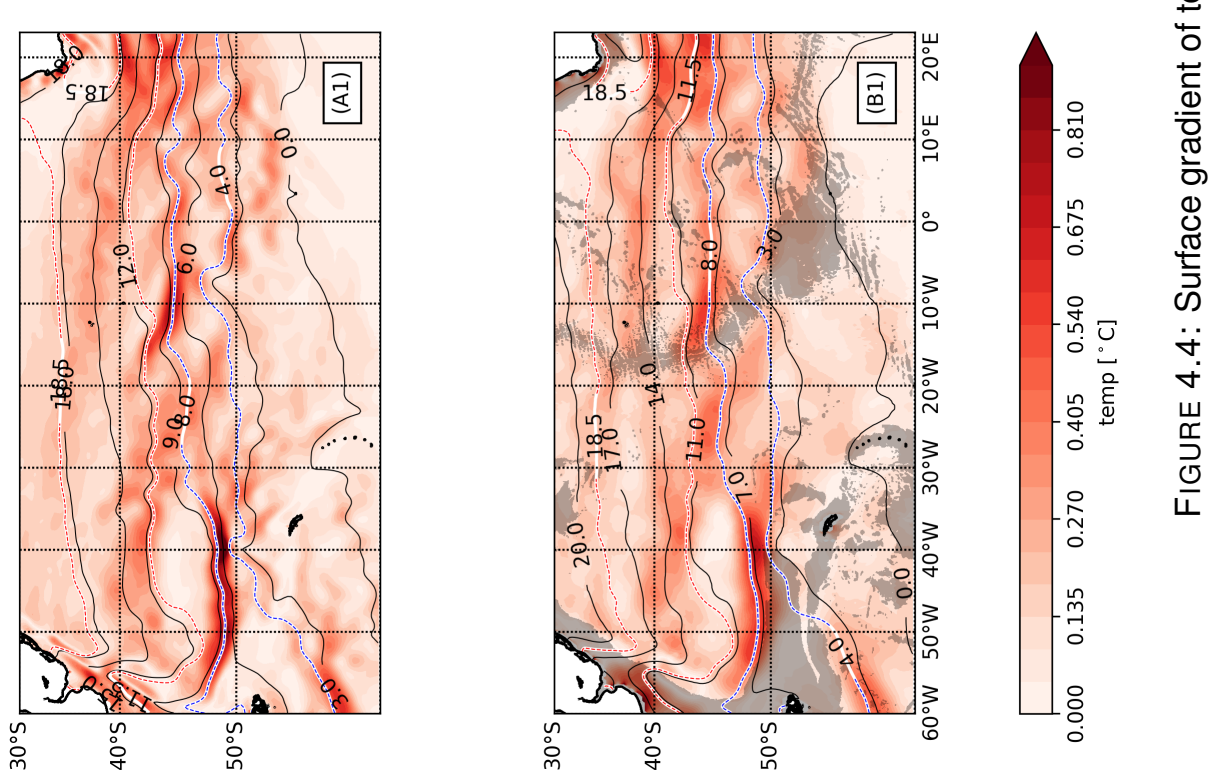


\subsubsection{Surface Geostrophic Velocities and Streamfunction}

From the geostrophic velocity (Figure 4.5), at the BMC, it can be seen two main jets flowing eastward at the north and southern branch, which would probably be the SAC and the northern branch of the ACC, respectively. At the surface level, between the BMC and the mid-oceanic ridge, both jets flow together making it visually indistinguishable. At this tectonic feature $\left(10^{\circ} \mathrm{W}\right)$ the currents change trajectory getting stapered and consequently stronger. Past it, they diverge and flows toward the Indian Ocean.

From the SAC flow pattern, at $30^{\circ} \mathrm{W}$, it is visible a detachment flowing separately from the current. This separation is likely resulting in the StHC streaming zonally along with SAC. However, while ARMOR3D and AVISO results in quite similar information, a few discrepancies from the data are present.

WOA, in general, shows a more coherent flow than the other data sets. At the BMC, the WOA results in a wider southern branch reaching speeds up to $0.31 \mathrm{~m} \mathrm{~s}^{-1}$, while at the northern a maximum speed of $0.15 \mathrm{~m} \mathrm{~s}^{-1}$, which is in agreement of Stramma and Peterson (1990). However, ARMOR3D and AVISO shows a maximum speed of 0.6 and $0.7 \mathrm{~m} \mathrm{~s}^{-1}$ for the northern branch, and 0.21 and $0.22 \mathrm{~m} \mathrm{~s}^{-1}$ for the southern branch, respectively. At the mid oceanic, WOA estimate a maximum speed of $0.25 \mathrm{~m} \mathrm{~s}^{-1}$, while ARMOR3D and AVISO 0.34 and $0.37 \mathrm{~m} \mathrm{~s}^{-1}$, respectively.

A similar pattern can be seen in the speed intensity difference between data sets (Figure 4.5.B). The smallest differences are seen in the comparison of ARMOR3D-AVISO (Figure 4.5.B3) reaching a maximum difference of $0.11 \mathrm{~m} \mathrm{~s}^{-1}$, but an average of $0.01 \pm 0.02 \mathrm{~m} \mathrm{~s}^{-1}$. WOA-ARMOR3D (Figure 4.5.B1), in contrast, show a maximum $0.49 \mathrm{~m} \mathrm{~s}^{-1}$, but an average of $0.02 \pm 0.05 \mathrm{~m} \mathrm{~s}^{-1}$, while WOA-AVISO (Figure 4.5.B2) result in differences up to $0.48 \mathrm{~m}$ $\mathrm{s}^{-1}$ and an average of $0.02 \pm 0.06 \mathrm{~m} \mathrm{~s}^{-1}$.

Most of these differences arise at the MC, where ARMOR3D and AVISO estimate a higher velocity than WOA, and AVISO estimates, in general, a higher velocity than ARMOR3D. Other significant difference happen at the $\mathrm{BeC}$ when comparing the datasets with WOA.

Analysing the current function of the three data sets we removed its mean fields and calculated the normalized RMS (Table 4.2). AVISO and ARMOR3D are show to be approximately $30 \%$ stronger than the WOA. Although the methodology acquired for each of the sets 

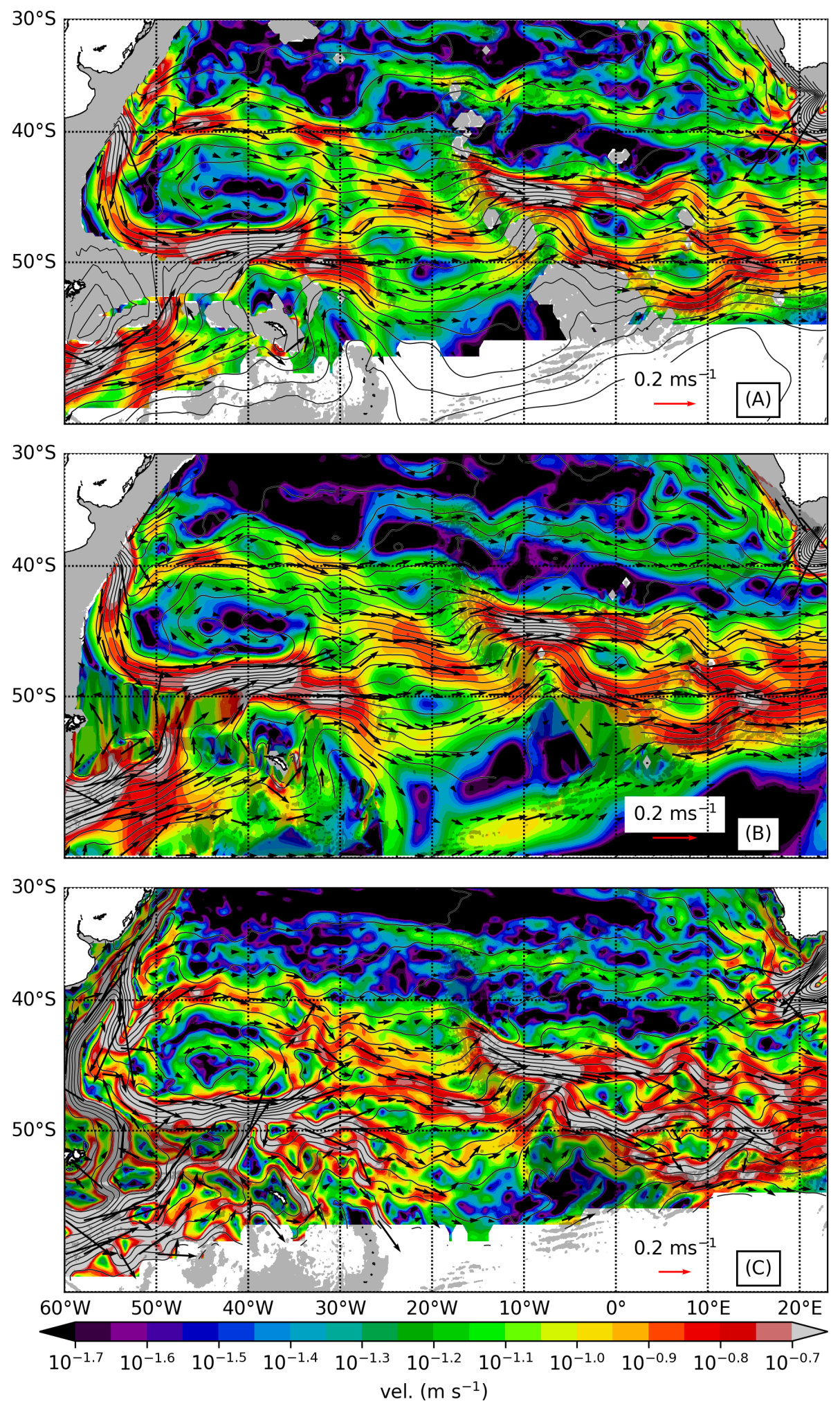

FIGURE 4.5: Surface geostrophic velocity (vectors) and the streamfunction field (red curves) of WOA (A), ARMOR3D (B) and AVISO(C). Isolines are the streamfunction. 
TABLE 4.2: RMS calculated between each of the data sets.

\begin{tabular}{c|ccc}
\hline & WOA-ARMOR3D & WOA-AVISO & AVISO-ARMOR3D \\
\hline RMS & 0.29 & 0.28 & 0.03 \\
\hline
\end{tabular}

are different, the results, however, are similar.

\section{2 $\mathbf{T S} \sigma_{0}$ Correlation Maps}

Given the conflicting information in literature regarding the STF position, it is possible that there are also discrepancies between its associated currents. To identify such currents we opt to perform an alternative methodology aiming to separate the subtropical current from the subantarctic and polar ones.

At $40^{\circ} \mathrm{W}$ we identify three main eastward flows: two originated the $\mathrm{BMC}$ and a more southern one traversing directly from the Passage of Drake. The TS profile curve at each of the three cores are distinct (Figure 4.6) and we can see that each current carries a different water mass, and, therefore, present different TS structures. The most evident distinction between the composition of water masses is the presence of SACW (a long quasi-linear decrease of TS with depth at around $26.9 \mathrm{~kg} \mathrm{~m}^{-3} \sigma_{4}$ ) at the SAC origin flow. In contrast, the other currents do not show a salient temperature variation and are mostly confined at cold temperatures. It is suggested that these profiles are within the subtropical, subantarctic and polar vertical structure, for the north $\left(40^{\circ} \mathrm{S}\right)$, central $\left(49^{\circ} \mathrm{S}\right)$, and south $\left(56^{\circ} \mathrm{S}\right)$ profiles.

Since there is a fair distinction among these sites, there is, therefore, a justification to use the correlation method to visualize the actual position of the SAC. Figures 4.7 and 4.8 shows the correlation for the temperature, salinity and density parameters. For the temperature, the band that best correlates with the SAC is within $97 \%-100 \%$; for the salinity, is the $90 \%-100 \%$; and for the density is between $99.5 \%-100 \%$.

The parameter that best seems to reflect the SAC seems to be the temperature for both datasets. A main zonal band is visible following zonally from the westward portion of the SASG southern limb basin to its eastward limit. For both datasets is also seen a strong temperature correlation within the BMC. East from the mid oceanic ridge the temperature correlation seems stronger at the northern part of the amalgamate current with a expressive 

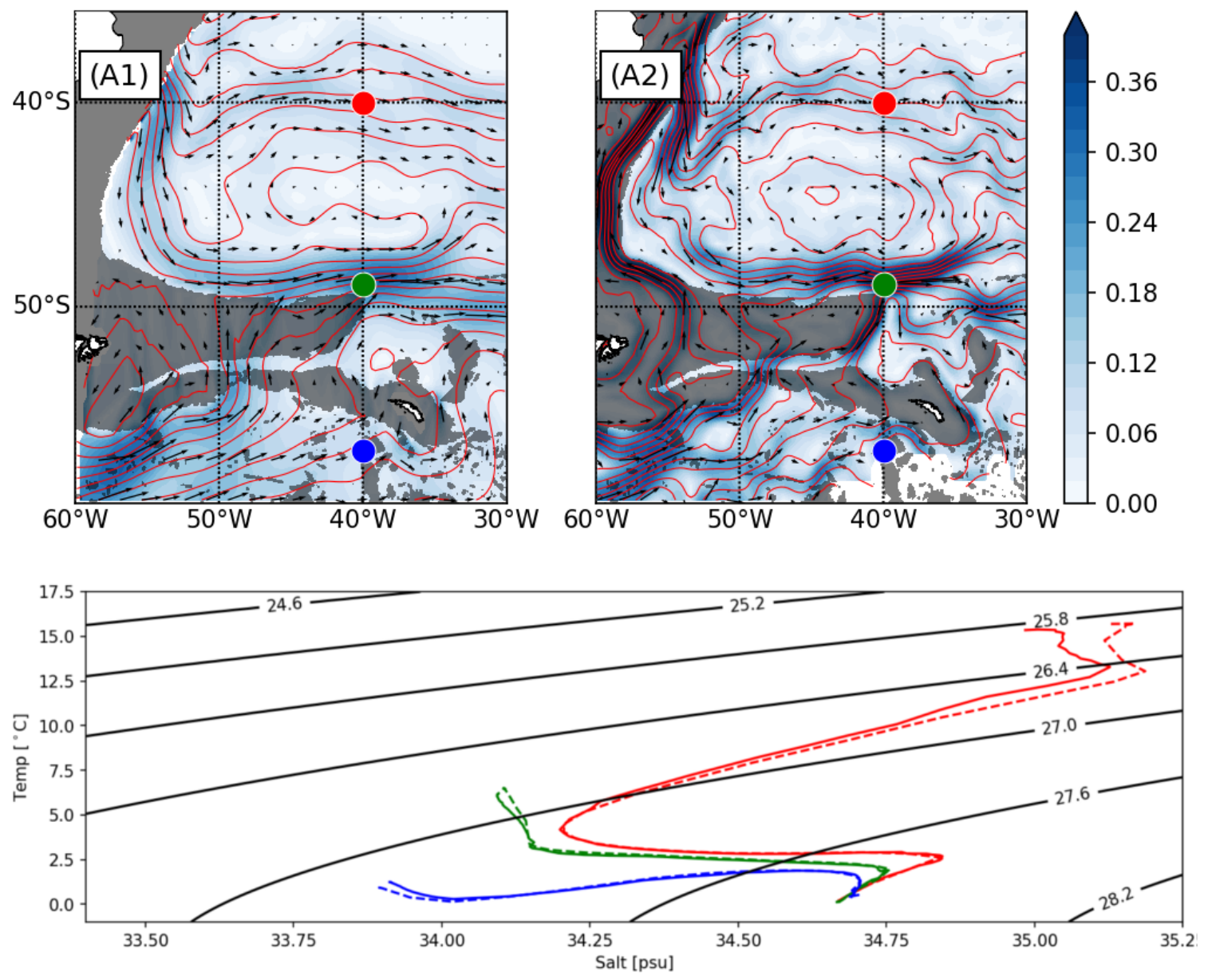

FIGURE 4.6: Location of the core of the SAC (red), ACCn (green), and ACCs (blue) for WOA (A1) and ARMOR3D (A2), and respective TS profile (bottom panel) for WOA (solid lines) and ARMOR3D (dashed lines). Red isolines represent the streamfunction.

polarward decrease of correlation, suggesting that the current amalgamate does not mix its water mass composition.

The salinity structure correlation parameter extends from the westward limit to only $10^{\circ} \mathrm{W}$ and also shows a strong correlation close to the antarctic sea divided by a narrow zonal band of low correlation. This is likely related to the meridional variability of the salinity not being as expressing as the temperature. Additionally, the correlation SAC correlation significantly drecreases zonally east of the MAC.

The density correlation parameter does not show any substantial patterns for the SAC. Just as the salinity, the density does not varies greatly meridionally within the region, and, therefore, the minimun correlation for the region is $98.5 \%$. 

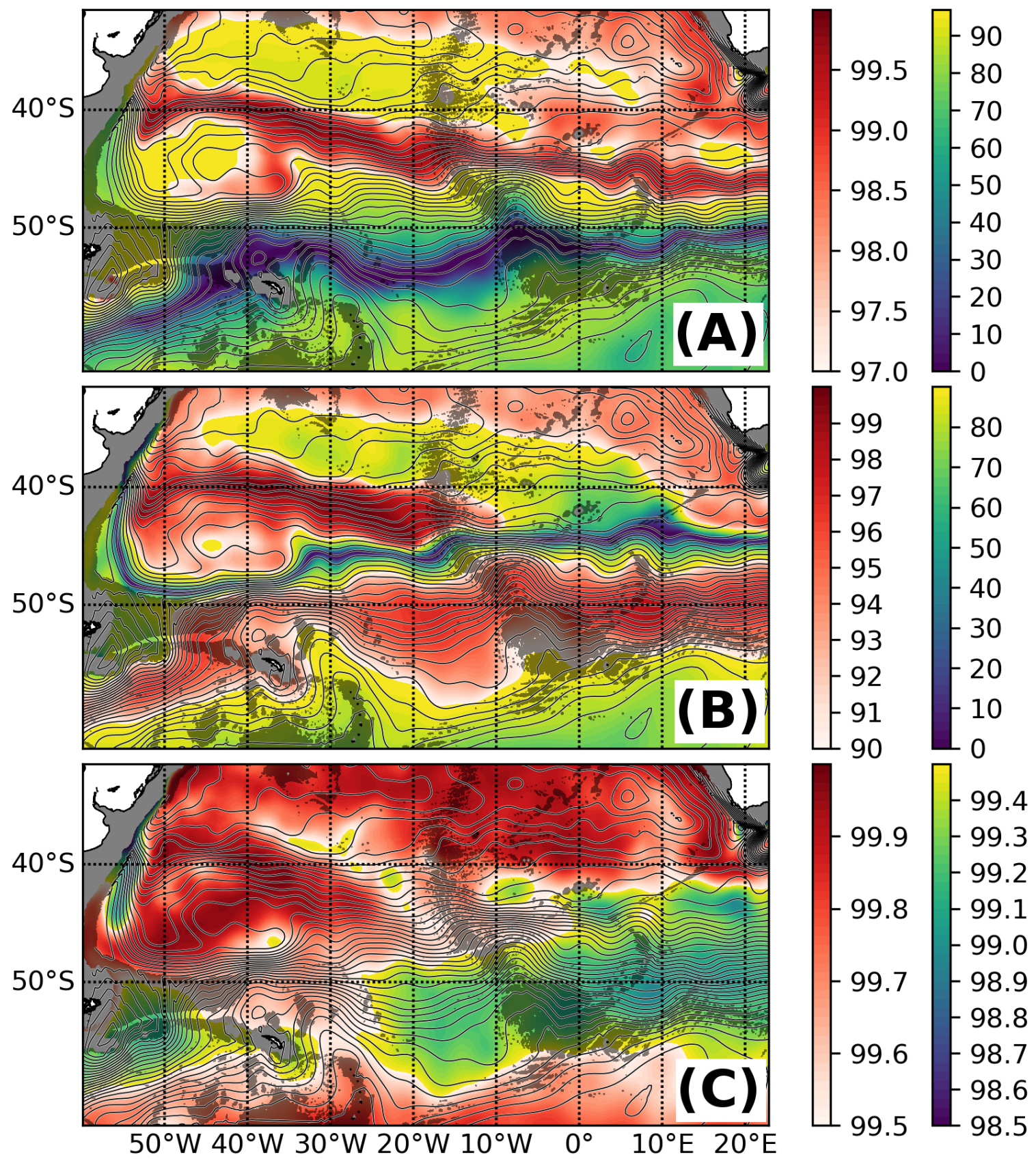

FIGURE 4.7: Water correlation for the WOA dataset for the temperature (A), salinity (B) and density (C) variables. The isolines represent the streamfunction parameter. Isolines represent the streamfunction. 

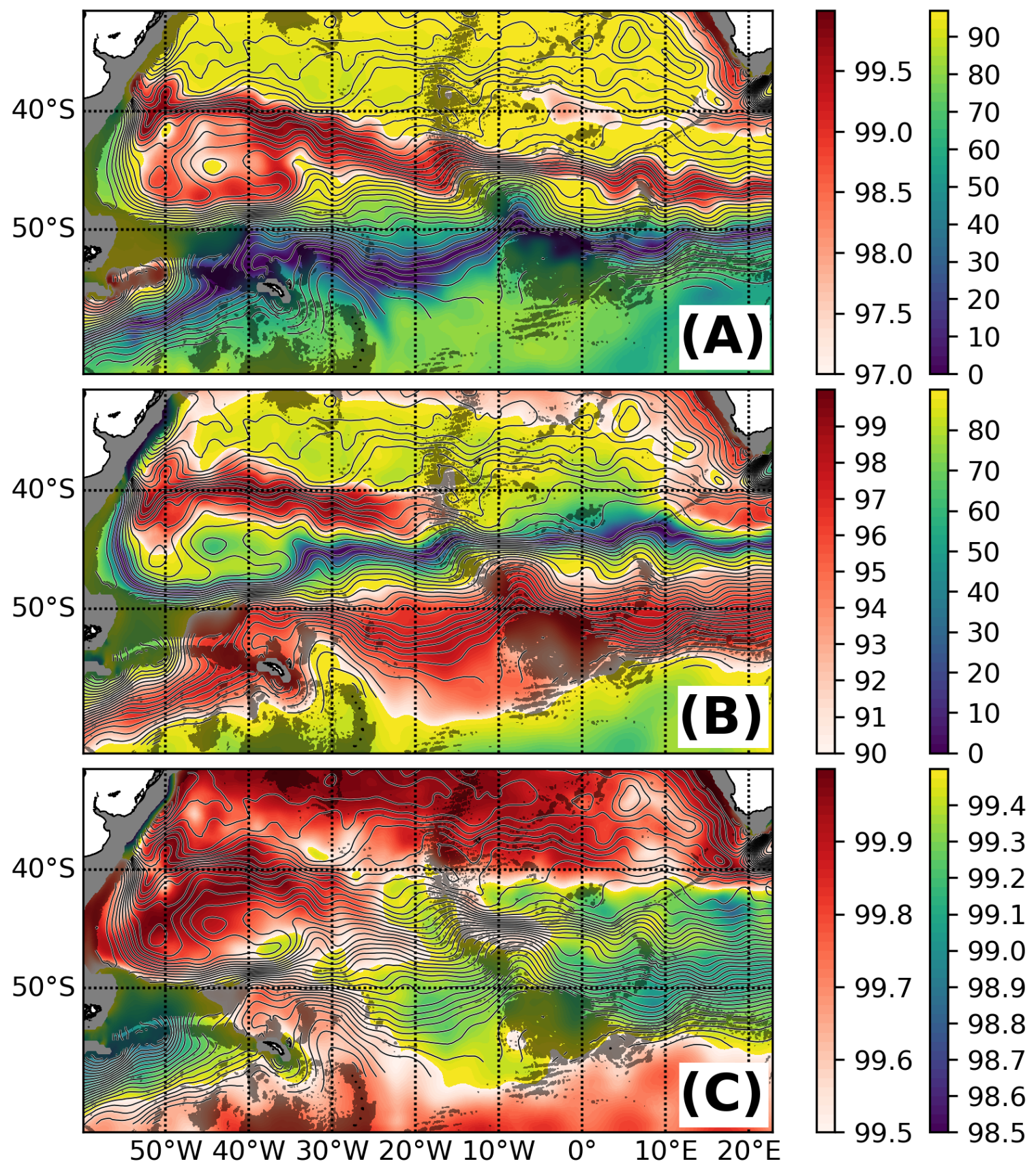

FIGURE 4.8: Water correlation for the ARMOR3D dataset for the temperature $(A)$, salinity $(B)$ and density $(C)$ variables. The isolines represent the streamfunction parameter. Isolines represent the streamfunction. 


\subsubsection{Current Persistence}

We delimited the band of occurrence of the subtropical correlation by the SAC and StHC, subantarctic correlation by the nothern branch of the ACC (ACCn), and polar correlation by the southern branch of the ACC (ACCs) with the analysis conducted in the previous section. We now focus on the two subtropical jets direction and persistence. In order to do so we employ the whole AVISO absolute dynamic topography series and plot a windrose map at each of the six selected longitudes. The latitudes were chosen to uniquivocally capture the SAC and StHC jets.

At $40^{\circ} \mathrm{W}$ we can see that the SAC has a $36 \%$ probability of going between southeastward and northeastward (Figure 4.9). However, it does not have a predominant direction, probably due to the current still being highly affected by the BMC feature which also makes its speed over $0.6 \mathrm{~ms}^{-1}$ in most of the eastward directions. In contrast, the StHC is much slower (with a maximum speed between $0.2-0.4 \mathrm{~ms}^{-1}$ ) and predominantly southeastward with an almost $41 \%$ probability (Figure 4.10). This flow is likely not directly associated with the BMC feature, but from the first BC retroflection. This has been already argued by Juliano and Alves (2007) in their original description of the StHC.

At $30^{\circ} \mathrm{W}$ the SAC is now much weaker (maximum of $0.4-0.5 \mathrm{~ms}^{-1}$ ) and predominantly southeastward (with $35 \%$ probability). It also has an $18 \%$ probability of going northeastward. However, the StHC flows predominantly between the southeastward and northeastward with a $42 \%$ probability.

Close to the Mid-Oceanic Ridge, at $20^{\circ} \mathrm{W}$ the SAC is slightly stronger (reaching a maximum between 0.2-0.4 $\mathrm{ms}^{-1}$ ) and with a much more dominant direction (56\% mainly eastward). This predominant path followed by SAC might be caused due to proximity of the mid-atlantic ridge or through the influence of ACC current. On the other hand, the StHC has stronger temperature structure correlation (Figure 4.7 and 4.8) and it also is much more intense (having comparable speeds to the SAC). Its flow pattern also presents a preferred direction, with a main eastward flow (with a $47 \%$ probability) which might corroborate with the presence of the ridge system.

At $10^{\circ} \mathrm{W}$ the SAC-ACC merge into a single flow. Although most of the SAC flows along with ACC, having a southeastward predominance (around 50\%) part of the SAC branches off (around 15\%) and turns northeastward and probably merge into the StHC. This latter 


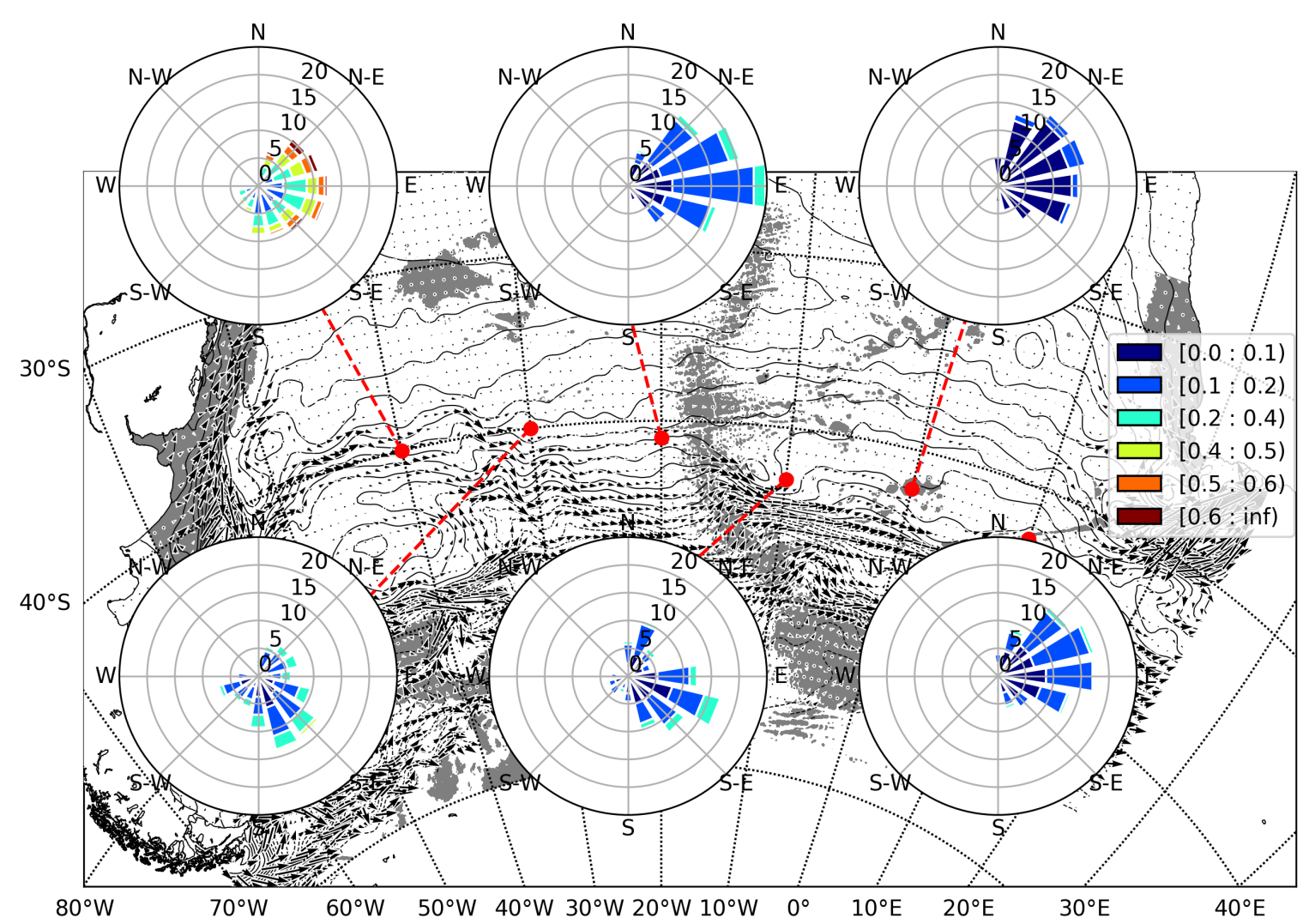

FIGURE 4.9: AVISO Windrose geostrophic current time series for SAC at $40^{\circ}$ $\mathrm{W}, 30^{\circ} \mathrm{W}, 20^{\circ} \mathrm{W}, 10^{\circ} \mathrm{W}, 0^{\circ}, 10^{\circ} \mathrm{E}$. Isolines represent the streamfunction.

current does not change remarkably east from the Mid Atlantic Ridge. Around $41 \%$ the current has a tendency to flow eastward.

At $0^{\circ}$ the SAC still flows along with the ACC. However, the current has now a more notable direction variability, but it preserves its northeastward tendency of around $41 \%$. Likewise the StHC has also more variability, but with a preferred southeastward direction (35\% probability). At this latitude the StHC branches off into two nuclei flowing eastward (Figure 4.5). However, the precise position of the this branching varies slightly from each data set. For this current, this branching and probably the higher current variability might be in consequence of the proximity to the $\mathrm{AgC}$ influence.

At $10^{\circ} \mathrm{E}$ the SAC still has a northeast tendency (49\% probability) feeding the southern branch of the StHC. In contrast, this latter current is now absent of a prevailing flow direction and much more intense than its previous locations, which corroborates our suggestion that there is significant influence of the $\mathrm{AgC}$ in the StHC current. 


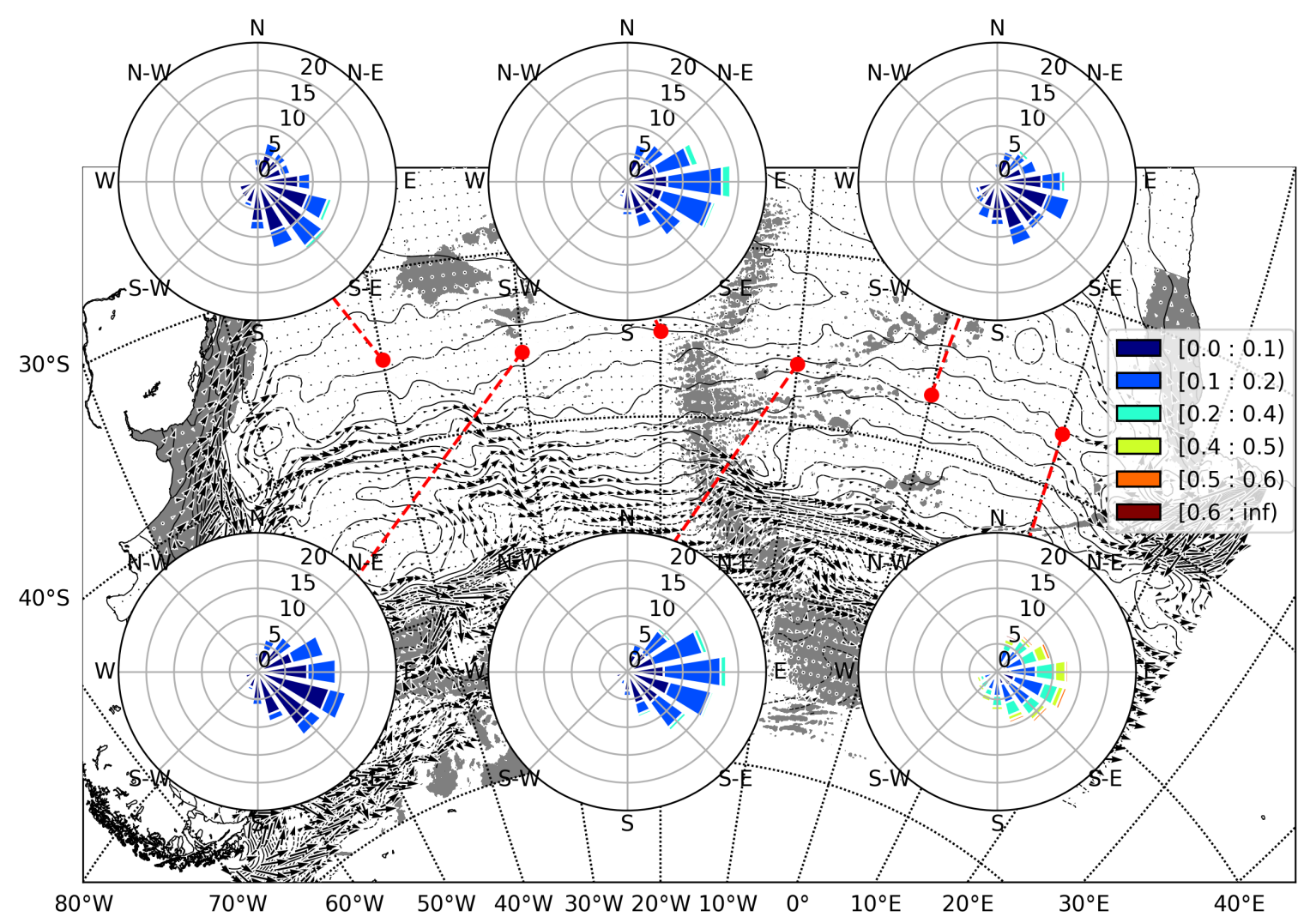

FIGURE 4.10: AVISO Windrose geostrophic current time series for StHC at $40^{\circ} \mathrm{W}, 30^{\circ} \mathrm{W}, 20^{\circ} \mathrm{W}, 10^{\circ} \mathrm{W}, 0^{\circ}, 10^{\circ} \mathrm{E}$. Isolines represent the streamfunction. 


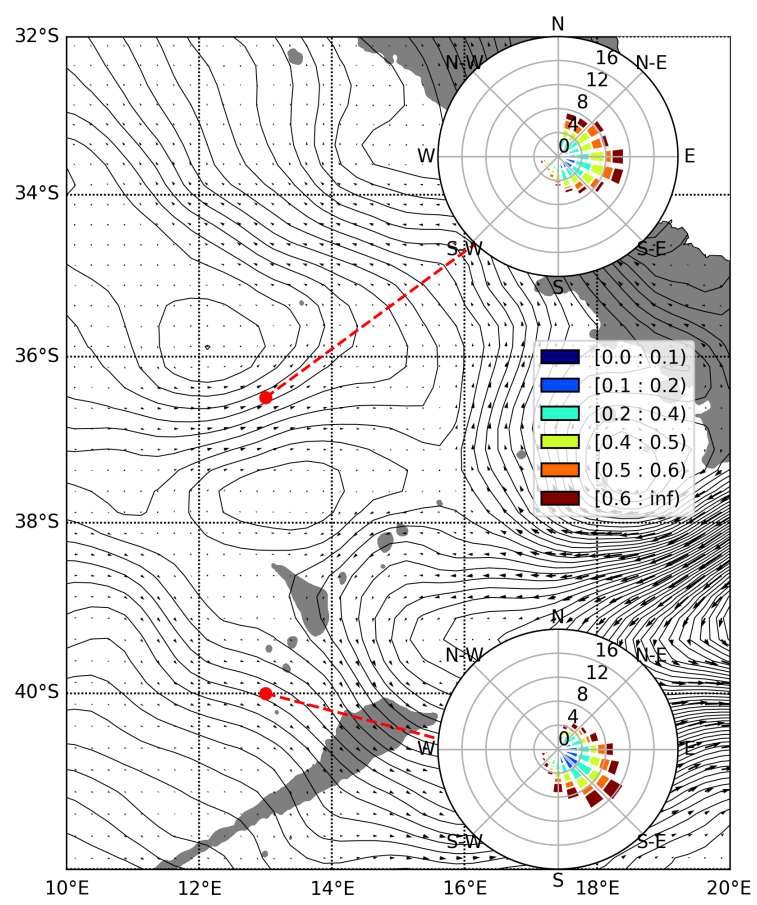

FIGURE 4.11: AVISO Windrose geostrophic current time series for the northern and southern branch of the $\mathrm{StHC}$ at $13^{\circ} \mathrm{E}$. Isolines represent the streamfunction.

At $13^{\circ} \mathrm{E}$ we now check the windrose from each branch of the StHC (Figure 4.11). Both of them reach a maximum over $0.6 \mathrm{~ms}^{-1}$. Climatologically, the northern branch turns northwestward flowing along the $\mathrm{BeC}$, while the southern branch flows southeastward and flows along $\mathrm{AgC}$ retroflection to the Indian Ocean. Although the latter branch shows preferred northeastward direction (33\%), the northern branch has a higher variability, but still with $45 \%$ of it flowing northeastward.

\subsubsection{Velocity Vertical Structure and Volume Transports}

In this section we will analyse climatologically the vertical section of the speed of both WOA and ARMOR3D data sets. We will associate this analysis with the density correlation map computed.

East of the BMC (at $40^{\circ} \mathrm{W}$ ) the SAC is located between $44^{\circ} \mathrm{S}-35^{\circ} \mathrm{S}$ as a double nuclei jet (Figure 4.12). The transport of these jets are found to be around 32.1/31.6 Sv and 10.1/11.6 Sv for the southern and northern jet, respectively (as found in WOA/ARMOR3D data). Transport estimates at this site differs little of that found by Stramma and Peterson 


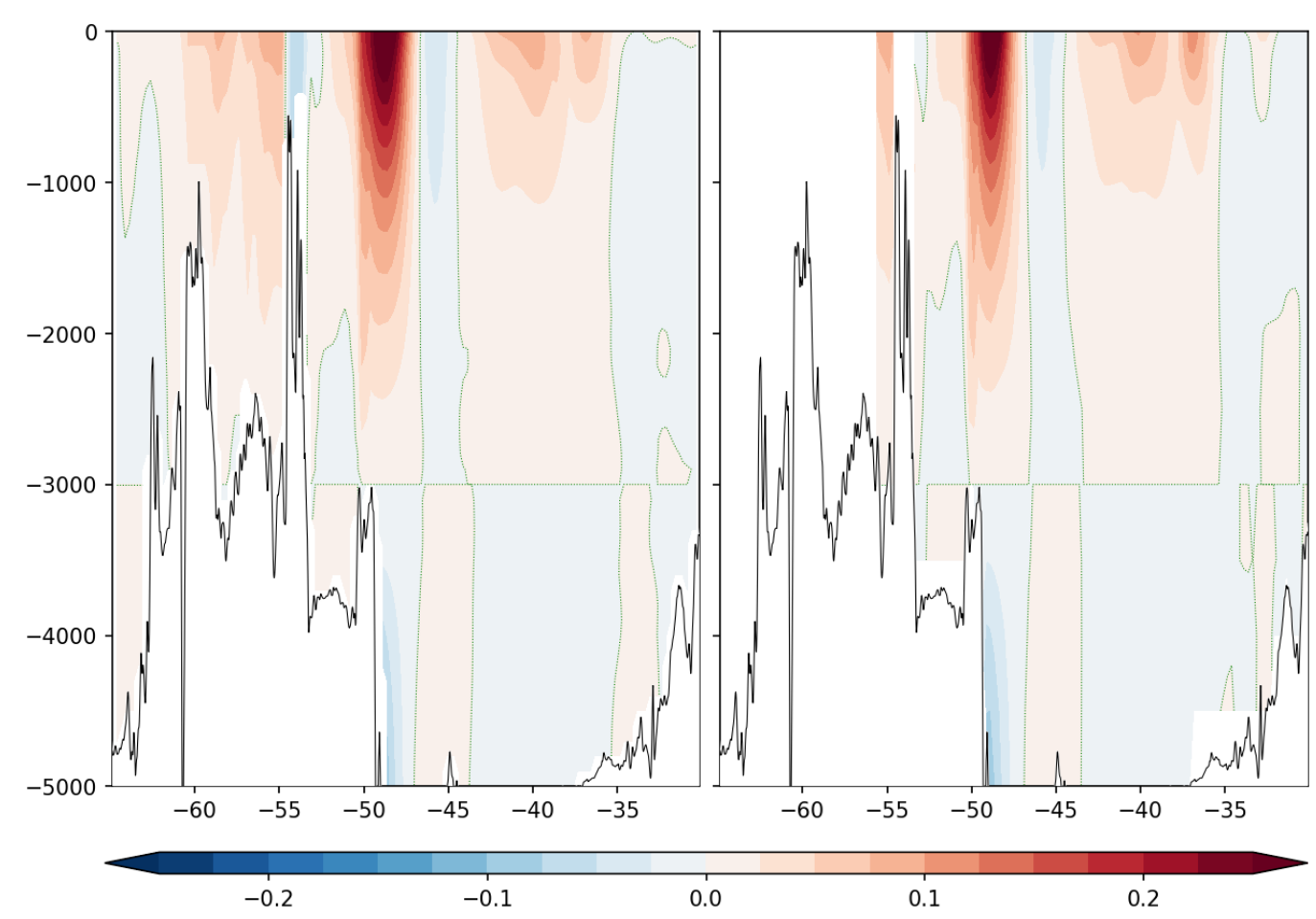

FIGURE 4.12: Vertical section of WOA (left) and ARMOR3D (right) for $40^{\circ} \mathrm{W}$.

(1990) at $45^{\circ} \mathrm{W}(14.1 \mathrm{~Sv})$. We also observe the ACC at between $45^{\circ} \mathrm{S}-65^{\circ} \mathrm{S}$. For the WOA data set we can estime the whole transport of the ACC as $118.2 \mathrm{~Sv}$. However, the ARMOR3D data set has the same spatial coverage as the AVISO data set, and, therefore, there is no information south of $55^{\circ} \mathrm{S}$. We can only estimate its transport as probably being higher than $70.4 \mathrm{~Sv}$. A small eastward flow is present between $35-30^{\circ} \mathrm{S}$ with a transport of 0.1/0.7 Sv. This flow is probably the precursor of the StHC. It is clear that there is superposition between the subtropical and subantarctic vertical profile correlation at this region. This might be accounted for the mix between $\mathrm{BC}$ and $\mathrm{MC}$ at the $\mathrm{BMC}$.

Away from the BMC (at $35^{\circ} \mathrm{W}$ ) around $1 \mathrm{~Sv}$ of the northern flow of the SAC joins the StHC. In contrast, the southern jet communicates with both its northern flow and the ACC. At $30^{\circ} \mathrm{W}$, the calculated transport for the SAC is of around 59/56.2 Sv, in contrast with Rodrigues et al. (2010) and Stramma and Peterson (1990), all of whom derived a transport of about 50 Sv. While for WOA we estimate the transport of the ACC as $90.3 \mathrm{~Sv}$, for ARMOR3D the transport is at least $65.95 \mathrm{~Sv}$.

At $20^{\circ} \mathrm{W}$ (Figure 4.13), the SAC southern jet is merged with the ACC, making the latter increase its transport up to $121.5 \mathrm{~Sv}$ (> $92.3 \mathrm{~Sv}$ for ARMOR3D) and decreasing the SAC 
transport down to $19.8 / 13.0$ Sv. Part of the SAC northern flow also merges with the StHC making the latter current increases its volume transport to around $4.8 / 7.5 \mathrm{~Sv}$.

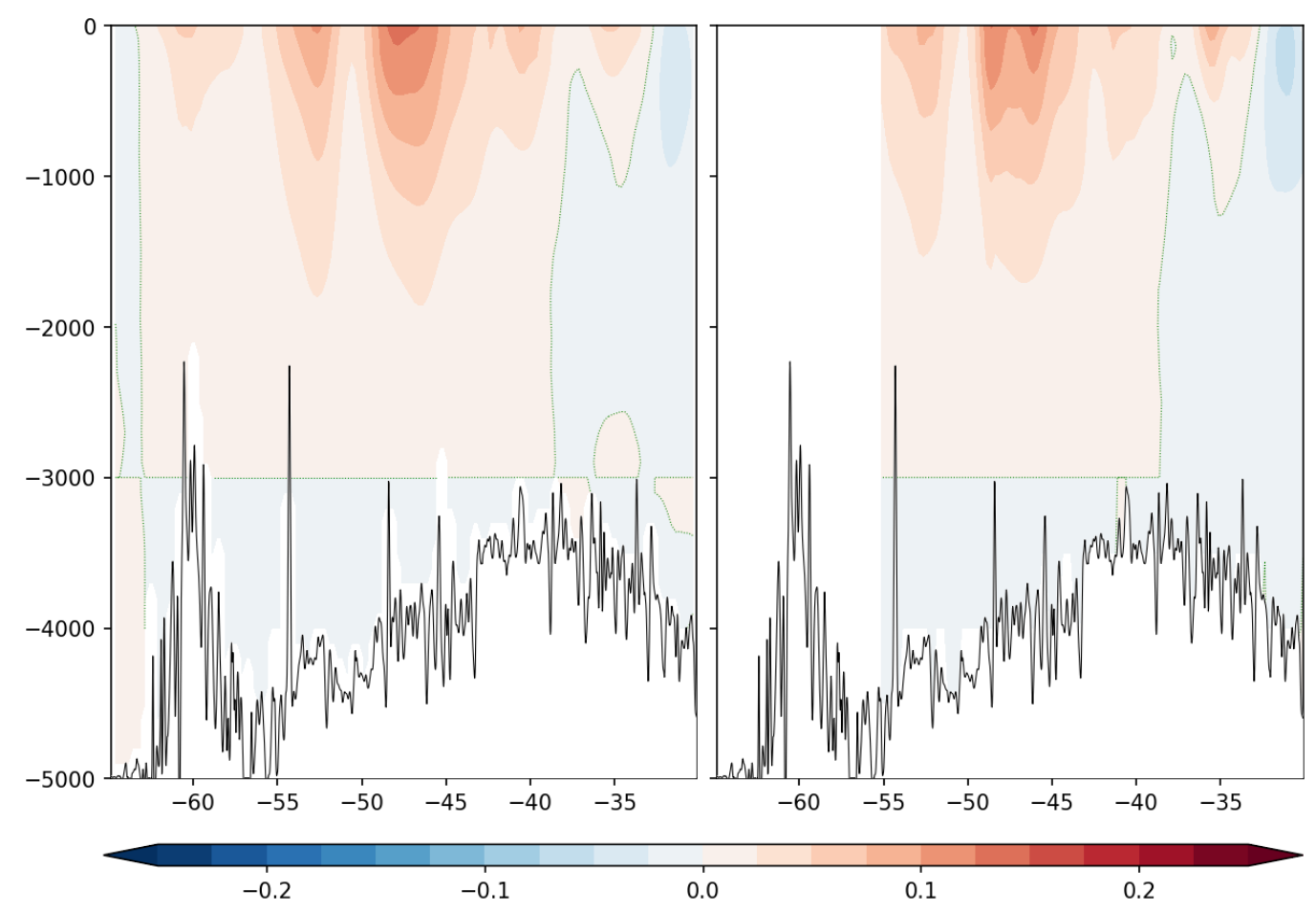

FIGURE 4.13: Vertical section of WOA (left) and ARMOR3D (right) for $20^{\circ} \mathrm{W}$.

East from the mid-ocean ridge, at $10^{\circ} \mathrm{W}$ (Figure 4.14), the ACC and most of the northern jet of the SAC merge and flow in a single intensified flow transporting around 71.7/104.7 Sv. The ACCs transport a maximum of $28.0 \mathrm{~Sv}$ (>16.5 for ARMOR3D). The StHC presents an even higher transport at this longitude (around 7.9/11.45 Sv) probably from some interaction between the SAC northern nucleus. There is a narrow and weak remaining SAC flow with a transport of about 0.6/0.3 Sv close to the SAC-ACC jet. The ACC now transports both water from subantarctic and subtropical areas (around $45^{\circ} \mathrm{S}$ ).

From the data, at $7^{\circ} \mathrm{W}$, we could not detect the presence of a defined SAC split as indicated by Richardson (2007) and Rodrigues et al. (2010) in any of our data sets. The latter authors argue that this split only occurs when analysing the barotropic component of the currents, which it was likely eliminated when referencing both WOA and ARMOR3D to the $3000 \mathrm{dbar}$ isobaric level. It is important to note, however, that the StHC and a small flow of the SAC are still present within this region and their location fits with the results portrayed by these authors. 


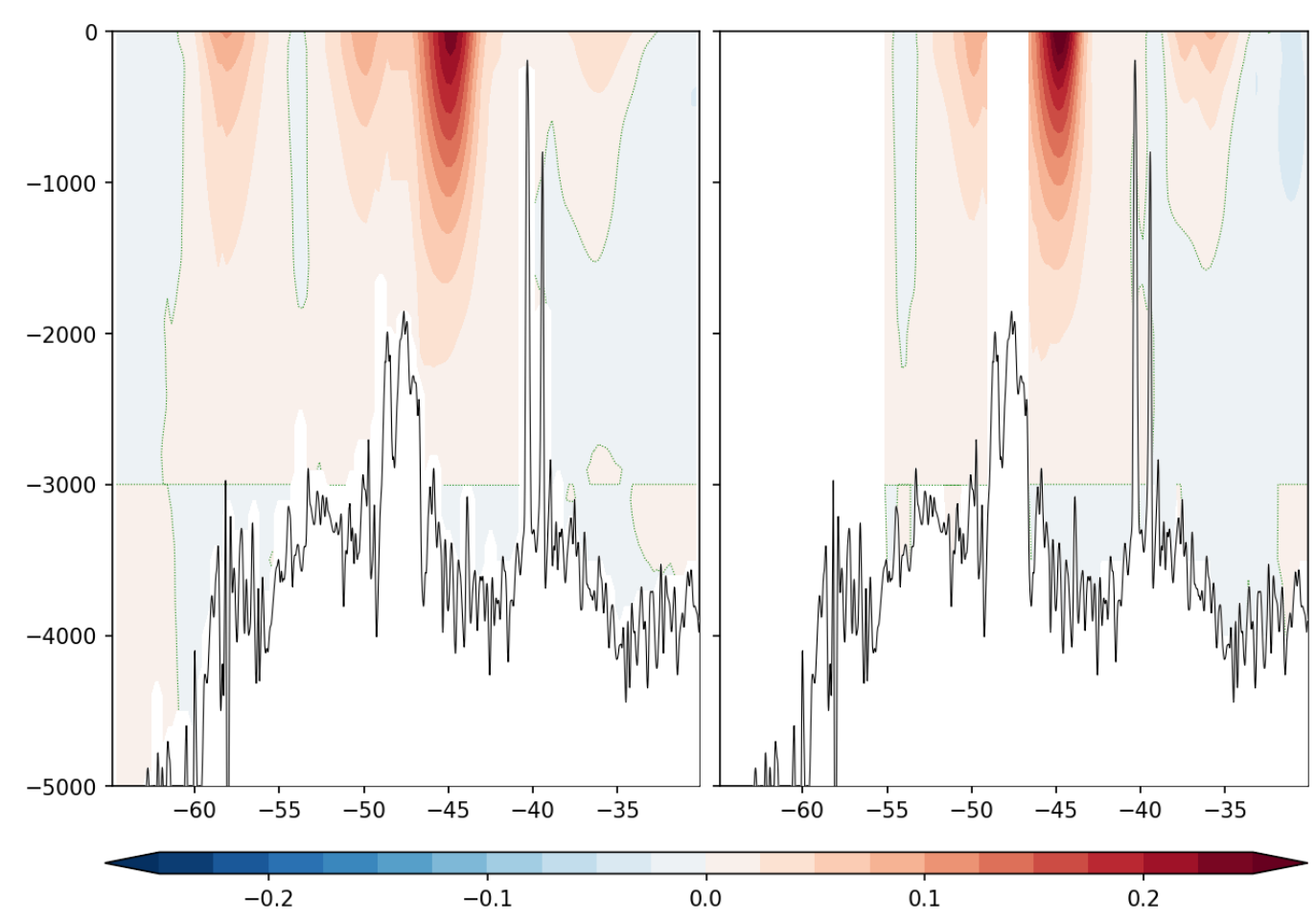

FIGURE 4.14: Vertical section of WOA (left) and ARMOR3D (right) for $10^{\circ} \mathrm{W}$.

At the Greenwich Meridian ( $\left.0^{\circ} \mathrm{GM}\right)$, the StHC branches off into two jets. The southern jet is slightly deeper and receives an input of the SAC-ACC system and transports a volume of $10.19 / 15.86 \mathrm{~Sv}$. The northern branch, in contrast, is slightly weaker and transports approximately 3.4/3.3 Sv. The presence of the SAC is not aparent at this longitude, since most of the volume this is either at the StHC or the ACC. However, the literature still considers the presence of the SAC and derive a transport of 19 Sv Rodrigues et al. (2010) and 8 Sv (Stramma and Peterson, 1990). From our results, we argue that the current actually analysed by both authors is the southern jet of the StHC. The combined ACC-SAC flow transport around 51.7/42.1 Sv. While for ARMOR3D, we do not have information south from $51^{\circ} \mathrm{S}$, for WOA we can estimate the whole ACC system transport as $125.1 \mathrm{~Sv}$.

At $10^{\circ} \mathrm{E}$ (Figure 4.15), we do not observe any remaining jet associated with the SAC, but rather we observe a robust double-core StHC jet. The southern and northern cores of the StHC transport a volume of around 9.6/14 Sv and 8.6/6.5 Sv, respectively. While for the ACC-SAC system we have a transport of 69.1/70.3 Sv, the whole ACC system can be estimated by WOA as being $98.3 \mathrm{~Sv}$. From this longitude to the eastward limit of the Atlantic Ocean, we observe a meandering pattern of about $500 \mathrm{~km}$. This possibly may occur due 
to formation of Lee Waves due to the crossing of the Mid Atlantic Ridge which might be possible from the results of Scott et al. (2011).

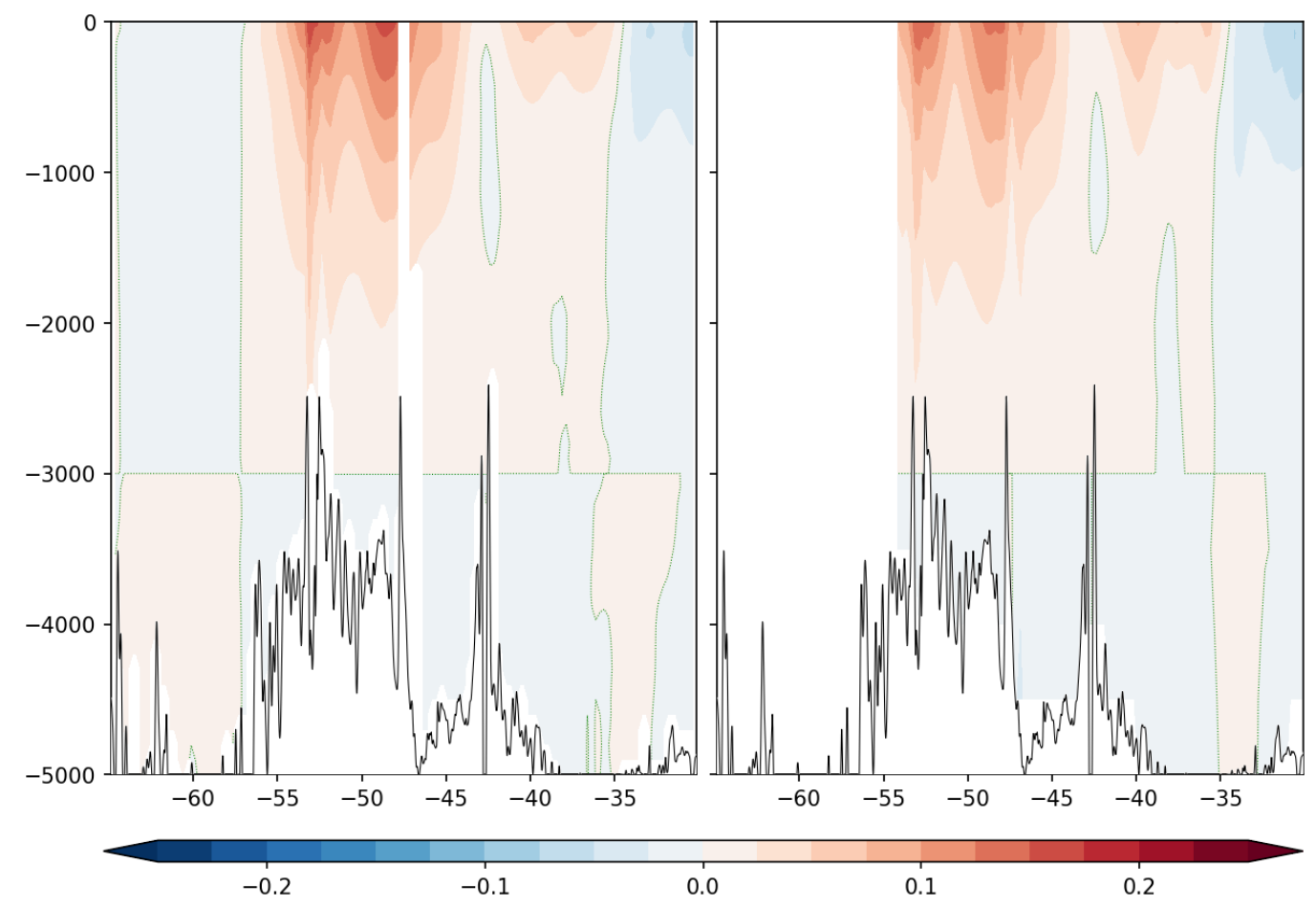

FIGURE 4.15: Vertical section of WOA (left) and ARMOR3D (right) for $10^{\circ} \mathrm{E}$.

Close to the eastward limit of the Atlantic Ocean (at $20^{\circ} \mathrm{E}$ ), the southern jet of the $\mathrm{StHC}$ merges with the AgC retroflection and flows into the Indian Ocean with a transport of 19.1/20.4 Sv. At this longitude, the ACC system transports 121.2 Sv (or at least $70.3 \mathrm{~Sv}$ for ARMOR3D) into Indian Ocean.

\subsubsection{Synthesis}

We now summarize our results with the most notable findings. Given the similarity between the two climatological data sets (ARMOR3D and WOA) we opt to synthesize the results using the average between both.

At the westward edge of the Atlantic Ocean, the SAC is originated from the southern most part of the $\mathrm{BC}$ retroflection as it collides with the $\mathrm{MC}$. At $40^{\circ} \mathrm{W}$ the SAC presents two branches (with total maximum transport of around $42 \mathrm{~Sv}$ ) and still is highly influenced by the BMC structure. The SAC branches circumvent the northern border of the Zapiola Rise. On 
the other hand, the MC extension contours the Zapiola Rise on its southern border, and as it is formed essentially by subpolar waters, it is defined as the ACCn. At about $35^{\circ} \mathrm{S}$ the $\mathrm{StHC}$ is formed from the northernmost portion of $\mathrm{BC}$ retroflection feature and presents water mass characteristics similar to those of southeast Brazil.

From $40^{\circ} \mathrm{W}$ to $20^{\circ} \mathrm{W}$, the SAC feeds both ACCn and StHC, making southern branch of the SAC merge completely with the ACC. Making the northern branch of the SAC transporting toughly of $15 \mathrm{~Sv}$. As it reaches the Mid-Atlantic Ridge, the SAC veers southeastward and merges almost completely with the ACCn. They then form a broad jet with a transport of around 80-100 Sv with remarkable changes in water mass properties meridionally. From $10^{\circ}$ $\mathrm{W}$ to $10^{\circ} \mathrm{E}$, the SAC-ACCn jet presents robust meandering downstream of the ridge in the climatological fields, which could be accounted by the fact of passing through the mid-ocean ridge.

In contrast, the StHC at its formation site transports a mere $0.1 \mathrm{SV}$ and is fed by the northern branch of the SAC across the whole Atlantic Ocean. While it increases notably its volume transport throughout its path, between $30^{\circ} \mathrm{W}-20^{\circ} \mathrm{W}$ the SAC feeding is more vigorous which causes the StHC to reach the mid-oceanic ridge with 5-7.5 Sv. At $0^{\circ}$ the $\mathrm{StHC}$ splits into two branches. The southern branch of the StHC follows into the Indian Ocean with a transport of around 10-14 Sv, while still being fed by the SAC, and the 6.5-8.6 Sv as StHC northern branch closes the SASG.

Both WOA and ARMOR3D data sets roughgly agree in terms ofvolume transport results, aside from the most southern region (south of $55^{\circ} \mathrm{S}$ ) where ARMOR3D presents no information. We summarize this chapter findings by following Rodrigues et al. (2010) (see authors Figure 11) and building an schematic flow map with the corresponding volume transports (Figure 4.16). 


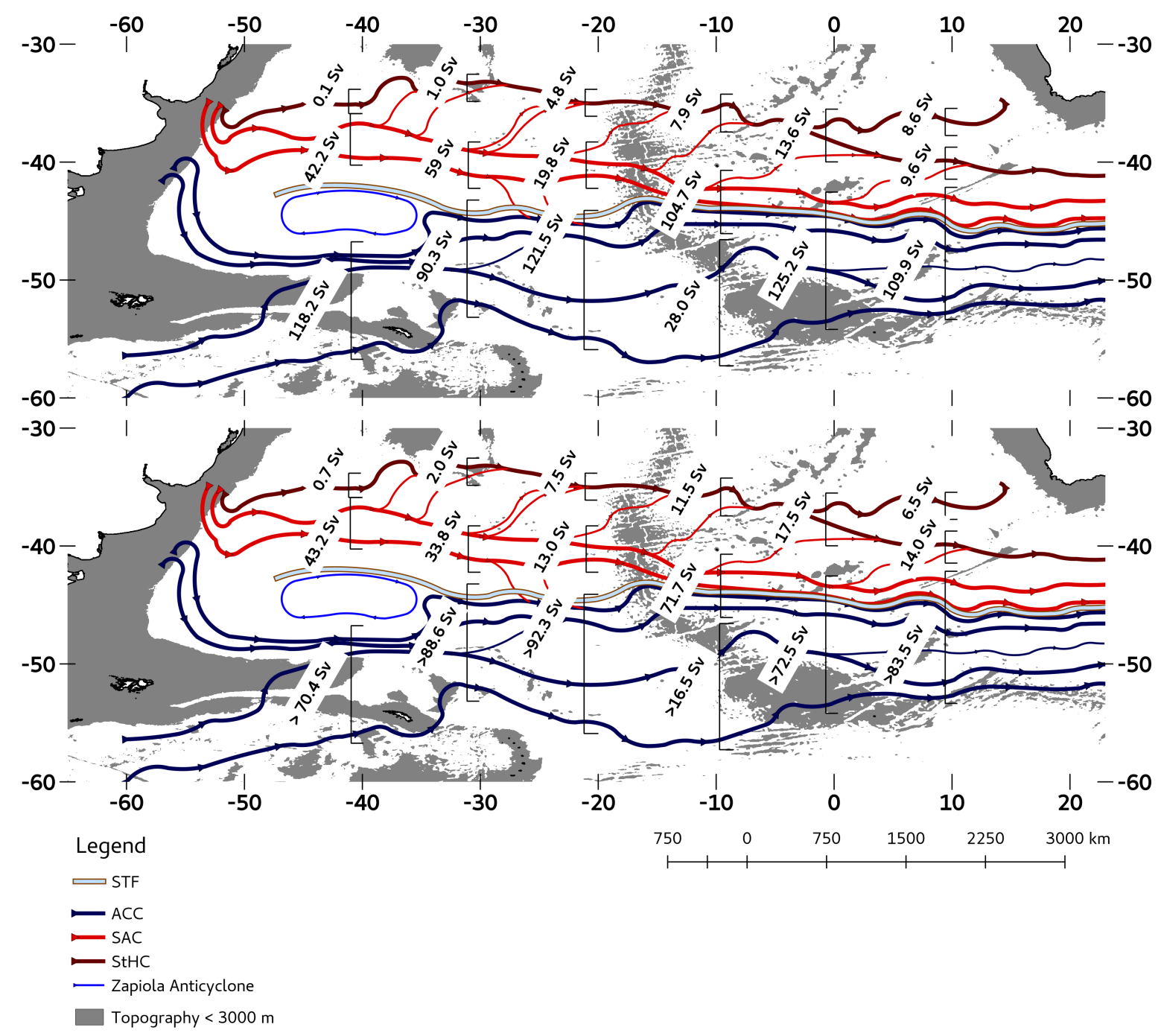

FIGURE 4.16: Schematic representation of the flow pattern and accompanying volume transport values for the upper $3000 \mathrm{dbar}$ in the SASG southern border: WOA (upper panel) and AMOR3D (lower panel). 


\section{Chapter 5}

\section{The SAC System Mesoscale Dynamics}

In this Chapter we analysed the mesoscale dynamics associated with the SAC system in terms of energetics and quasi-geostrophic instability. The energetics part was computed from AVISO and discussed the partitioning between the mean kinectic energy (MKE) and mean eddy kinectic energy (MEKE). The instability analysis aims to address the change in linear instability properties, such as growth rate and phase speeds of the zonally changing currents at the southern borders of the subtropical gyre.

\subsection{Energetics}

\subsubsection{Anual Climatological Energetics}

In term of energetics the higher kinectic energy are constrained to the SAC and ACC within the BMC (Figure 5.1). Specially the flow that originates the ACC has the highest MKE and MEKE. This energy can be seen translated in the Okubo-Weiss parameter field variation (Figure 5.2).

Away from the BMC, there is a significant drop in MEKE and the standard deviation of Okubo-Weiss; MKE, however, remains slightly stable up to the MAC. The StHC, in contrast, acquires MKE as it flows eastward, in spite of that, its eddy energy does not significantly increase as its OW standard deviation. This increase in kinectic energy occurs due to the feeding by the SAC, which corroborates the previous results of volume transport (Chapter 4). This drainage, however, does not seem enough to increase its MEKE. 

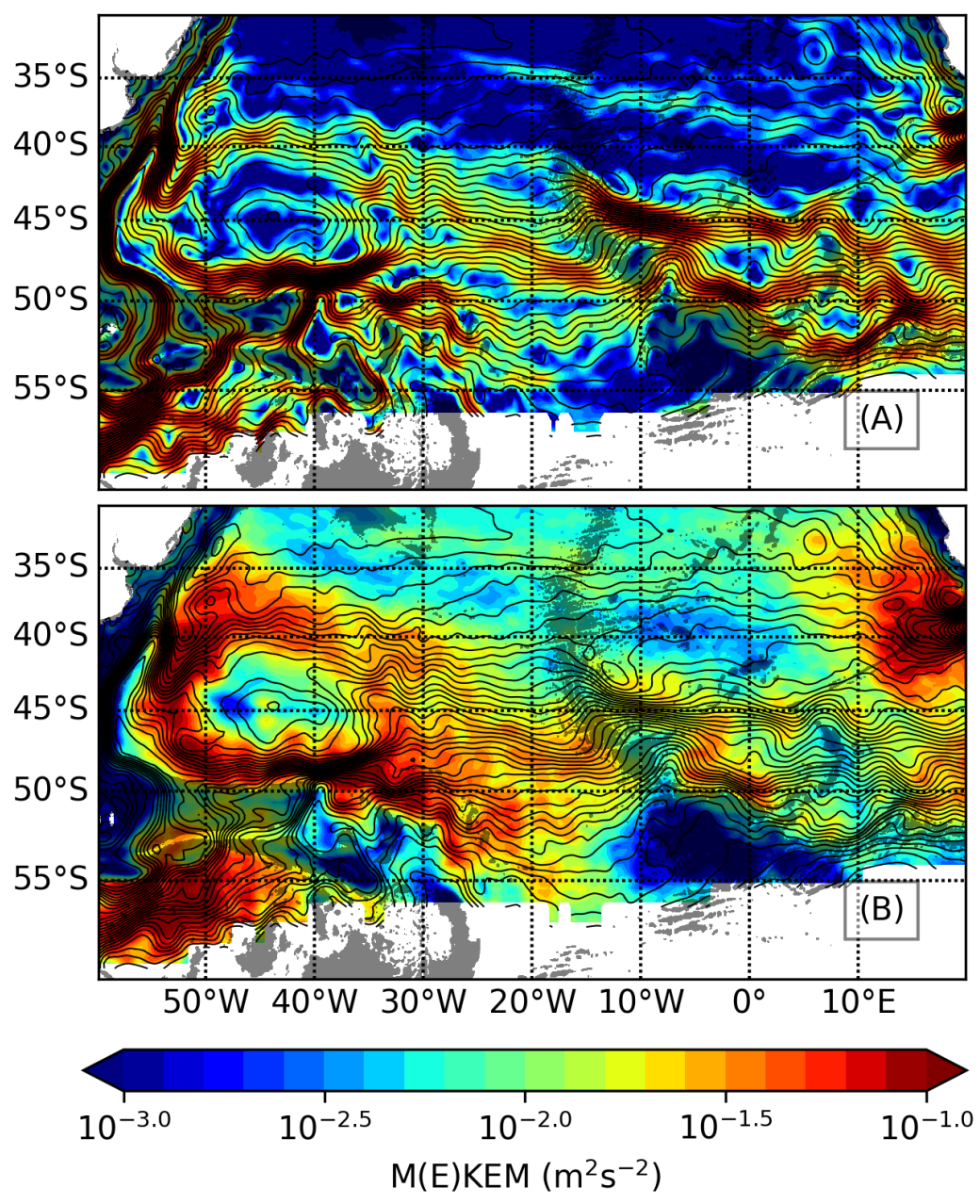

FIGURE 5.1: AVISO mean total (A) and eddy (B) Kinectic Energy. Isolines represent the streamfunction.

When both SAC and ACC pass through the MAC, part of their flow merge into a single intense stream (as described in the previous chapter), this significantly increases both MKE and MEKE. However, it seems that the ACCs $\left(5^{\circ} \mathrm{W} / 55^{\circ} \mathrm{S}\right)$ gets more unstable than the SAC/ACC amalgamate, this increase in MEKE is translated into higher eddy shedding as it can be seen in OW parameter variation (Figure 5.2). A pool of low MEKE just northward of the SAC/ACC amalgamate can also be seen. This might occur due to this current merging leaving a low unstable region.

Although the MKE energy at StHC is not significantly changed as it crosses the MAC, there is a slight decrease in the MEKE. This slight decrease does not follow from OW data, as it seems slightly higher west from the MAC. This suggests that the field variability within 


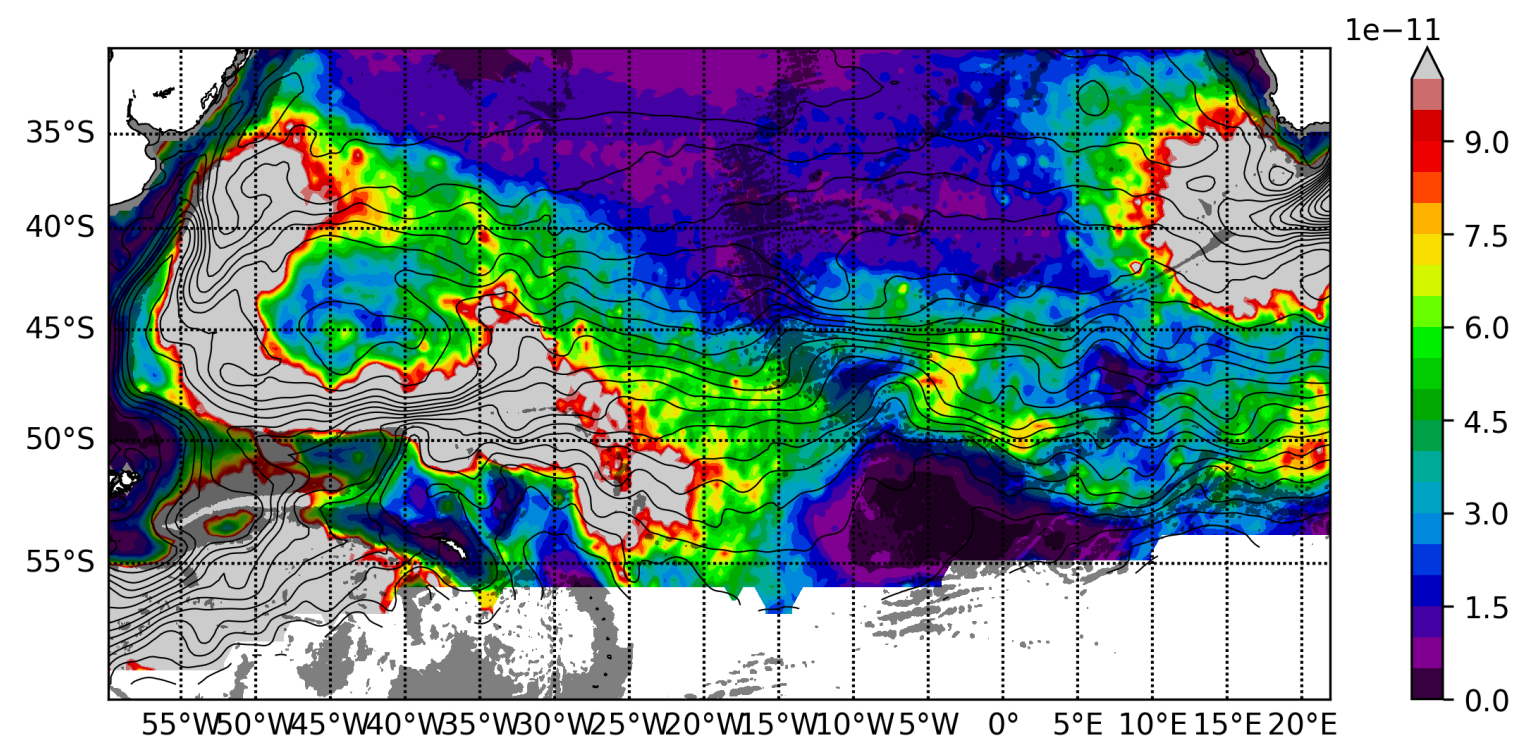

FIGURE 5.2: Okubo-Weiss Standard Deviation from sea surface anomaly of AVISO. Isolines represent the streamfunction.

this region was not locally originated, but carried to there somehow. This variability is likely being originated in the $\mathrm{AgC}$ and propagated westward until reaching the $\mathrm{StHC}$ domain.

\subsubsection{Monthly climatological Energetics}

In this section we brothen the analysis carried out in the previous section by examining the SAC system energetics monthly variations. Figure 5.3 shows that the highest MEKE is found near the BMC and $\mathrm{AgC}$ in all months. It also shows the presence of a higher time dependent variation of energy on these two locations than the other regions. In addition, it is possible to see again that to the west of the MAC (at the $40^{\circ} \mathrm{W}, 30^{\circ} \mathrm{W}, 20^{\circ} \mathrm{W}$ ) both MKE and MEKE decrease (Figure 5.4). This contrasts to what is observed to the east of the MAC: the SAC keeps its nominal energy until it reaches the AgC.

At the SAC formation site $\left(\approx 40^{\circ} \mathrm{W}\right)$, the MEKE is often higher than the MKE. The highest eddy energy are between June-August (austral winter) with a maximum of $7 \times 10^{-2} \mathrm{~m}^{2} \mathrm{~s}^{-2}$. The MKE highest values occur during the period of August-January with a maximum of $5.2 \times 10^{-2} \mathrm{~m}^{2} \mathrm{~s}^{-2}$. On the other hand, the lowest values of both MEKE and MKE are observed during the period of February-April. MEKE has a minimum of $4.2 \times 10^{-2}$ in April, and MKE $0.1 \times 10^{-2}$ in May. 

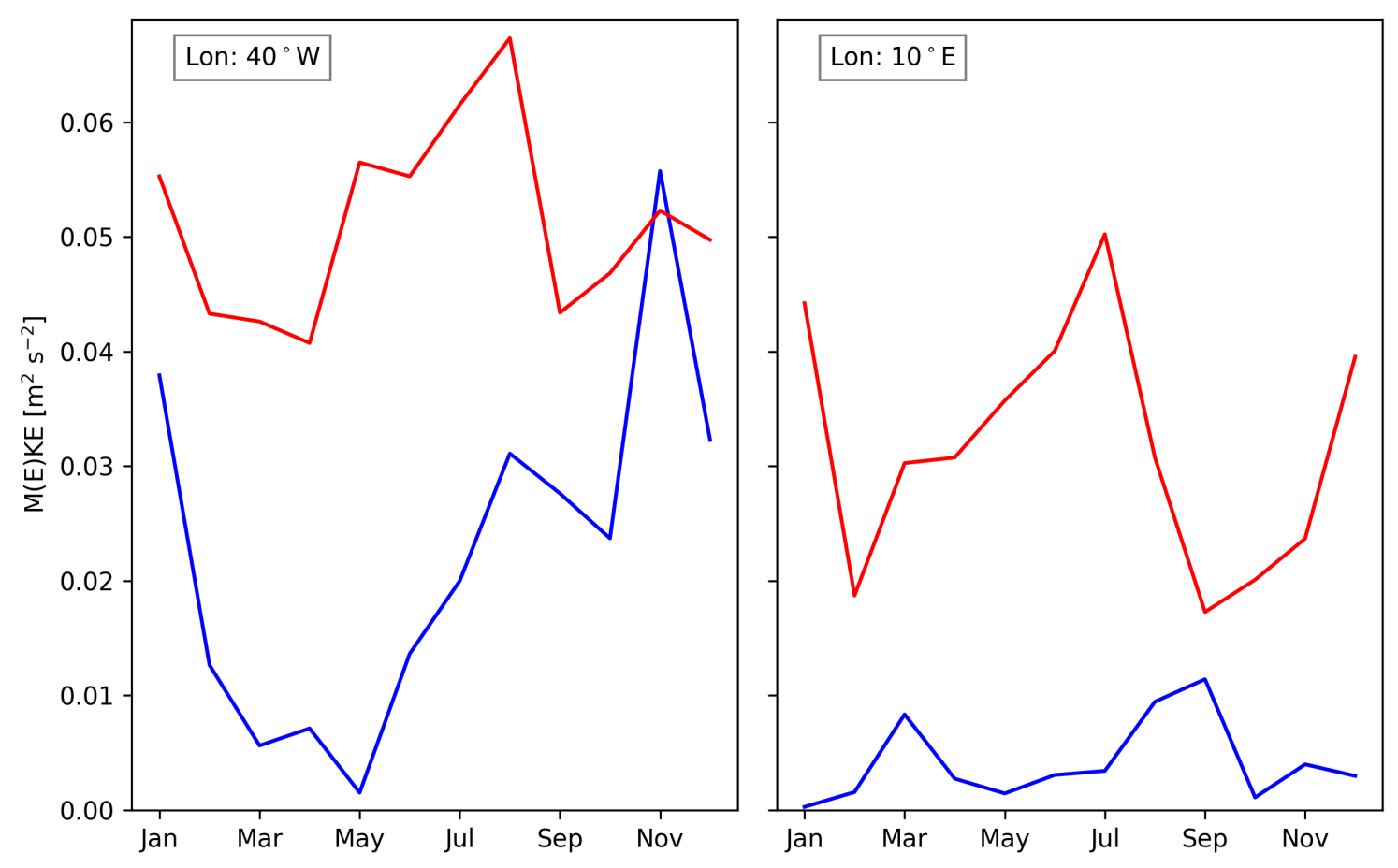

FIGURE 5.3: Mean Kinetic Energy (MKE) and Mean Eddy Kinetic Energy (MEKE) monthly climatology. Red line indicates MEKE, while blue line indicates the MKE

At $30^{\circ} \mathrm{W}$, we see a notable decrease of both MKE and MEKE, although the MEKE is still higher than the MKE. At this site, the highest eddy energy are found at May and at the period from August to December. The maximum energy is of $2.4 \times 10^{-2} \mathrm{~m}^{2} \mathrm{~s}^{-2}$ in August. However, the MKE has its maximum energy in February and March $\left(0.7 \times 10^{-2} \mathrm{~m}^{2} \mathrm{~s}^{-2}\right.$ in March). However, In April we see a decrease of $0.5 \times 10^{-2} \mathrm{~m}^{2} \mathrm{~s}^{-2}$. We speculate that the increase in the maximum MEKE in May is associated with this decrease in MKE. From May to October we see a constant decrease of MKE which seems to also be associated with the period of high MEKE.

At $20^{\circ} \mathrm{W}$, we see that both MKE and MEKE reaches their lowest values with very little variations of both. While the maximum MEKE is found in November with $0.9 \times 10^{-2} \mathrm{~m}^{2} \mathrm{~s}^{-2}$, the minimum is found in july with $0.3 \times 10^{-2} \mathrm{~m}^{2} \mathrm{~s}^{-2}$. However, the MKE has its maximum in july with $0.2 \times 10^{-2} \mathrm{~m}^{2} \mathrm{~s}^{-2}$ and minimum in December slightly over $0.01 \times 10^{-2} \mathrm{~m}^{2} \mathrm{~s}^{-2}$.

In contrast, at $10^{\circ} \mathrm{W}$, the MKE and MEKE starts increasing again likely due to the SACACCn interaction. However, at this site the MKE is slightly over MEKE in the period of 

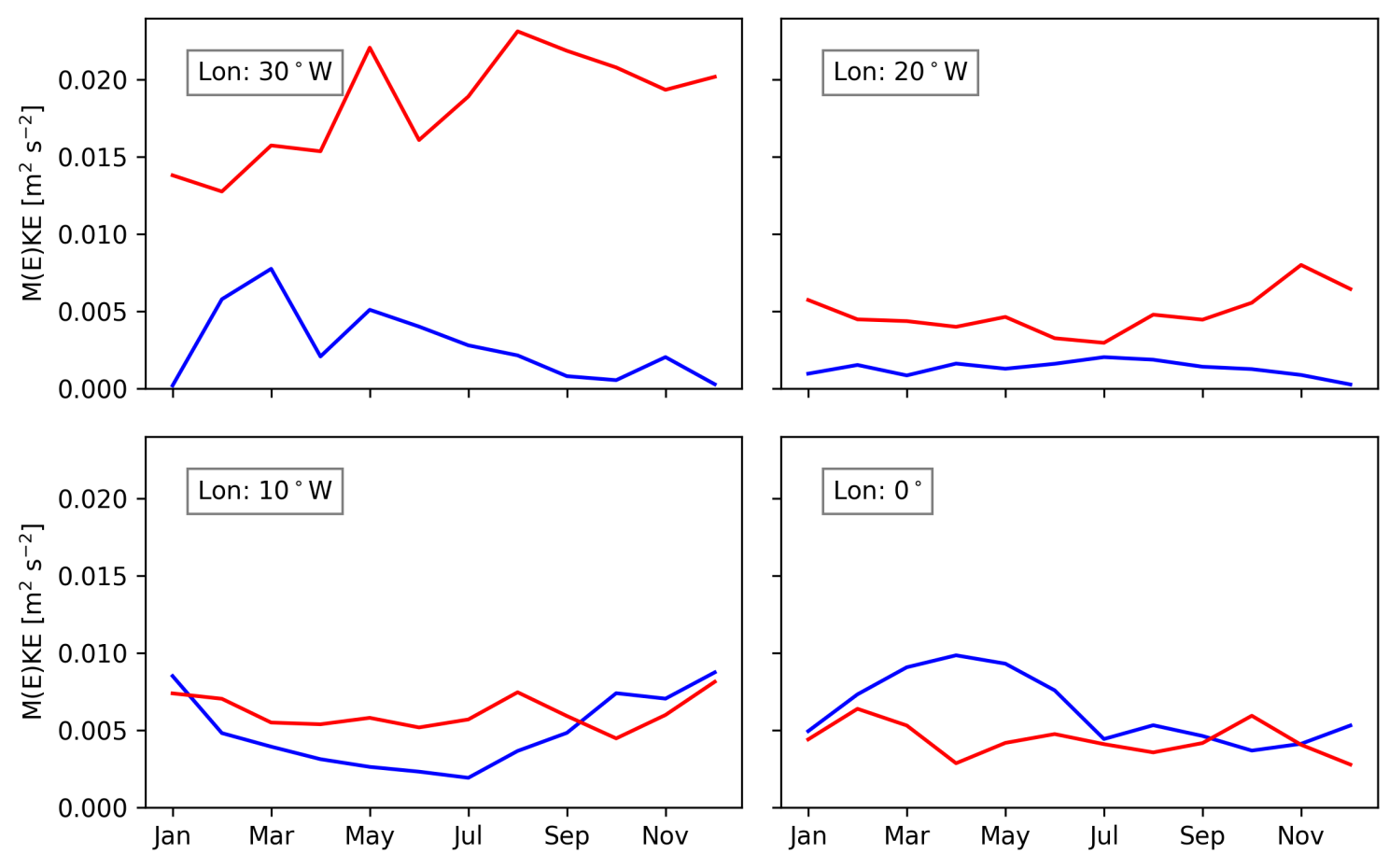

FIGURE 5.4: Same as Figure 5.3, but for the sections between $30^{\circ} \mathrm{W}$ and $0^{\circ}$.

october-january where MKE is the highest (with a maximum of $0.9 \times 10^{-2} \mathrm{~m}^{2} \mathrm{~s}^{-2}$ in December). The MEKE does not change notably in the period of January-July, but in August it increases to $0.8 \times 10^{-2} \mathrm{~m}^{2} \mathrm{~s}^{-2}$ and decreases until October. From this month to december, it increases its MEKE along with the MKE.

At the Greenwich Meridian $\left(0^{\circ}\right)$, the MEKE only surpasses the MKE in October. The MKE shows a paraboloidal shape between January to July, reaching a maximum in April of $1.0 \times 10^{2} \mathrm{~m}^{2} \mathrm{~s}^{-2}$. At this month, we also see a minimum of MEKE of $0.4 \times 10^{-2} \mathrm{~m}^{2} \mathrm{~s}^{-2}$. However, in october we see a peak of MEKE of $0.6 \times 10^{-2} \mathrm{~m}^{2} \mathrm{~s}^{-2}$, but also a minimum of MKE of $0.5 \times 10^{-2} \mathrm{~m}^{2} \mathrm{~s}^{-2}$.

Near the $\mathrm{AgC}\left(10^{\circ} \mathrm{E}\right)$, we see a return of the pattern near the BMC. We see again the MEKE surpassing notably the MKE, but we see less monthly variation of the MKE. The latter shows maximum peaks at March $\left(0.9 \times 10^{-2} \mathrm{~m}^{2} \mathrm{~s}^{-2}\right)$ and August-September $\left(1.1 \times 10^{-2}\right.$ $\left.\mathrm{m}^{2} \mathrm{~s}^{-2}\right)$. Near these peaks, we see a sharp decrease in MEKE from january $\left(4.3 \times 10^{2} \mathrm{~m}^{2} \mathrm{~s}^{-2}\right)$ to february $\left(1.9 \times 10^{-2} \mathrm{~m}^{2-2}\right)$ and another decrease from July $\left(5.1 \times 10^{2} \mathrm{~m}^{2} \mathrm{~s}^{-2}\right)$ to September $\left(1.8 \times 10^{-2} \mathrm{~m}^{2} \mathrm{~s}^{-2}\right)$. 


\subsubsection{Synthesis}

We synthesize the results previoiusly presented in which will be used to supplement the instability analysis of the next section as follows. The StHC has a remarkable increase in MKE and MEKE at around $35^{\circ} \mathrm{W}$. In Section 4.2.2 we observe that in the vicinities of the $25^{\circ} \mathrm{W}$ meridian the StHC increases in transport five times due to more heavily feeding by the SAC. Between $35^{\circ} \mathrm{W}-10^{\circ} \mathrm{E}$, its MKE is not notably changed in its path. The current's MEKE only slightly increases in the surroudings of the MAC.

The SAC, in contrast, has a high MKE and MEKE associated with its formationsite. The eddy energy at this region seems to be highly seasonal dependent (higher in winter months). Eastward from its formation, but west from the MAC, we see a decrease of MEKE, specially when the current crosses the MAC system. At that site, the absolute values of MKE and MEKE as well as its seasonal variability are the lowest. The standard deviation of OW also shows a local low of eddy presence on the MAC for this current.

East of the MAC, where the SAC and ACCn merge $\left(\approx 10^{\circ} \mathrm{W}\right)$, we see an increase of both MKE and MEKE of the SAC-ACCn and ACCs. We can see in the OW standard deviation an increase of eddy variability in the region, suggesting that the energy present is enough to make the currents highly unstable. Near Meteor Rise $\left(5^{\circ} \mathrm{E}\right)$ we see another decrease in MEKE which could suggest the tectonic feature plays an important role on the current stability and instability since there is a presence of high eddy presence in the region east of the rise.

\subsection{Linear Instability Analysis}

In this section we address the problem of linear instability of the SAC system by means of examining the baroclinic instability phenomenon locally and seeking the SAC system jet mixed instability properties.

For the first approach, in Section 5.2.1, we follow the guidelines proposed by Smith (2007) and Tulloch et al. (2011) but employing an adapted version of Johns (1988) 1-D, QG model, as presented in Section 3.2. For the second approach, in Section 5.2.2, we built a version of the Kontoyiannis (1997) model using the meridional velocity vertical sections 
obtained in Section 4.2.2 for the six selected longitudes $\left(40^{\circ} \mathrm{W}, 30^{\circ} \mathrm{W}, 20^{\circ} \mathrm{W}, 10^{\circ} \mathrm{W}, 0^{\circ}\right.$, $\left.10^{\circ} \mathrm{E}\right)$.

\subsubsection{Local Baroclinic Analysis}

Figure 5.5 presents the growth rate and phase speed maps of the unstable waves embedded in the SAC system. As it can be observed in the upper panel of Figure 5.5 it is not surprising to us that the $\mathrm{BMC}$ and $\mathrm{AgC}$ region do not present extremely high values compared to the South Atlantic Basin interior. We only considered the zonal component of the velocities and both regions are marked by dominant meridional flow patterns (see Figure 4.5).

Corroborating Smith (2007) and Tulloch et al. (2011), the SASG southern border region is in overall unstable. Exceptions of stable flow are found (i) over the MAC and Meteor Rise, and (ii) a sort of near-quiescent flow between $8^{\circ} \mathrm{W}$ and $8^{\circ} \mathrm{E}$ at $42^{\circ} \mathrm{S}$, east of the location that the SAC veered south to merge with the ACCn.

At $40^{\circ} \mathrm{W}$, it can be can be seen a high growth rate values at $37^{\circ} \mathrm{S}$ and south of $40^{\circ} \mathrm{S}$. The former latitude maximum growth is centered at the core of the SAC northern branch, while the latter maxima seems to be related to both SAC and ACCn since it is located in ther northern edge of the Zapiola Rise (see also Figure 4.7).

East from the MAC, it is notable the presence of a high growth rate spot at the region where SAC-ACCn merges. This is in accordance with MEKE results, which shows these regions to present high levels of eddy energy.

It is interesting to note that around $25^{\circ} \mathrm{W}$, there is a high growth rate of the StHC which is the region where the SAC donates volume and momentum to the StHC. This result seems to correlate with the MEKE map (Figure 5.1). This suggests the StHC is potentially unstable from its formation site to the eastward edge of the basin. The current instability from $10^{\circ} \mathrm{W}$ to $10^{\circ} \mathrm{E}$ seems to condractict our previous speculation that the tongue of local maximum values of MEKE (depicted in Figure 5.1) between $10^{\circ} \mathrm{W}$ to $10^{\circ} \mathrm{E}$ connects the $\mathrm{AgC}$ domain with the StHC. We do not, however, disregard the possibility of the interplay between both on the local dynamics of the region.

In terms of phase speeds, most of the unstable waves within the southern SAASG region propagates eastward. The fastest propagating waves are generated in the southern branch 

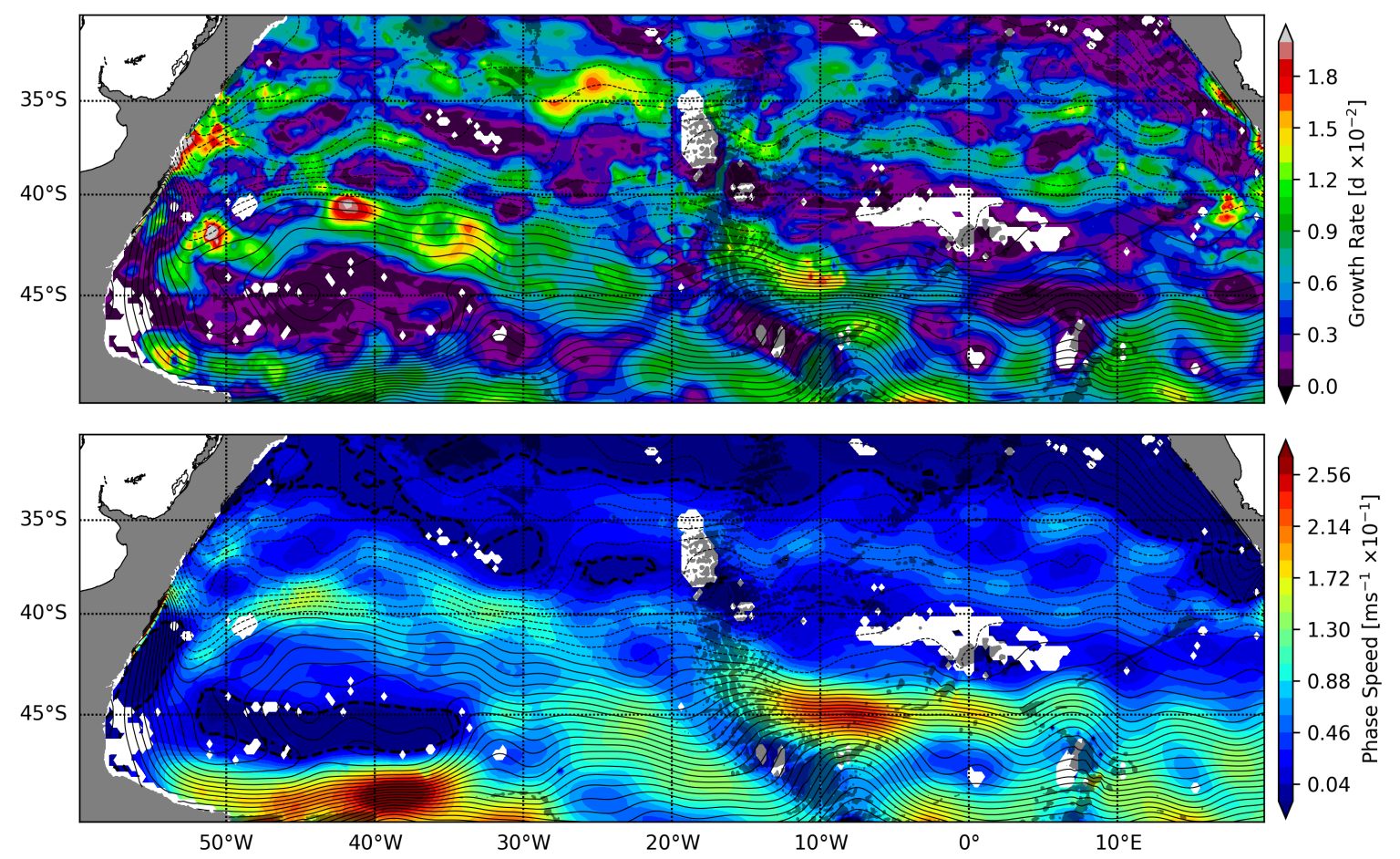

FIGURE 5.5: (upper panel) Growth rate and (lower pannel) phase speed of the local most unstable vorticity wave obtained via baroclinic instability analysis.

Streamlines of the main flow are plotted over the linear model results.

of the BMC. The most unstable mode at the formation site of the SAC shows a propagating wave of around $1.5 \times 10^{-1} \mathrm{~ms}^{-1}$. This speed decreases at the MAC and increases to $2.8 \times 10^{-1} \mathrm{~ms}^{-1}$ as both SAC-ACCn merge. This speed slightly decrease until it reaches the Indian Ocean. In contrast, the StHC's waves highest phase speed are found around $35^{\circ} \mathrm{W}$ of about $0.7 \times 10^{-1} \mathrm{~ms}^{-1}$ and maintains this celerity across the South Atlantic Ocean. However, the exception is at the MAC where the model could not model unstable waves of the StHC.

\subsubsection{Seccional Mixed Instability Analysis}

In this section, we discuss the mixed instability model analysis following Kontoyiannis (1997). In the very first part of this section, since the QG model was fully constructed in house, we validate the results with analytical jet sections. 


\section{Model Validation}

In order to validate the validate the model we opt to test barotropic and baroclinic instability separately. We then formulate a sectional distribution of (i) a jet in an stratified ocean which is stable baroclinically and unstable barotropically; and (ii) a jet which does not satisfy the Rayleigh-Kuo instability criterion, but its unstable baroclinically. The general formulation for the zonal jet and the Brünt-Väisälä frequency seccional distributions are given by:

$$
\left\{\begin{array}{l}
u(y, z)=U_{0}(y) F(z) \\
N^{2}(z)=N_{0}^{2} G(z),
\end{array}\right.
$$

where $F(z)$, and $G(z)$ are the vertical structure functions for $N^{2}$ and $u$, respectively. $U_{0}(y)$ is the horizontal structure function for the jet. The theoretical expressions for $F(z), G(z)$, and $U_{0}(y)$ are given by:

$$
\left\{\begin{array}{l}
U_{0}(y)=u_{0} \operatorname{sech}\left(y / L_{0}\right)^{2} \cos \left(\gamma 2 \pi y / L_{u}\right) \\
F(z)=1 /\left(u_{1}+u_{2}\right)\left(u_{1} e^{-z / h_{u}}+u_{2} e^{-z / h_{N}}\right) \\
G(z)=e^{-z / h_{N}}
\end{array}\right.
$$

The corresponding values for the barotropically and baroclinically unstable tests, respectively, are presented in Table 5.1.

For the barotropically unstable jet (Figure 5.6.A1), we created an intense (with a core velocity of $0.16 \mathrm{~ms}^{-1}$ ) and gaussian shaped structure horizontally, which decreases exponentially with depth and reaches the null velocity at $2600 \mathrm{~m}$ depth. Th estratification was set to have a Brünt-Väisälä seccional distribution constant along the $y$-axis, and that also decreases as a simple exponential function with depth. We see that the ambient potential vorticity meridional gradient (Figure 5.6.B1) just changes of sign horizontally.

Numerically, the profile resolution was of $20 \mathrm{~km}$ and $137 \mathrm{~m}$ horizontally and vertically, respectively. The results of the seccional model was confronted with a simple 1D barotropic model which was run with the same horizontal resolution of the seccional one, i.e. $20 \mathrm{~km}$. We see that the ambient potential vorticity meridional gradient (Figure 5.6.B1) just basically changes of sign horizontally. There are indeed very small sign inversions probably due to 
TABLE 5.1: Jet parameters for the validation cases of the baroclinically and barotropically unstable wave.

\begin{tabular}{ccc}
\hline & Barotr Unstable & Barocl unstable \\
\hline $\mathrm{L}_{0}(\mathrm{~km})$ & 70 & 400 \\
$\mathrm{~L}_{u}(\mathrm{~km})$ & 700 & 700 \\
$\mathrm{~h}_{u}(\mathrm{~m})$ & 900 & 100 \\
$\mathrm{~h}_{N}(\mathrm{~m})$ & 200 & 900 \\
$\mathrm{u}_{0}\left(\mathrm{~ms}^{-1}\right)$ & 0.16 & 0.05 \\
$\mathrm{u}_{1}\left(\mathrm{~ms}^{-1}\right)$ & -0.006 & 1 \\
$\mathrm{u}_{2}\left(\mathrm{~ms}^{-1}\right)$ & 0.106 & 0 \\
$\mathrm{~N}_{0}^{2}\left(\mathrm{~s}^{-2}\right)$ & $2.5 \times 10^{-5}$ & $2.5 \times 10^{-5}$ \\
$\gamma$ & 1 & 0 \\
\hline
\end{tabular}

numerical round off errors on computing the ambient potential vorticity gradient. Nevertheless, the 1D local baroclinic model solved with the same vertical resolution of the seccional one revealed that the jet is stable.

The comparison between both models for the batrotropic case, shown in Figure 5.7.A1 and 5.7.B1, shows a virtually total agreement between the datasets. The only notable difference is where between the wavenumber $1.3 \times 10^{-2} \mathrm{~km}^{-1}$ and $1.4 \times 10^{-2} \mathrm{~km}^{-1}$. These difference might be related to the fact that the model might be only an approximate affine function ${ }^{1}$.

The results for the calibration test for the baroclinc case, shown in Figure 5.7.B1 and Figure 5.7.B2, also exhibits a striking similarity between them. However, there are a few differences worth noticing. At around $5 \times 10^{-3} \mathrm{~km}^{-1}$, the growth rate curve of the $2 \mathrm{D}$ model, was somewhat lower than that of the 1D model. The model fails to reproduce the $1 \mathrm{D}$ results for wavenumbers lower than $12 \times 10^{-3} \mathrm{~km}^{-1}$. This suggests that perhaps there are limitations on the 2D model on estimating the instability properties in the long wave limit.

\section{Model Application to Selected Longitudes}

We describe next the application of the 2-D model onto the velocity sections obtained for the WOA-derived jet configurations. We use the six selected meridional sections: $40^{\circ} \mathrm{W}$, $30^{\circ} \mathrm{W}, 20^{\circ} \mathrm{W}, 10^{\circ} \mathrm{W}, 0^{\circ}, 10^{\circ} \mathrm{E}$. After validation, the analysis of the sections from WOA can

\footnotetext{
${ }^{1}$ An affine function differs from a linear function in the sense that: $f(x+y) \neq f(x)+f(y)$. Which means that a mixed instability model, might not be necessarily the same as the sum of a baroclinic and barotropic model individually.
} 

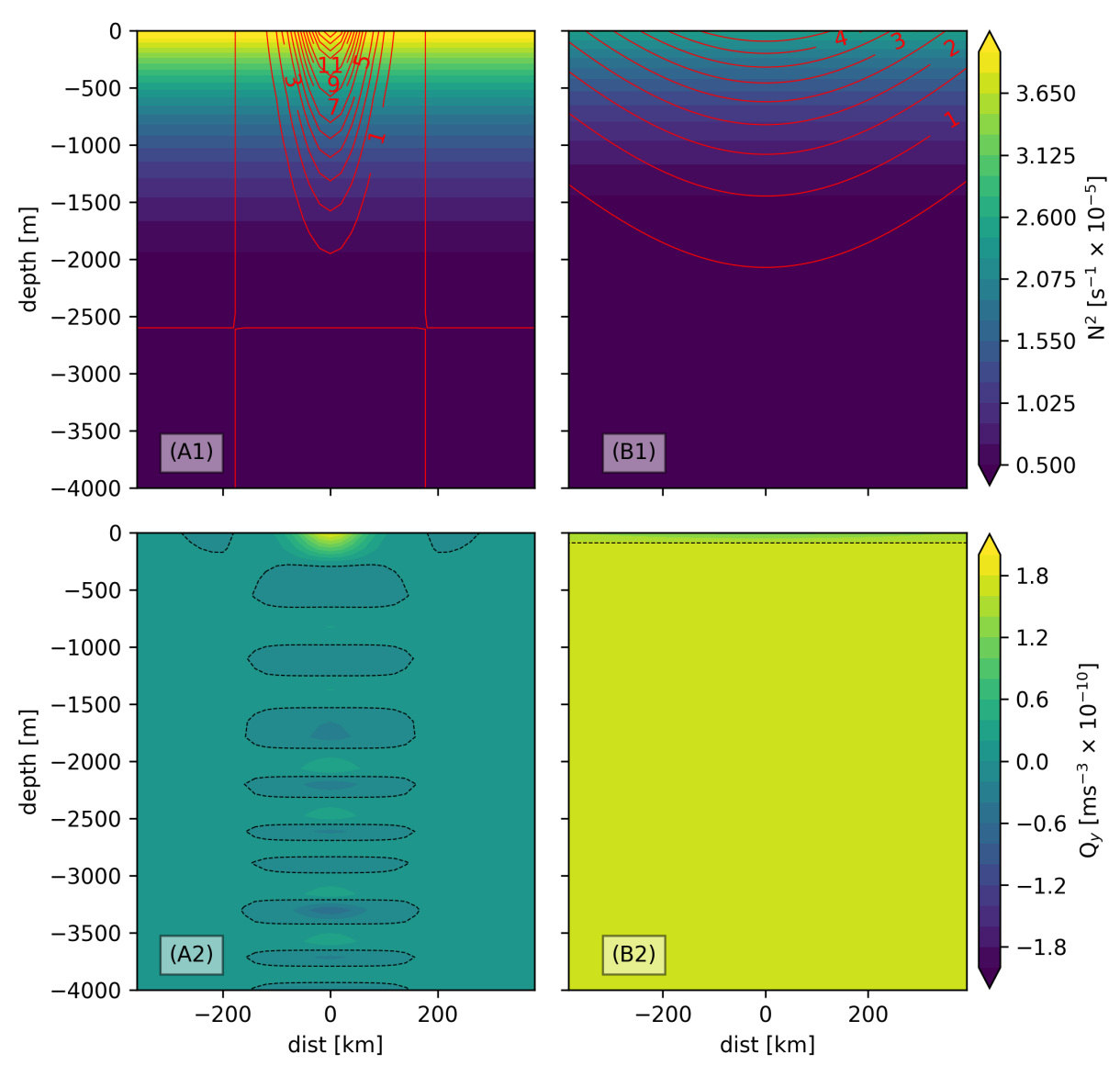

FIGURE 5.6: Baroclinically and Barotropically (A/B) unstable bidimensional jets with the Brünt-Väisälä and Ambient Potential Vorticity profile (1/2). The red lines are jet velocity in $\mathrm{cms}^{-1}$

be finally performed. The analysis will be limited to a maximum wavenumber of $0.1 \mathrm{~km}^{-1}$ as explained in section 3.2.1.

\section{1. $40^{\circ} \mathrm{W}$}

The first section, near the BMC $\left(40^{\circ} \mathrm{W}\right)$, between $45^{\circ} \mathrm{W}-34^{\circ} \mathrm{W}$, comprises of a current of two cores (with maximum velocity of $8 \times 10^{-2} \mathrm{~ms}^{-1}$ and $7.5 \times 10^{-2} \mathrm{~ms}^{-1}$ ), as described in the Chapter 4, reaching a maximum depth of $3600 \mathrm{~m}$ (Figure 5.8). The northern core has a steeper vertical velocity decay as the southern core, which in itself might suggest that the former core is more unstable than the latter.

The instability model results indicate a growth rate curves with three distinctive maxima. The highest growth rate is at the wavenumber $5.8 \times 10^{-2} \mathrm{~km}^{-1}$ of about $2.6 \times 10^{-2}$ 

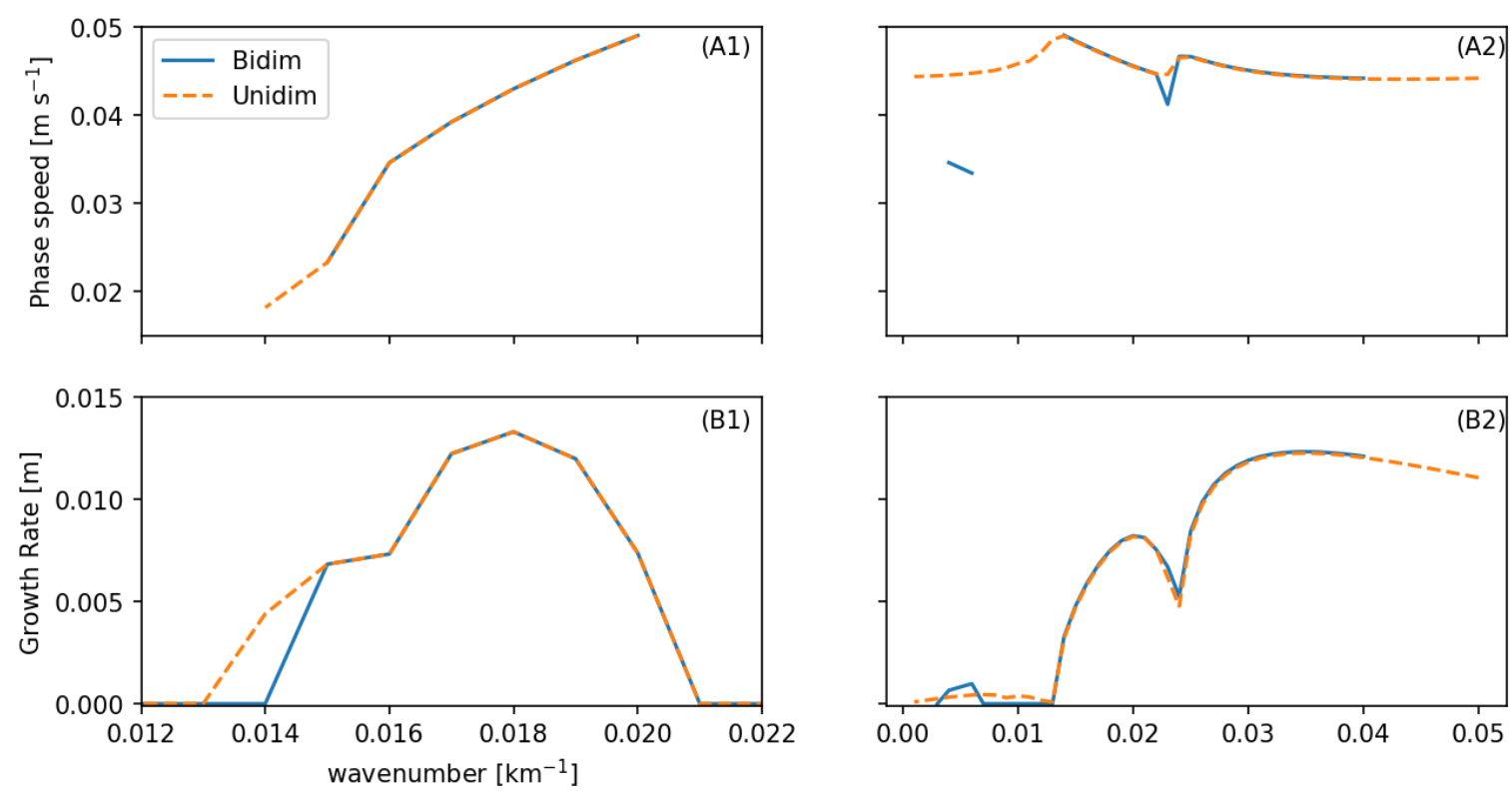

FIGURE 5.7: Instability results of the uni/bidimensional model for the phase speed (A) and growth rate (B) for the barotropic (1) and baroclinic (2) instability results.

days $^{-1}$ slightly higher than the local baroclinically instability result. The phase propagation speed of the fastest growing mode is estimated by the model as $4.4 \times 10^{-2} \mathrm{~ms}^{-1}$ (Figure 5.9). Using the relation between wavenumber, wavefrequency and the wave phase speed, we can easily estimate the period of the waves (Figure 5.10). The wave period of the fastest growth rate is of around 28 days.

We identify, by reconstructing the perturbed meridional velocity vertical profile for the most unstable mode $\left(V_{\max }^{\prime}=\operatorname{Re}\left\{\Phi_{\max } e^{i \theta_{\max }}\right\}\right.$ ), that the unstable meander core is associated with the northern branch of the SAC (Figure 5.9). The velocity perturbation structure is confined to $2000 \mathrm{~m}$ with a core located at $150 \mathrm{~m}$. The relevant width is about $75 \mathrm{~km}$ only. In other words, the most unstable meander occurs essentially at the core of the SAC northern branch. However, as the range of unstable $k \mathrm{~s}$ is long, other meander patterns and core locations with less degree of instability are possible.

\section{2. $\underline{30^{\circ} \mathrm{W}}$}

At this longitude, the SAC still exhibits two cores. Its northern core (between $42^{\circ} \mathrm{S}-37^{\circ}$

S) is more intense than the southern one with maximum velocities of about $9 \times 10^{-2}$ 
$\mathrm{ms}^{-1}$. The southern core has a maximum velocity of around $7.5 \times 10^{-1} \mathrm{~ms}^{-1}$. These cores now have a less pronounced decay as the ones at $40^{\circ} \mathrm{W}$.

The most unstable wave at this longitude grows with an approximate rate of $2.6 \times 10^{-2}$ days ${ }^{-1}$, similar to the rate obtained $40^{\circ} \mathrm{W}$ in terms of not only the rate itself, but also the most unstable wavenumber at $0.07 \mathrm{~km}^{-1}$. The unstable wave phase speeds are eastward for the whole computed $k$ range. The model estimates the phase speed for the fastest growing mode as $8.2 \times 10^{-2} \mathrm{~ms}^{-1}$.

We see that for the fastest growth rate, the velocity vertical structure is again centered at the northernmost core with a period of about 12 days. The core of this perturbation mode is located at $200 \mathrm{~m}$ depth while its structure is confined in depth by $1500 \mathrm{~m}$ and width by $121 \mathrm{~km}$. Hence, we observe that despite the basic jet between $40^{\circ} \mathrm{W}$ and $30^{\circ}$ $W$ retains similar characteristics, the waves at the latter longitude seems to propagate faster than those at the former.

\section{3. $20^{\circ} \mathrm{W}$}

Near the west edge of the MAC, the southermost SAC core is almost negligible with a velocity of about $5.5 \times 10^{-2} \mathrm{~ms}^{-1}$, while the northernmost core has a velocity of around $7.3 \times 10^{-2} \mathrm{~ms}^{-1}$. Therefore, the SAC presents a more conventional parabolic jet profile. The mean jet structure decays faster with depth than the previously analysed section. The growth curve pattern resembles those of calculated for $40^{\circ} \mathrm{W}$ and $30^{\circ} \mathrm{W}$ with single maximum well defined at the wavenumber of $0.05 \mathrm{~km}^{-1}$. The corresponding growth rate is $2.4 \times 10^{-2}$ days $^{-1}$. The phase speed regime for the $k$ range of interest shows eastward propagating waves increasing in speed with decreasing wavelength. The phase speed of the fastest growing phase meander is $5 \times 10^{-2} \mathrm{~ms}^{-1}$. The most unstable wave has a characteristic period of 28 days.

The maximum amplitude of the perturbed meridional velocity is foudn again at the core of the northern branch with a maximum at $150 \mathrm{~m}$ depth and with a vertical structure confined in the upper $2300 \mathrm{~m}$. The more relevant amplitudes are limited to about 43 $\mathrm{km}$ around the $v^{\prime}$ core.

\section{4. $\underline{10^{\circ} \mathrm{W}}$}




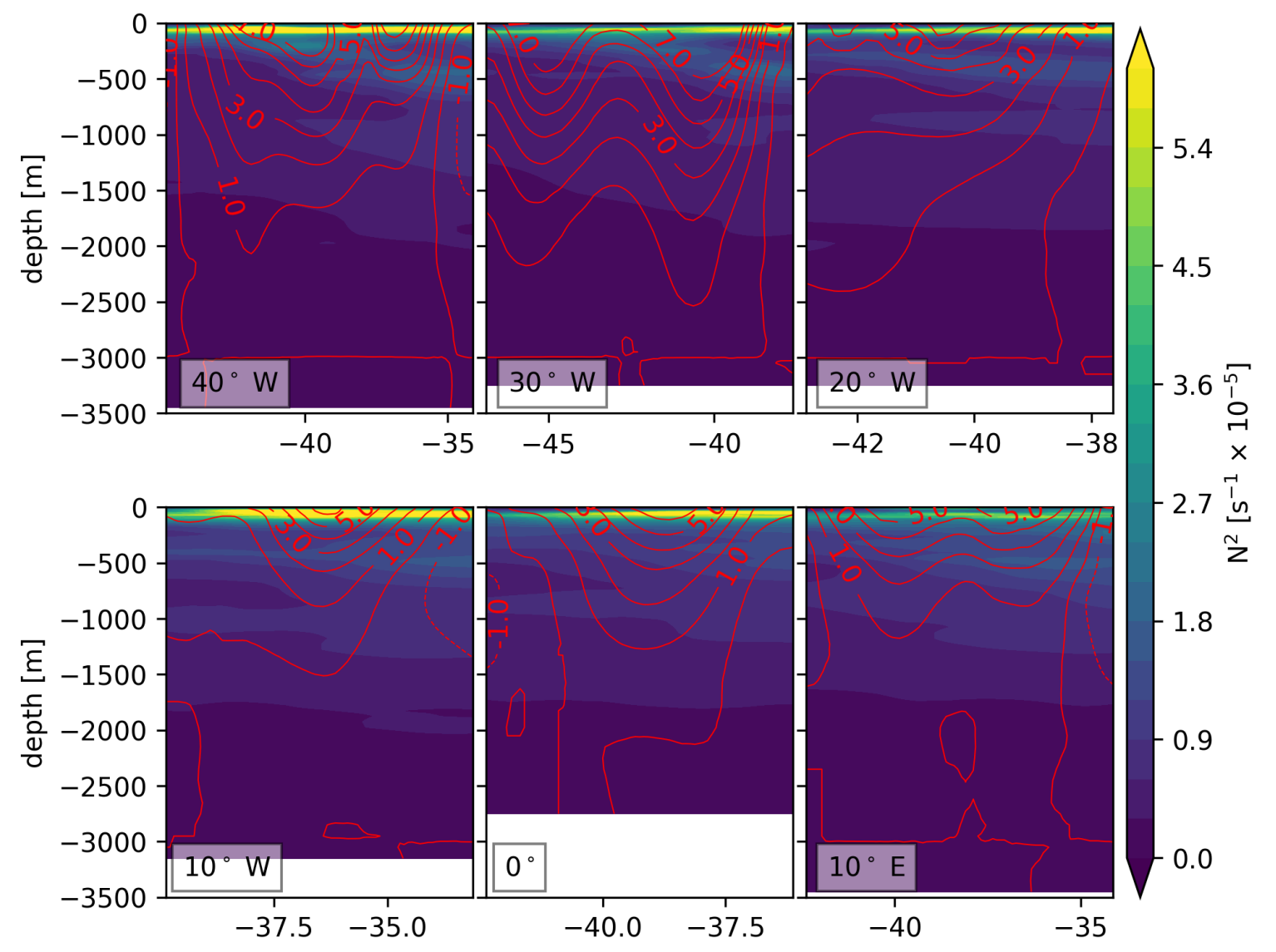

FIGURE 5.8: Sectional profile of $u$ and contour levels of $N^{2}$ (top). 


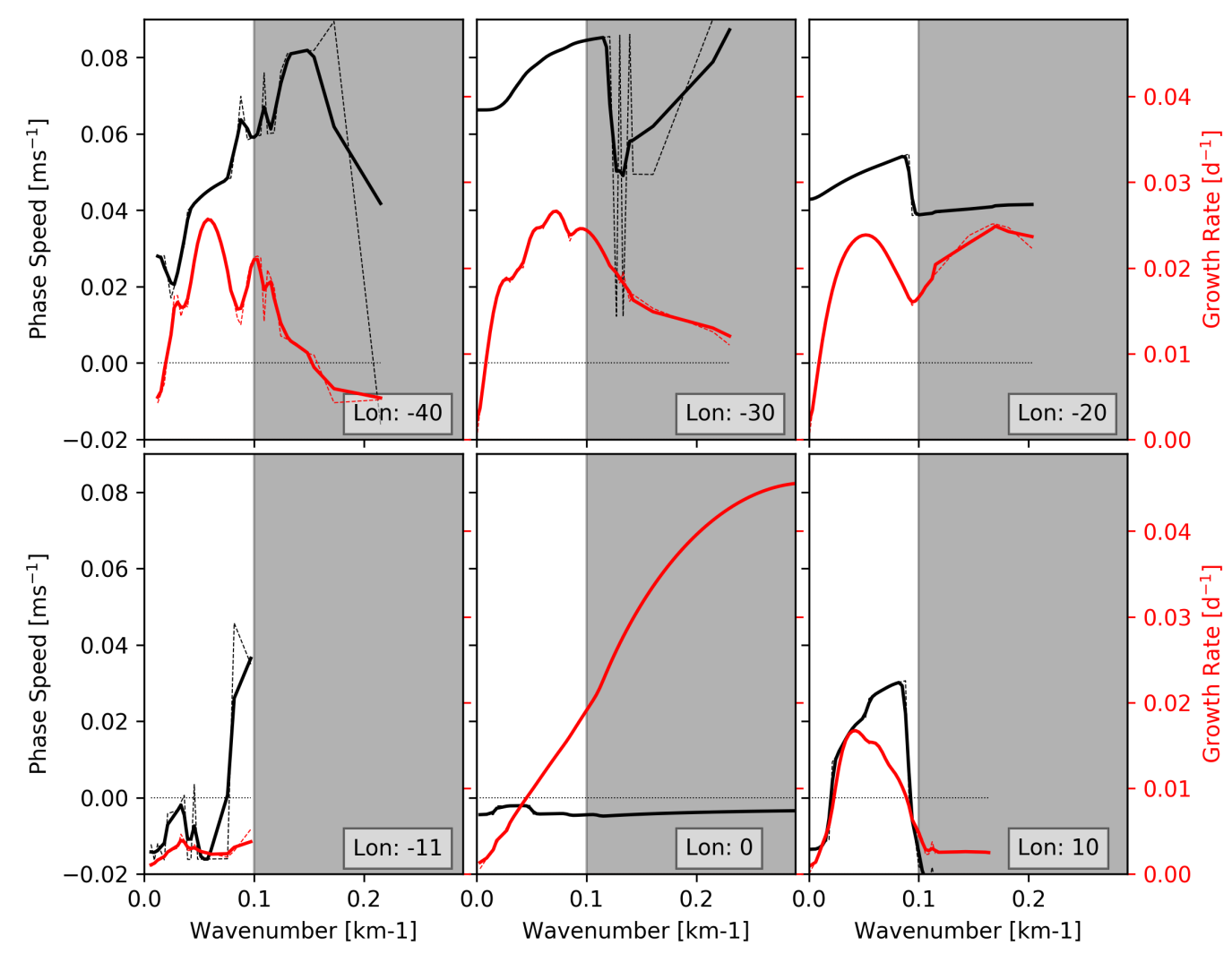

FIGURE 5.9: Model instability results (phase speed and growth rate). The shadowed region represents the domain not analysed

Near the east edge of the MAC, the mean jet configuration of the SAC (located at $40^{\circ}$ $\mathrm{S}$ and $38^{\circ} \mathrm{S}$ ) have a vertical velocity of $1 \times 10^{-2} \mathrm{~ms}^{-1}$ with a very weak vertical decay. Between $38^{\circ} \mathrm{S}-32^{\circ} \mathrm{S}$, the StHC current presents a core $6 \times 10^{-2} \mathrm{~ms}^{-1}$ with a strong baroclinic vertical decay and, therefore, a vertical structure confined at the upper 1500 m.

The instability property curves are remarkably different from the more western sections studied previously. The fastest growth rate is $0.5 \times 10^{-2}$ days ${ }^{-1}$ for the $0.03 \mathrm{~km}^{-1}$ wavenumber. The speed of the propagating wave of the fastest growth rate is westward of around $3 \times 10^{-2} \mathrm{~ms}^{-1}$ and a wave period of 21.5 days.

The perturbed velocity pattern exhibits lobes and counterlobes with opposing signs and are, as in all other cases, centered at the StHC current core. The maximum absolute $v^{\prime}$ value is found at $400 \mathrm{~m}$. The depth and width of the meander patter is found to be $600 \mathrm{~m}$ and $67 \mathrm{~km}$, respectively. 
5. $\underline{0^{\circ} \mathrm{W}}$

At this longitude, the $\mathrm{StHC}$ core has properties resulting from the merging between the original StHC and portion of the SAC northern branch (which mainly occurred at $20^{\circ}$ W). Its maximum velocity is about $6 \times 10^{-2} \mathrm{~ms}^{-1}$. The StHC vertical structure reaches the ocean floor. The jet presents a clssical parabolic shape with about $666 \mathrm{~km}$.

The modeled growth rate curve increases almost monotonically as a function of the wavenumber. Therefore, its fastest growth rate within the wavenumber range of interest was found at $0.1 \mathrm{~km}^{-1}$ (which is the upper bound $k$ chosen for our analysis). The phase speed curve is virtually a straight line with westward constant values of $0.4 \times 10^{-2}$ $\mathrm{ms}^{-1}$. The period of the corresponding fastest growing wave is 165 days.

The instability velocity was found at the southernmost part of the section at the bottom of the column. This very narrow structure $(17 \mathrm{~km})$, has its core located at $2600 \mathrm{~m}$ depth with $1000 \mathrm{~m}$ height. As this velocity pattern presents abnormal structure, we choose to disregard this result in comparison with the previous ones.

6. $10^{\circ} \mathrm{E}$

Closer to the $\mathrm{AgC}$ retroflection system, the $\mathrm{StHC}$ is split into two cores where, as discussed in section 4.2.3 (Figure. 4.16), its southern branch flows southward, joins the SAC-ACCn jet, and flows towards the Indian Ocean. The northern branch is the one to close the SASG.

The growth rate curve of this section resembles a gaussian shape and, therefore, only one maxima $\left(1.5 \times 10^{-2}\right.$ days $\left.^{-1}\right)$ which corresponds to the wavenumber $0.04 \mathrm{~km}^{-1}$. The most unstable wave travels eastward with $c=1.9 \times 10^{-2} \mathrm{~ms}^{-1}$. This unstable waves has periods of 89 days.

The perturbed velocity profile presents its maximum amplitude at $200 \mathrm{~m}$ and extends down to $3100 \mathrm{~m}$. It presents a width of $262 \mathrm{~km}$ and unlike the previous results its maximum is located in the region in between the two branches. 

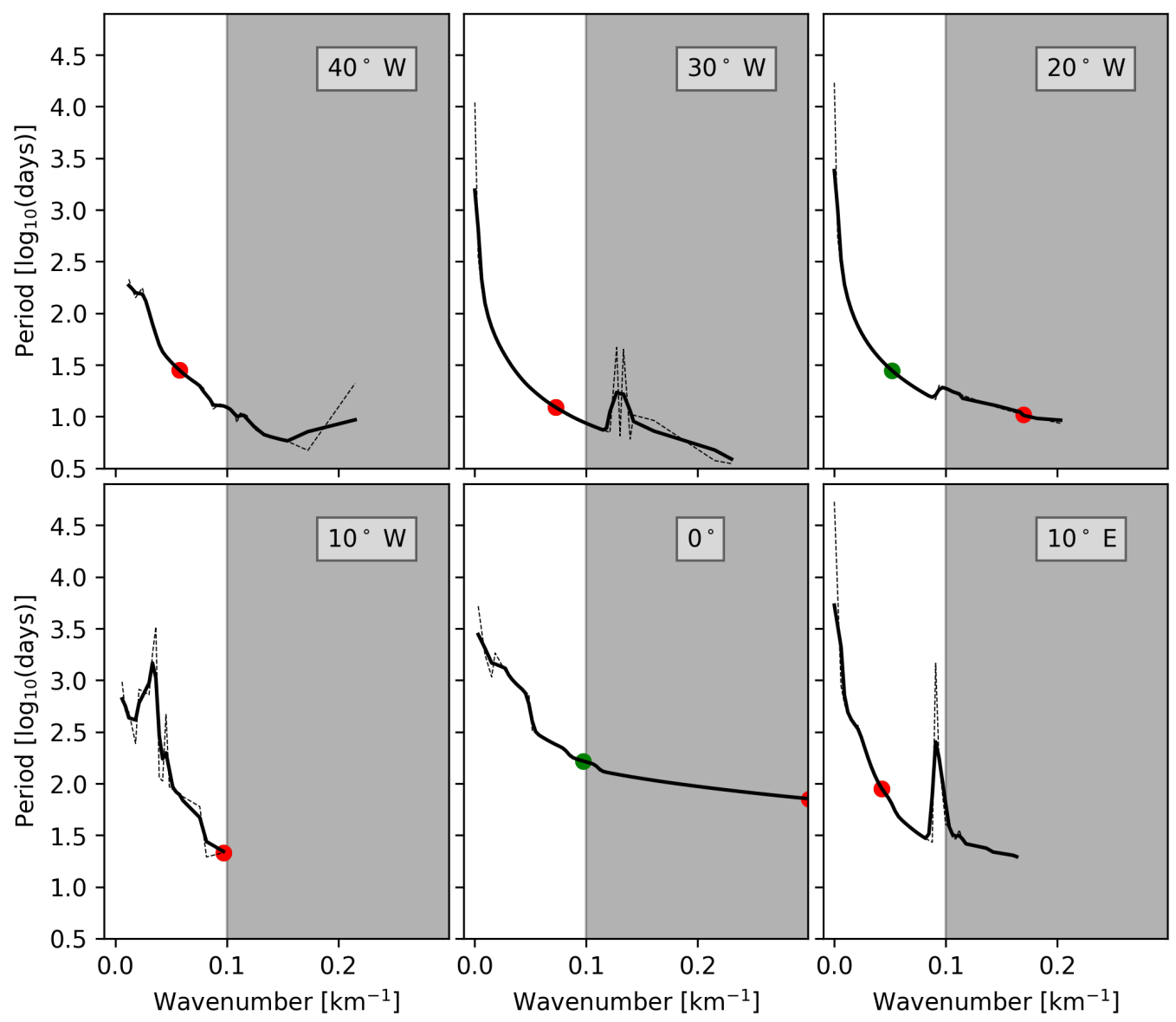

FIGURE 5.10: Period calculated from the model results for each longitude section. The shadowed region represents the domain not analysed

\subsubsection{Discussion and Synthesis}

In this section we summarize the mesoscale dynamics of the SAC as having a significant change throughout its path. The MAC seems to act not only to change the kinematic of the current system (see Chapter 4), but also its instability. The linear instability properties are summarized in Tables 5.2 and 5.3 .

From the seccional model analysis we observe two clear distinctive regimes: one at west and another at east of the MAC. West of the MAC the growth rates and phase speeds are, on average, $2.5 \times 10^{-2}$ days ${ }^{-1}$ and $5.9 \times 10^{-2} \mathrm{~ms}^{-1}$, respectively. Just east of the MAC $\left(10^{\circ}\right.$ W), growth rates are very slow and velocities are weakly westward in the seccional model and weakly eastward in the local baroclinic model. Our interpretation is that in this sense the topographic feature seemed to somehow stabilize the SAC-StHC jet. With the merging 

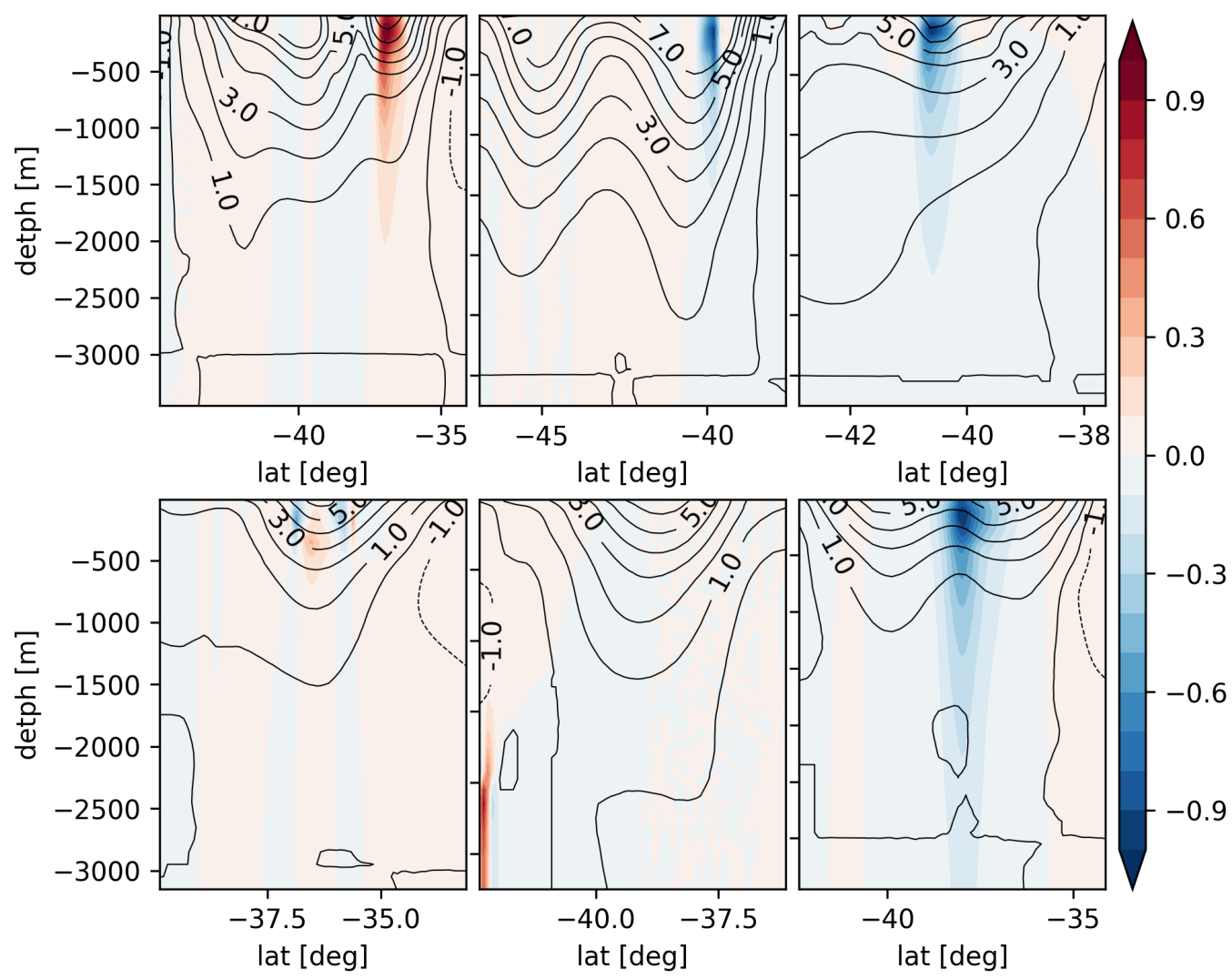

FIGURE 5.11: Velocity vertical structure estimated from model for each section for the fastest growth rate.

of part of the SAC with the ACC we see that along with the increase of the MKE we see an increase of the current instability which is in agreement of the MEKE results.

Closer to the eastern boundaries, the growth rates and phase speeds are $1.7 \times 10^{-2}$ and $1.9 \times 10^{-2}$, respectively. Although, at $10^{\circ} \mathrm{E}$, the instability analysis of the seccional model shows an instability between both northern southern cores of the StHC, the local instability model presents a high instability at both northern and southern cores of the jets. This result could indicate a presence of a significant barotropic instability within this section.

We are not aware of any specific studies regarding the mesoscale dynamics and instability in the southern border of the SASG to date. The only ones seem to be the global study focused on local baroclinic instability by Smith (2007) commanded in the previous subsection. Although they are much faster than the local baroclinic model, which averages around of $1.6 \times 10^{-2}$ days $^{-1}$, the patterns between both models are roughly similar, i.e. the growth rates west of the Mid-Atlantic Ridge are slightly faster than those at east of it. However, 
TABLE 5.2: Detailed results for growth rate (GR), phase speed $\left(\mathrm{c}_{r}\right)$, wavenumber $(k)$ and period of the fastest growing wave for each longitude analysed.

\begin{tabular}{ccccc} 
Lon [deg] & $\mathrm{GR}\left[\mathrm{d}^{-1}\right]$ & $\mathrm{c}_{r}\left[\mathrm{~ms}^{-1}\right]$ & $\mathrm{k}\left[\mathrm{km}^{-1}\right]$ & Period [d] \\
\hline $40^{\circ} \mathrm{W}$ & $2.6 \times 10^{-2}$ & $4.5 \times 10^{-2}$ & 0.06 & 28 \\
$30^{\circ} \mathrm{W}$ & $2.7 \times 10^{-2}$ & $8.1 \times 10^{-2}$ & 0.07 & 12 \\
$20^{\circ} \mathrm{W}$ & $2.4 \times 10^{-2}$ & $5.0 \times 10^{-2}$ & 0.05 & 28 \\
$10^{\circ} \mathrm{W}$ & $0.5 \times 10^{-2}$ & $-3.5 \times 10^{-2}$ & 0.97 & 21 \\
$10^{\circ} \mathrm{E}$ & $1.7 \times 10^{-2}$ & $1.9 \times 10^{-2}$ & 0.04 & 89 \\
\hline
\end{tabular}

TABLE 5.3: Detailed results of the height, width, core depth and maximum speed of the perturbation velocity structure.

\begin{tabular}{ccccc} 
Lon [deg] & Height [m] & Width $[\mathrm{km}]$ & core depth $[\mathrm{m}]$ & $\mathrm{v}_{\max }\left[\mathrm{ms}^{-1}\right]$ \\
\hline $40^{\circ} \mathrm{W}$ & 2000 & 75 & 150 & $8.5 \times 10^{-2}$ \\
$30^{\circ} \mathrm{W}$ & 1500 & 121 & 200 & $-11.7 \times 10^{-2}$ \\
$20^{\circ} \mathrm{W}$ & 2300 & 87 & 150 & $-8.2 \times 10^{-2}$ \\
$10^{\circ} \mathrm{W}$ & 450 & 27 & 450 & $-8.7 \times 10^{-2}$ \\
$10^{\circ} \mathrm{E}$ & 3100 & 262 & 200 & $-6.6 \times 10^{-2}$ \\
\hline
\end{tabular}

the values found are still lower than those calculate by Tulloch et al. (2011) in our region for the Ocean Comprehensible Atlas (OCCA) data set (which is approximately 0.05 days $^{-1}$ ). Although Kontoyiannis (1997) also finds substantially faster growth rates for the Gulf Stream (around 0.15 days $^{-1}$ ), the wavenumber of the fastest growth rate for this current is around $0.025 \mathrm{~km}^{-1}$ which is roughly similar to our region (Figure 5.9). Smith (2007) calculated a growth rate of 0.16 days $^{-1}$ for the ACC south of Tasmania and 0.036 days $^{-1}$ for the Kuroshio extension which is the most similar instability results as our region.

The unstable wave phase speeds of our seccional model are partly in agreement with our local baroclinic model results having simulated eastward-propagating waves, but at faster speeds. Aside from the spurious results of the $0 \%$ ongitude, the $10^{\circ} \mathrm{W}$ is the only longitude that produces opposite wave speed propagation for both models. Hughes (1995) through altimetry results found that Rossby waves propagating eastward are common in the southern oceans which is in agreement with our findings for the SAC current. They also found that within the ACC core Rossby waves propagates eastward, however, away from the core, Rossby waves propagates westward, which was not identified by our local baroclinic model. Hughes (1996) argues that propagation of baroclinic Rossby waves are strongly affected by the mean flow in high latitudes. The author argues that large-scale eastward flows with speeds greater than those of long Rossby waves advect all of these waves eastward. 
The perturbation velocity does not greatly changes across sections, except the $10^{\circ} \mathrm{W}$ which is a very narrow and shallow jet with the deepest core. Smith (2007) found that the ACC south of Tasmania presents a $v^{\prime}$ core of about $1000 \mathrm{~m}$ depth. On the other hand, the author reported the Kuroshio extension presented $200 \mathrm{~m} v^{\prime}$ maximum velocity, which is in agreement with our model. A first inspection on the $Q_{y}, U$, and $v^{\prime}$ fields of the selected six longitudinal transects suggests that the SAC system are dominated by baroclinic Phillips-like instabilities. Indeed, from the results of Tulloch et al. (2011) Charney-type are more common within low latitudes, which does not seem to be the case for our region. 


\section{Chapter 6}

\section{Conclusions}

In this chapter we conclude our findings and present our interpretation to our hypotheses estipulated in Section 1.3. To confirm or reject our first hypothesis, we answer the questions raised in the same section which themselves led to the hypothesis formulated:

1. Is the StHC indeed an independent current fed by the first retroflection of the $B C$ as claimed by Juliano and Alves (2007) or part of the SAC?

Our results show that there is slight difference between the temperature correlation of the SAC and StHC. Additionally, it was identified a trivial transport of the StHC at $40^{\circ} \mathrm{W}$ which only significantly increase east of $30^{\circ} \mathrm{W}$. So, the formation of this current might not be located at the BMC, but rather at the SAC itself. Therefore, our results do not significantly support the idea of the StHC being an independent current. It is likely that the StHC is a nothern branch of the SAC (SACn) that travels zonally along its other branch (SACs).

2. Does the water mass composition allows the differentiation between the $S A C$ and the ACC as well as the identification of their longitudes as they merge and exit the Atlantic Ocean basin?

We interpret that the T-S- $\sigma_{0}$ correlation analysis provided a clear result differentiating both SAC and ACC. The SAC is easily visible within subtropical correlation structure as it flows zonally until the MAC. At this site, however, the velocity analysis structure indicates that the SAC is not distinguishable from the ACCn. Their water mass properties are transported to Indian Ocean as a broad jet (with a meridional span of $5^{\circ}$ ). The ACCn and ACCs jets are easily distinguishable through most of the ocean basin. We 
can therefore say that through the water mass composition we can estimate the region where the waters are most closely correlated with the current, but as they merge we cannot identify them separately.

3. What is the role of the StHC (SACn) in the SASG southern limb?

The SACn is the branch which indeed closes the SASG. As it approach the eastern South Atlantic boundary, it also splits in two branches. The southern branches follows zonally to the Indian Ocean, while the northern veers northeastward along with $\mathrm{BeC}$ closing the gyre. The SACs, however, is fully merged with the ACCn $\left(10^{\circ} \mathrm{W}\right)$ and flows along to the Indian Ocean. Part of this current feeds StHC from its formation to about $10^{\circ} \mathrm{E}$.

From the answers provided above, we do not reject our first hypothesis that The SACStHC (SACn-SACs) with the same T-S signature travels zonally along the SASG southern limb and close the gyre. The T-S- $\sigma_{0}$ correlation provides a slight distinction between the SACS-SACn (which should be further investigated), but provides a clear distinction between these currents and the ACC. Additionally the transport analysis suggest that the location of the SACn is at the SAC current.

The second hypothesis formulated is related to the instability analysis. To further confirm or reject our hypothesis, we again turn to answer our question from section 1.3:

1. Is the SAC current unstable throughout its flow path and does the MAC acts a stabilizer to the SASG southern limb current system?

Yes, we find that, in general, the whole SAC system is unstable throughout the SASG. From our local baroclinic and seccional mixed model, suplemmented our energetic analysis, we identify a clear change of instability characteristics and eddy energy. Although, the current at the eastern side of the MAC $\left(10^{\circ} \mathrm{S}\right)$ seems more stable than in the western side, the eddy energy seems to not be affected, suggesting a more complex phenomena involving the unstable zonal jets and $\mathrm{AgC}$ rings region. We should mention that in the vicinities and over the Meteor Rise the current are stable by the local model simulations and marginally unstable by the mixed seccional model.

We therefore do not reject our second hypothesis of The SAC system undergoes through important zonal changes in their jet configurations as they cross the South Atlantic basin, 
which in turn yields different patterns of mesoscale activity. The SAC does undergoes through changes as it crosses the Atlantic Ocean. The most relevant differences are found when the current crosses the MAC, and also through the Meteor Rise. We suspect the formation of lee waves at the site, but we did not investigated it further.

In order to advance in the understanding of the heat and salt fluxes at southern limb of the SASG, more in situ observations are needed. In particular, direct velocity profiling on the SAC system must be carried out. We found only one hydrographic transect from the WOCE program which crossed the BMC that had LADCP profiles available.

As future work, we aim to conduct further investigation using global model outputs and satellite altimetry in order to better understand the instability wave and the related eddy fluxes associated with them. We know that the South Atlantic ocean is probably the last frontier of the worlds ocean to be unraveled in its role to the world climate. 


\section{Appendix A}

\section{The Partial Differential Instability Equation}

From the linearized quasi-geostrophic potential vorticity equations:

$$
\left\{\begin{array}{l}
D_{t}\left(v_{x}-u_{y}\right)+\beta v=f_{0} w_{z} \\
D_{t} \rho+w \overline{\rho_{z}}=0
\end{array}\right.
$$

where $D_{t}$ is the total derivative; $\beta$ is defined as $\beta=f_{y} ; w$ is the $\hat{k}$ component of velocity; and $\rho$ and $\bar{\rho}$ is the density and its horizontal average. With the hydrostatic equation, and considering $u$ and $v$ as geostrophic we get:

$$
\left\{\begin{array}{l}
{\left[1 /\left(\rho_{0} f_{0}\right)\right]\left[D_{t}\left(\nabla^{2} p\right)+\beta p_{x}\right]=f_{0} w_{z}} \\
\left(1 / \rho_{0}\right) D_{t}\left(\rho_{z}\right)+N^{2} w=0
\end{array}\right.
$$

where $p$ is pressure; and $\rho_{0}$ is the density from Bousinesq Approximation. The problem will be established as being zonal with rigid walls with constant depth, rigid lid and no normal flow along vertical boundaries:

$$
\begin{cases}w=0 & z=0, H \\ v=0 & y=0, W\end{cases}
$$

From these equation, we assume the fields can be decomposed in its respective average and an small perturbation: 


$$
\left\{\begin{array}{l}
p(x, y, z, t)=\bar{p}(y, z)+p^{\prime}(x, y, z, t) \\
u(x, y, z, t)=U(y, z)+u^{\prime}(x, y, z, t) \\
v(x, y, z, t)=v^{\prime}(x, y, z, t) \\
w(x, y, z, t)=w^{\prime}(x, y, z, t)
\end{array}\right.
$$

where $U$ is defined as $U=-\overline{p_{y}} /\left(\rho_{0} f_{0}\right)$. If we substitute the previous equations (Eq. A.4) in Equation A.2, A.3, we get:

$$
\begin{gathered}
\left(\partial_{t}+U \partial_{x}\right)\left\{\nabla^{2} p^{\prime}+\partial_{z}\left[\left(\frac{f_{0}}{N}\right)^{2} p_{z}^{\prime}\right]\right\}+p_{x}^{\prime} Q_{y}=0 \\
\left\{\begin{array}{l}
\left(\partial_{t}+U \partial_{x}\right) p_{z}^{\prime}=U_{z} p_{x}^{\prime} \quad z=0, H \\
p_{x}^{\prime}=0 \quad y=0, W
\end{array}\right.
\end{gathered}
$$

where:

$$
Q_{y}=\beta-U_{y y}+\partial_{z}\left[\left(\frac{f_{0}}{N}\right)^{2} U_{z}\right]
$$

is the cross-stream gradient of basic potential vorticity. We, finally, assume the solution as:

$$
p^{\prime}(x, y, z, t)=\operatorname{Re}\left[\Phi(y, z) e^{i k(x-c t)}\right]
$$

where $c \in \mathbb{C}$. If $c_{i}<0$ for a $k$, we will then have an instability process. Substituting Equation A.7 in Equation A.5 and A.6:

$$
(U-c)\left\{\Phi_{y y}-k^{2} \Phi+\partial_{z}\left[\left(\frac{f_{0}}{N}\right)^{2} \Phi_{z}\right]\right\}+Q_{y} \Phi=0
$$

with its boundary conditions as:

$$
\left\{\begin{array}{l}
(U-c) \Phi_{z}=U_{z} \Phi \quad z=0, H \\
\Phi=0 \quad y=0, W
\end{array}\right.
$$




\section{Appendix B}

\section{Numerical Differentiation of the Instability PDE Equation}

The equation to be discretize will be Equation ?? with its respective boundary conditions (Eq. ??). The model can be thought of a bidimensional grid space with equidistant $d y_{n}$ and $\mathrm{dz} \mathrm{z}_{n}$ (Fig. B.1).

The indexes are assumed as: $\{i, j \in \mathbb{N} \quad \mid \quad 0 \leq i \leq N, 0 \leq j \leq N\}$. The points where $i=0, i=N$, and $j=0, j=N$ are the defined boundaries.

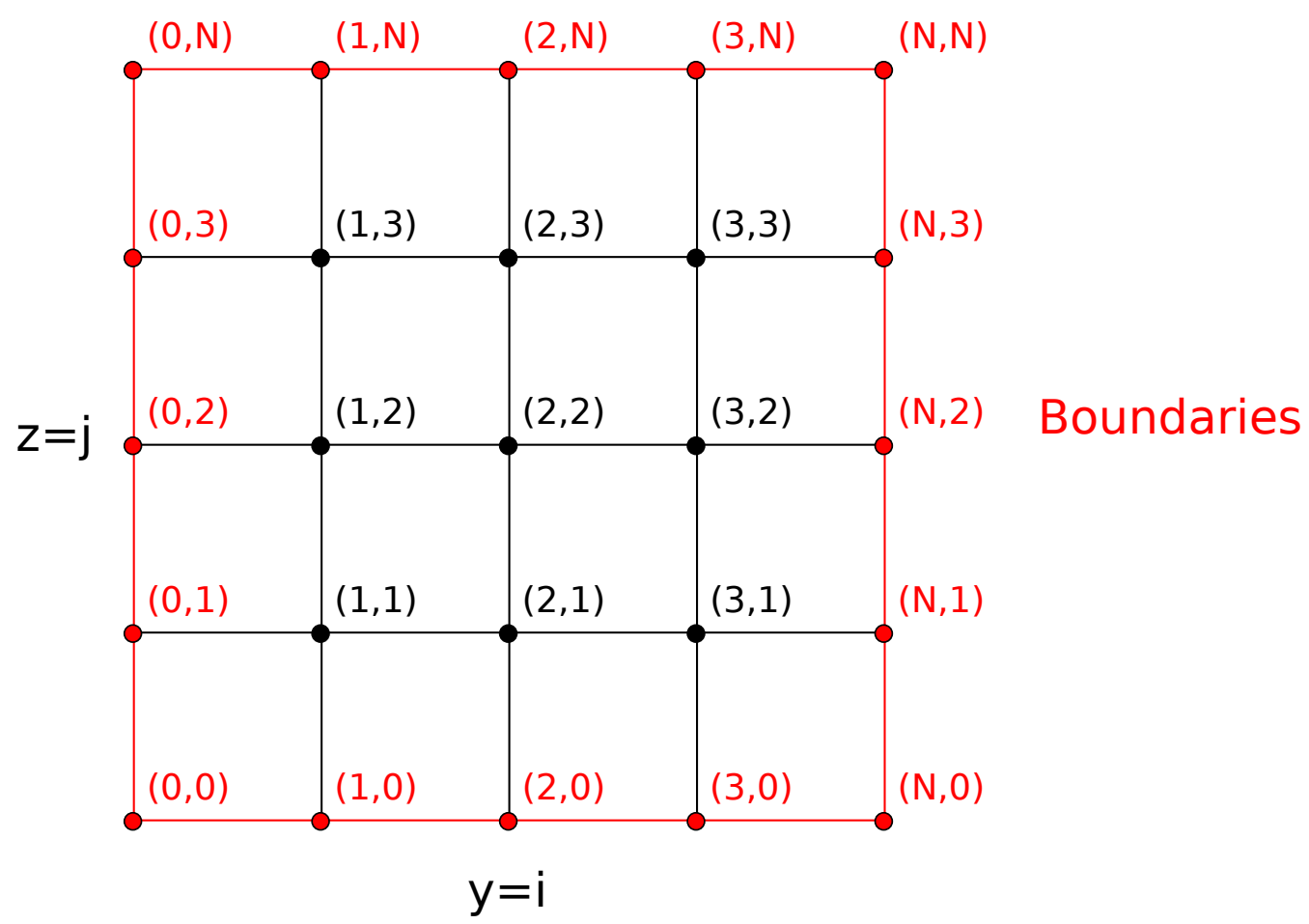

FIGURE B.1: Model grid for the discretized model. The red lines and points represent the boundaries of the model. 


\section{B.1 Discretization}

The centered difference scheme discretization is used fo both the boundary conditions and the main PDE as follows:

$$
\left\{\begin{array}{l}
\Phi_{z}=\left(\phi_{i, j+1}-\phi_{i, j-1}\right) /(2 \Delta z) \\
\Phi_{z z}=\left(\phi_{i, j+1}-2 \phi_{i, j}+\phi_{i, j-1}\right) / \Delta z^{2} \\
\Phi_{y y}=\left(\phi_{i+1, j}-2 \phi_{i, j}+\phi_{i-1, j}\right) / \Delta y^{2}
\end{array}\right.
$$

\section{B.1.1 Boundary Conditions}

Starting with the boundary conditions, it can be defined as:

$$
\left\{\begin{array}{l}
(U-c)\left[\phi_{i, j+1}-\phi_{i, j-1}\right] /(2 \Delta z)=U_{z} \phi_{i, j} \quad z=0, H \\
\phi_{i, j}=0
\end{array}\right.
$$

For $z=0, H$

- $z=0(j=0)$ : Although the Boundary condition is at $j=0$, the calculations are done for $j=1$ :

$$
\begin{gathered}
(U-c)\left[\frac{\phi_{i, 2}-\phi_{i, 0}}{2 \Delta z}\right]=U_{z} \phi_{i, 1} \\
(U-c)\left[\frac{\phi_{i, 2}-\phi_{i, 0}}{2 \Delta z}\right]-U_{z} \phi_{i, 1}=0=> \\
(U-c) \phi_{i, 2}-(U-c) \phi_{i, 0}-2 U_{z} \Delta z \phi_{i, 1}=0=> \\
\phi_{i, 0}=\phi_{i, 2}-\frac{2 U_{z} \Delta z}{(U-c)} \phi_{i, 1}
\end{gathered}
$$

- $z=H(j=N)$ : Although the Boundary condition is at $j=N$ the calculations are done for $j=N-1$ :

$$
(U-c)\left[\frac{\phi_{i, N}-\phi_{i, N-2}}{2 \Delta z}\right]=U_{z} \phi_{i, N-1}
$$




$$
\begin{array}{r}
(U-c)\left[\frac{\phi_{i, N}-\phi_{i, N-2}}{2 \Delta z}\right]-U_{z} \phi_{i, N-1}=0=> \\
(U-c) \phi_{i, N}-(U-c) \phi_{i, N-2}-2 U_{z} \Delta z \phi_{i, N-1}=0=> \\
\phi_{i, N}=\phi_{i, N-2}+\frac{2 U_{z} \Delta z}{(U-c)} \phi_{i, N-1}
\end{array}
$$

For $y=0, W(i=0, N)$

$$
\left\{\begin{array}{l}
\phi_{0, j}=0 \quad y=0(i=0) \\
\phi_{N, j}=0 \quad y=W(i=N)
\end{array}\right.
$$

\section{B.1.2 The Main Equation}

For the main equation, it is first derivated through the chain rule to reach:

$$
(U-c)\left\{\Phi_{y y}-k^{2} \Phi+(f / N)^{2} \Phi_{z z}-2(f / N)^{2}\left(N_{z} / N\right) \Phi_{z}\right\}+Q_{y} \Phi=0 .
$$

Applying the discretization:

$$
\begin{array}{r}
(U-c)\left\{\frac{\phi_{i+1, j}-2 \phi_{i, j}+\phi_{i-1, j}}{\Delta y^{2}}+(f / N)^{2}\left[\frac{\phi_{i, j+1}-2 \phi_{i, j}+\phi_{i, j-1}}{\Delta z^{2}}\right]-(f / N)^{2}\left(N_{z} / N\right)\left[\frac{\phi_{i, j+1}-\phi_{i, j-1}}{\Delta z}\right]\right\}+ \\
{\left[Q_{y}-k^{2}(U-c)\right] \phi_{i, j}=0}
\end{array}
$$

$$
\begin{array}{r}
(U-c)\left\{1 / \Delta y^{2} \phi_{i+1, j}+1 / \Delta y^{2} \phi_{i-1, j}+\right. \\
(f / N)^{2}\left[1 / \Delta z^{2}-\left(N_{z} / N\right) / \Delta z\right] \phi_{i, j+1}+ \\
\left.(f / N)^{2}\left[1 / \Delta z^{2}+\left(N_{z} / N\right) / \Delta z\right] \phi_{i, j-1}\right\}+ \\
\left\{Q_{y}-\left\{k^{2}+2\left[(f / N)^{2} / \Delta z^{2}+1 / \Delta y^{2}\right]\right\}(U-c)\right\} \phi_{i, j}=0
\end{array}
$$

Declaring the following variables: 


$$
\left\{\begin{array}{l}
L_{1}=\left(f_{0} / N\right)^{2}\left[1 / \Delta z^{2}+\left(N_{z} / N\right) / \Delta z\right] \\
L_{2}=k^{2}+2\left[\left(f_{0} / N\right)^{2} / \Delta z^{2}+1 / \Delta y^{2}\right] \\
L_{3}=(f / N)^{2}\left[1 / \Delta z^{2}-\left(N_{z} / N\right) / \Delta z\right] \\
L_{4}=1 / \Delta y^{2}
\end{array}\right.
$$

The equation then becomes:

$$
(U-c)\left\{L_{4} \phi_{i+1, j}+L_{4} \phi_{i-1, j}+L_{3} \phi_{i, j+1}+L_{1} \phi_{i, j-1}\right\}+\left[Q_{y}-L_{2}(U-c)\right] \phi_{i, j}=0
$$

\section{Discretizing for different $i$ 's and $j$ 's}

- For $i=1$

- For $j=1$

$$
(U-c)\left\{L_{4} \phi_{2,1}+L_{4} \phi_{0,1}+L_{3} \phi_{1,2}+L_{1} \phi_{1,0}\right\}+\left[Q_{y}-L_{2}(U-c)\right] \phi_{1,1}=0
$$

$$
\begin{array}{r}
(U-c)\left\{L_{4} \phi_{2,1}+L_{3} \phi_{1,2}+L_{1}\left[\phi_{1,2}-\frac{2 U_{z} \Delta z}{(U-c)} \phi_{1,1}\right]\right\}+\left[Q_{y}-L_{2}(U-c)\right] \phi_{1,1}=0=> \\
(U-c)\left\{L_{4} \phi_{2,1}+L_{3} \phi_{1,2}+L_{1} \phi_{1,2}\right\}+\left[Q_{y}-2 L_{1} U_{z} \Delta z-L_{2}(U-c)\right] \phi_{1,1}=0=> \\
L_{4} U \phi_{2,1}+L_{3} U \phi_{1,2}+L_{1} U \phi_{1,2}+\left[Q_{y}-2 L_{1} U_{z} \Delta z-L_{2} U\right] \phi_{1,1}= \\
c\left\{L_{4} \phi_{2,1}+\left(L_{3}+L_{1}\right) \phi_{1,2}-L_{2} \phi_{1,1}\right\}
\end{array}
$$

- For $j=l$

$$
\begin{array}{r}
(U-c)\left\{L_{4} \phi_{2, l}-L_{4} \phi_{0, l}+L_{3} \phi_{1, l+1}+L_{1} \phi_{1, l-1}\right\}+ \\
{\left[Q_{y}-L_{2}(U-c)\right] \phi_{1, l}=0}
\end{array}
$$




$$
\begin{array}{r}
L_{4}(U-c) \phi_{2, l}+L_{3}(U-c) \phi_{1, l+1}+L_{1}(U-c) \phi_{1, l-1}+ \\
{\left[Q_{y}-L_{2}(U-c)\right] \phi_{1, l}=0=>} \\
L_{4} U \phi_{2, l}+L_{3} U \phi_{1, l+1}+L_{1} U \phi_{1, l-1}+\left[Q_{y}-L_{2} U\right] \phi_{1, l}= \\
c\left\{L_{4} \phi_{2, l}+L_{3} \phi_{1, l+1}+L_{1} \phi_{1, l-1}-L_{2} \phi_{1, l}\right\}
\end{array}
$$

- For $j=N-1$

$$
(U-c)\left\{L_{4} \phi_{2, N-1}+L_{4} \phi_{0, N-1}+L_{3} \phi_{1, N}+L_{1} \phi_{1, N-2}\right\}+\left[Q_{y}-L_{2}(U-c)\right] \phi_{1, N-1}=0
$$

$$
\begin{array}{r}
(U-c)\left\{L_{4} \phi_{2, N-1}+L_{3} \phi_{1, N}+L_{1} \phi_{1, N-2}\right\}+\left[Q_{y}-L_{2}(U-c)\right] \phi_{1, N-1}=0=> \\
(U-c)\left\{L_{4} \phi_{2, N-1}+L_{3}\left[\phi_{1, N-2}+\frac{2 U_{z} \Delta z}{(U-c)} \phi_{1, N-1}\right]+L_{1} \phi_{1, N-2}\right\}+ \\
{\left[Q_{y}-L_{2}(U-c)\right] \phi_{1, N-1}=0=>} \\
(U-c)\left[L_{4} \phi_{2, N-1}+\left(L_{3}+L_{1}\right) \phi_{1, N-2}\right]+\left[Q_{y}+2 L_{3} U_{z} \Delta z-L_{2}(U-c)\right] \phi_{1, N-1}=0=> \\
\left.L_{4} U \phi_{2, N-1}+\left(L_{3}+L_{1}\right) U \phi_{1, N-2}\right]+\left[Q_{y}+2 L_{3} U_{z} \Delta z-L_{2} U\right] \phi_{1, N-1}= \\
c\left[L_{4} \phi_{2, N-1}+\left(L_{3}+L_{1}\right) \phi_{1, N-2}-L_{2} \phi_{1, N-1}\right]
\end{array}
$$

- For $i=k$

- For $j=1$

$$
\begin{array}{r}
(U-c)\left\{L_{4} \phi_{k+1,1}+L_{4} \phi_{k-1,1}+L_{3} \phi_{k, 2}+L_{1} \phi_{k, 0}\right\}+ \\
{\left[Q_{y}-L_{2}(U-c)\right] \phi_{k, 1}=0}
\end{array}
$$




$$
\begin{array}{r}
(U-c)\left\{L_{4} \phi_{k+1,1}+L_{4} \phi_{k-1,1}+L_{3} \phi_{k, 2}+L_{1}\left[\phi_{k, 2}-\frac{2 U_{z} \Delta z}{(U-c)} \phi_{k, 1}\right]\right\}+ \\
{\left[Q_{y}-L_{2}(U-c)\right] \phi_{k, 1}=0=>} \\
(U-c)\left[L_{4} \phi_{k+1,1}+L_{4} \phi_{k-1,1}+\left(L_{3}+L_{1}\right) \phi_{k, 2}\right]+ \\
{\left[Q_{y}-2 L_{1} U_{z} \Delta z-L_{2}(U-c)\right] \phi_{k, 1}=0=>} \\
\left.L_{4} U \phi_{k+1,1}+L_{4} U \phi_{k-1,1}+\left(L_{3}+L_{1}\right) U \phi_{k, 2}\right]+ \\
{\left[Q_{y}-2 L_{1} U_{z} \Delta z-L_{2} U\right] \phi_{k, 1}=} \\
c\left[L_{4} \phi_{k+1,1}+L_{4} \phi_{k-1,1}+\left(L_{3}+L_{1}\right) \phi_{k, 2}-L_{2} \phi_{k, 1}\right]
\end{array}
$$

- For $j=l$

$$
\begin{gathered}
(U-c)\left\{L_{4} \phi_{k+1, l}+L_{4} \phi_{k-1, l}+L_{3} \phi_{k, l+1}+L_{1} \phi_{k, l-1}\right\}+ \\
{\left[Q_{y}-L_{2}(U-c)\right] \phi_{k, l}=0} \\
L_{4}(U-c) \phi_{k+1, l}+L_{4}(U-c) \phi_{k-1, l}+L_{3}(U-c) \phi_{k, l+1}+L_{1}(U-c) \phi_{k, l-1}+ \\
{\left[Q_{y}-L_{2}(U-c)\right] \phi_{k, l}=0} \\
\\
L_{4} U \phi_{k+1, l}+L_{4} U \phi_{k-1, l}+L_{3} U \phi_{k, l+1}+L_{1} U \phi_{k, l-1}+\left(Q_{y}-L_{2} U\right) \phi_{k, l}= \\
c\left\{L_{4} \phi_{k+1, l}+L_{4} \phi_{k-1, l}+L_{3} \phi_{k, l+1}+L_{1} \phi_{k, l-1}-L_{2} \phi_{k, l}\right\}
\end{gathered}
$$

- For $j=N-1$

$$
\begin{array}{r}
(U-c)\left\{L_{4} \phi_{k+1, N-1}+L_{4} \phi_{k-1, N-1}+L_{3} \phi_{k, N}+L_{1} \phi_{k, N-2}\right\}+ \\
{\left[Q_{y}-L_{2}(U-c)\right] \phi_{k, N-1}=0}
\end{array}
$$




$$
\begin{array}{r}
(U-c)\left\{L_{4} \phi_{k+1, N-1}+L_{4} \phi_{k-1, N-1}+L_{3}\left[\phi_{k, N-2}+\frac{2 U_{z} \Delta z}{(U-c)} \phi_{k, N-1}\right]+L_{1} \phi_{k, N-2}\right\}+ \\
{\left[Q_{y}-L_{2}(U-c)\right] \phi_{k, N-1}=0=>} \\
(U-c)\left\{L_{4} \phi_{k+1, N-1}+L_{4} \phi_{k-1, N-1}+\left(L_{1}+L_{3}\right) \phi_{k, N-2}\right\}+ \\
{\left[Q_{y}+2 L_{3} U_{z} \Delta z-L_{2}(U-c)\right] \phi_{k, N-1}=0=>} \\
L_{4} U \phi_{k+1, N-1}+L_{4} U \phi_{k-1, N-1}+\left(L_{1}+L_{3}\right) U \phi_{k, N-2}+\left[Q_{y}+2 L_{3} U_{z} \Delta z-L_{2} U\right] \phi_{k, N-1}= \\
c\left[L_{4} \phi_{k+1, N-1}+L_{4} \phi_{k-1, N-1}+\left(L_{1}+L_{3}\right) \phi_{k, N-2}-L_{2} \phi_{k, N-1}\right]
\end{array}
$$

- For $i=N-1$

- For $j=1$

$$
\begin{array}{r}
(U-c)\left\{L_{4} \phi_{N, 1}+L_{4} \phi_{N-2,1}+L_{3} \phi_{N-1,2}+L_{1} \phi_{N-1,0}\right\}+ \\
{\left[Q_{y}-L_{2}(U-c)\right] \phi_{N-1,1}=0} \\
(U-c)\left\{L_{4} \phi_{N-2,1}+L_{3} \phi_{N-1,2}+L_{1}\left[\phi_{N-1,2}-\frac{2 U_{z} \Delta z}{(U-c)} \phi_{N-1,1}\right]\right\}+ \\
{\left[Q_{y}-L_{2}(U-c)\right] \phi_{N-1,1}=0=>} \\
(U-c)\left\{L_{4} \phi_{N-2,1}+\left(L_{3}+L_{1}\right) \phi_{N-1,2}\right\}+ \\
{\left[Q_{y}-2 L_{1} U_{z} \Delta z-L_{2}(U-c)\right] \phi_{N-1,1}=0=>} \\
L_{4} U \phi_{N-2,1}+\left(L_{3}+L_{1}\right) U \phi_{N-1,2}+\left[Q_{y}-2 L_{1} U_{z} \Delta z-L_{2} U\right] \phi_{N-1,1}= \\
c\left[L_{4} \phi_{N-2,1}+\left(L_{3}+L_{1}\right) \phi_{N-1,2}-L_{2} \phi_{N-1,1}\right]
\end{array}
$$

- For $j=l$

$$
\begin{array}{r}
(U-c)\left\{L_{4} \phi_{N, l}+L_{4} \phi_{N-2, l}+L_{3} \phi_{N-1, l+1}+L_{1} \phi_{N-1, l-1}\right\}+ \\
{\left[Q_{y}-L_{2}(U-c)\right] \phi_{N, l}=0}
\end{array}
$$




$$
\begin{array}{r}
(U-c)\left\{L_{4} \phi_{N-1, l}+L_{3} \phi_{N, l+1}+L_{1} \phi_{N, l-1}\right\}+ \\
{\left[Q_{y}-L_{2}(U-c)\right] \phi_{N, l}=0=>} \\
L_{4} U \phi_{N-1, l}+L_{3} U \phi_{N, l+1}+L_{1} U \phi_{N, l-1}+\left(Q_{y}-L_{2} U\right) \phi_{N, l}= \\
c\left\{L_{4} \phi_{N-1, l}+L_{3} \phi_{N, l+1}+L_{1} \phi_{N, l-1}-L_{2} \phi_{N, l}\right\}
\end{array}
$$

- For $j=N-1$

$$
\begin{gathered}
(U-c)\left\{L_{4} \phi_{N, N-1}+L_{4} \phi_{N-2, N-1}+L_{3} \phi_{N-1, N}+L_{1} \phi_{N-1, N-2}\right\}+ \\
{\left[Q_{y}-L_{2}(U-c)\right] \phi_{N, N-1}=0} \\
(U-c)\left\{L_{4} \phi_{N-2, N-1}+L_{3}\left[\phi_{N-1, N-2}+\frac{2 U_{z} \Delta z}{(U-c)} \phi_{N-1, N-1}\right]+L_{1} \phi_{N-1, N-2}\right\}+ \\
{\left[Q_{y}-L_{2}(U-c)\right] \phi_{N-1, N-1}=0=>} \\
(U-c)\left\{L_{4} \phi_{N-2, N-1}+\left(L_{1}+L_{3}\right) \phi_{N-1, N-2}\right\}+ \\
{\left[Q_{y}+2 L_{3} U_{z} \Delta z-L_{2}(U-c)\right] \phi_{N-1, N-1}=0=>} \\
L_{4} U \phi_{N-2, N-1}+\left(L_{1}+L_{3}\right) U \phi_{N-1, N-2}+\left(Q_{y}+2 L_{3} U_{z} \Delta z-L_{2} U\right) \phi_{N-1, N-1}= \\
c\left[L_{4} \phi_{N-2, N-1}+\left(L_{1}+L_{3}\right) \phi_{N-1, N-2}-L_{2} \phi_{N-1, N-1}\right]
\end{gathered}
$$




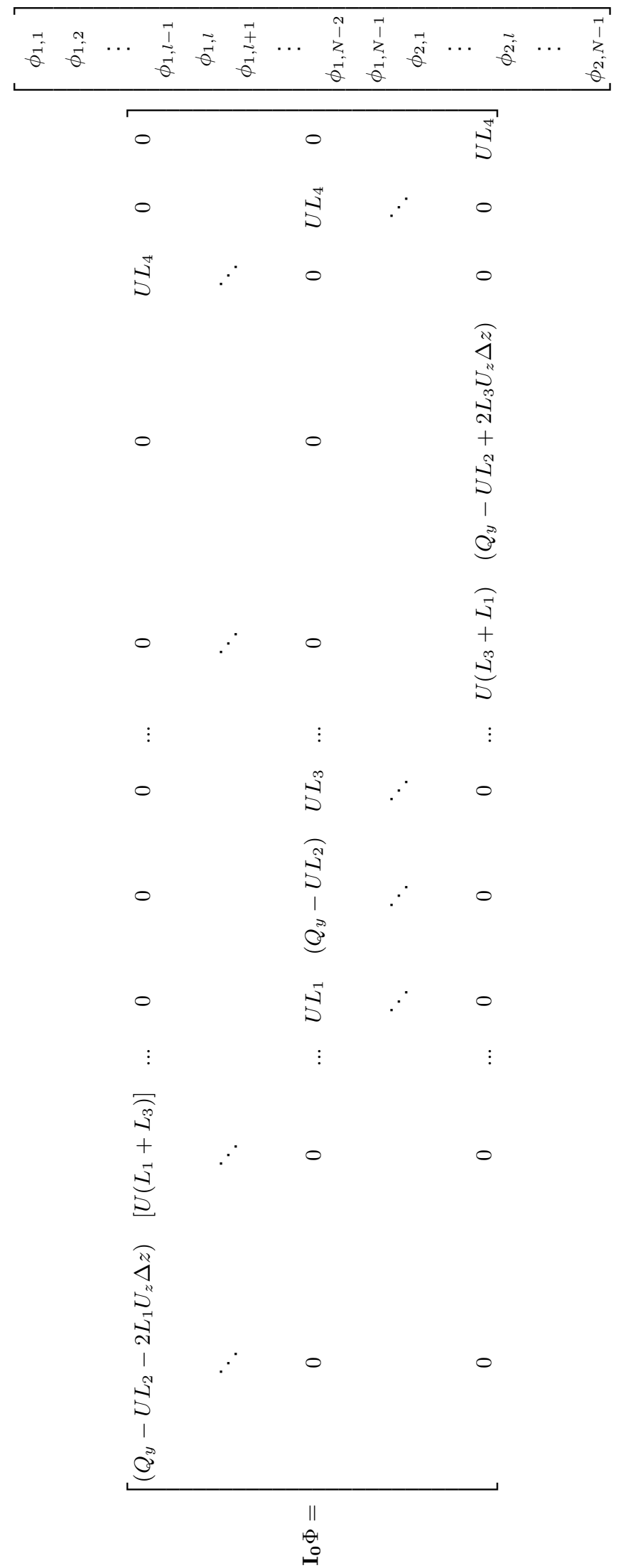




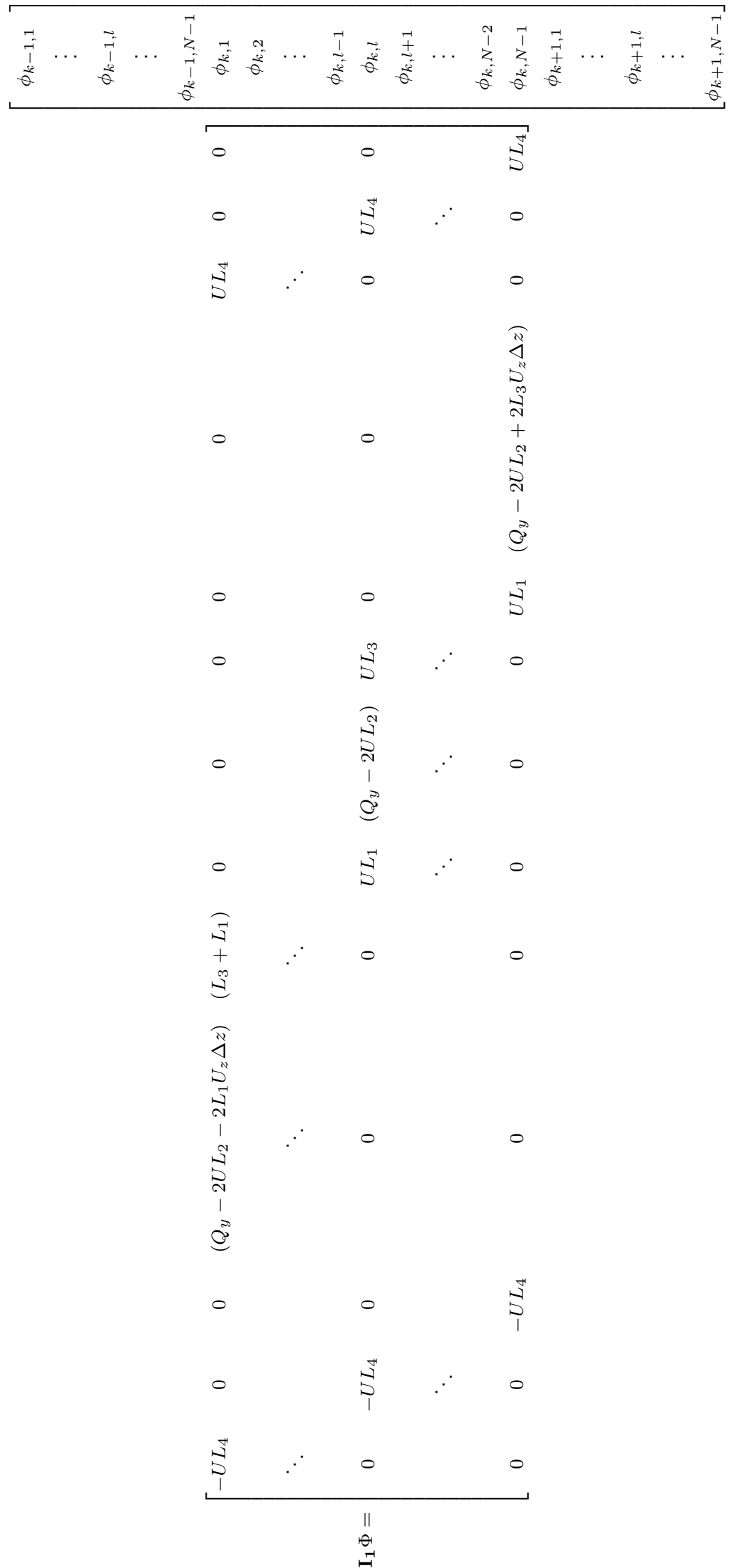




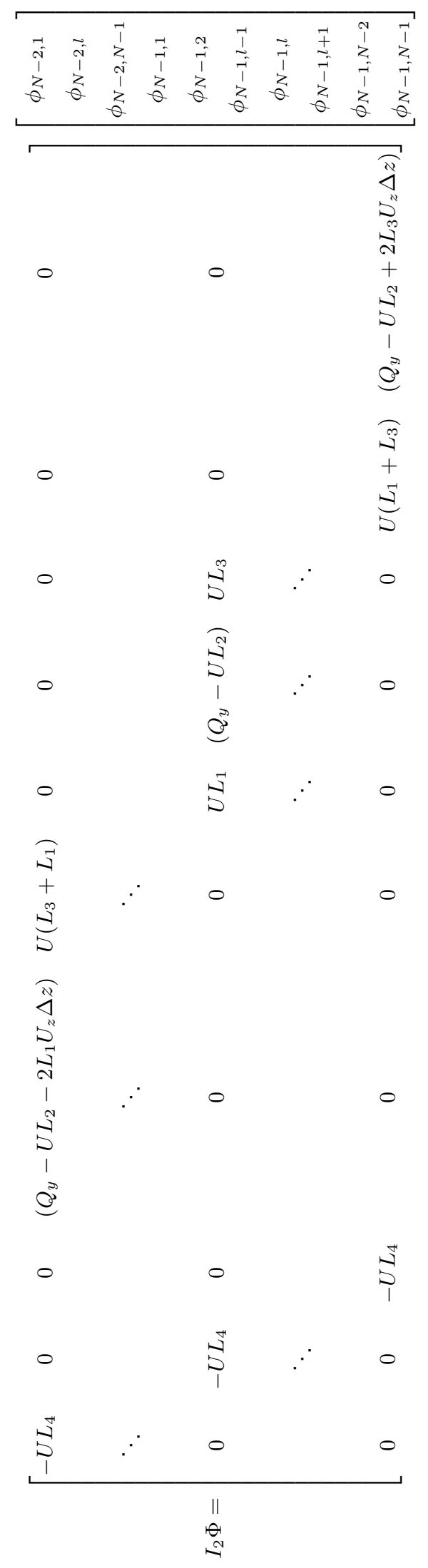


Dividing:

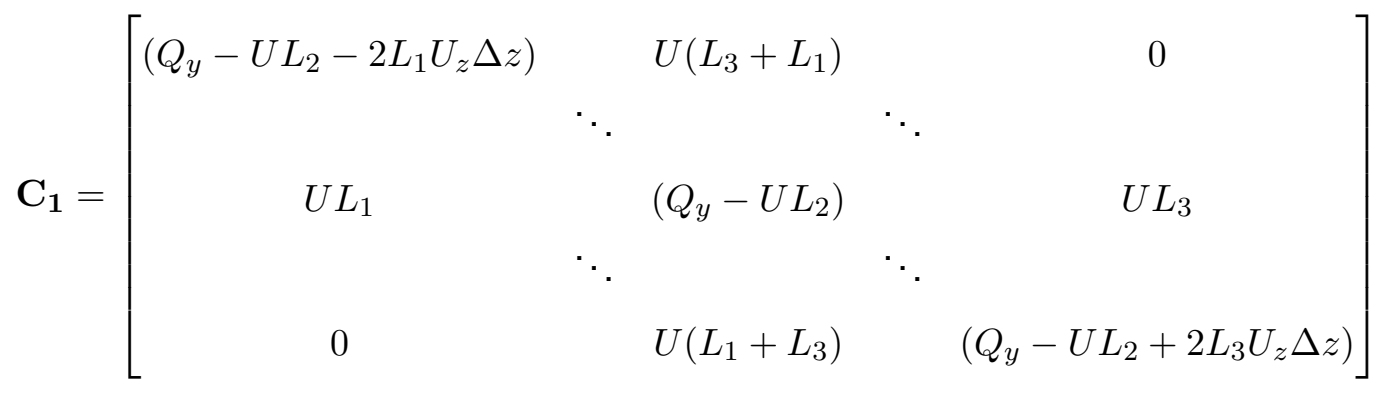

$$
\begin{aligned}
& \mathbf{C}_{2}=\left[\begin{array}{ccccc}
U L_{4} & & 0 & & 0 \\
& \ddots & & & \\
0 & & U L_{4} & & 0 \\
& & & \ddots & \\
0 & & 0 & & U L_{4}
\end{array}\right] \\
& \mathbf{0}=\left[\begin{array}{lllll}
0 & & 0 & & 0 \\
& \ddots & & \ddots & \\
0 & & 0 & & 0 \\
& \ddots & & \ddots & \\
0 & & 0 & & 0
\end{array}\right]
\end{aligned}
$$

Finally:

$$
\mathbf{A} \Phi=\left[\begin{array}{ccccc}
\mathbf{C}_{1} & \mathbf{C}_{2} & \mathbf{0} & \mathbf{0} & \mathbf{0} \\
\mathbf{C}_{2} & \mathbf{C}_{\mathbf{1}} & \mathbf{C}_{2} & \mathbf{0} & \mathbf{0} \\
\mathbf{0} & \ddots & \ddots & \ddots & \mathbf{0} \\
\mathbf{0} & \mathbf{0} & \mathbf{C}_{2} & \mathbf{C}_{1} & \mathbf{C}_{2} \\
\mathbf{0} & \mathbf{0} & \mathbf{0} & \mathbf{C}_{2} & \mathbf{C}_{1}
\end{array}\right]\left[\begin{array}{c}
\phi_{1} \\
\phi_{2} \\
\vdots \\
\phi_{N-2} \\
\phi_{N-1}
\end{array}\right]
$$




\section{Bibliography}

Belkin, I. M. and A. L. Gordon (1996). Southern ocean fronts from the greenwich meridian to tasmania. Journal of Geophysical Research: Oceans 101(C2), 3675-3696.

Bower, A. S. and W.-J. von Appen (2008). Interannual variability in the pathways of the north atlantic current over the mid-atlantic ridge and the impact of topography. Journal of Physical Oceanography 38(1), 104-120.

Boyer, T. P., J. I. Antonov, O. K. Baranova, C. Coleman, H. E. Garcia, A. Grodsky, D. R. Johnson, R. A. Locarnini, A. V. Mishonov, T. D. O’Brien, et al. (2013). World ocean database 2013.

Dewar, W. K. (1998). Topography and barotropic transport control by bottom friction. Journal of Marine Research 56(2), 295-328.

Gill, A., J. Green, and A. Simmons (1974). Energy partition in the large-scale ocean circulation and the production of mid-ocean eddies. Deep Sea Research and Oceanographic Abstracts 21(7), $499-528$.

Gordon, A. L., R. F. Weiss, W. M. Smethie, and M. J. Warner (1992). Thermocline and intermediate water communication between the south atlantic and indian oceans. Journal of Geophysical Research: Oceans 97(C5), 7223-7240.

Guinehut, S., A.-L. Dhomps, G. Larnicol, and P.-Y. Le Traon (2012). High resolution 3$\mathrm{d}$ temperature and salinity fields derived from in situ and satellite observations. Ocean Science 8(5), 845-857.

Hughes, C. W. (1995). Rossby waves in the southern ocean: A comparison of topex/poseidon altimetry with model predictions. Journal of Geophysical Research: Oceans 100(C8), 15933-15950. 
Hughes, C. W. (1996). The antarctic circumpolar current as a waveguide for rossby waves. Journal of Physical Oceanography 26(7), 1375-1387.

Johns, W. E. (1988). One-dimensional baroclinically unstable waves on the gulf stream potential vorticity gradient near cape hatteras. Dynamics of Atmospheres and Oceans 11(3), $323-350$.

Juliano, M. F. and M. L. G. R. Alves (2007). The atlantic subtropical front/current systems of azores and st. helena. Journal of Physical Oceanography 37(11), 2573-2598.

Kontoyiannis, H. (1997). Quasi-geostrophic modeling of mixed instabilities in the gulf stream near 73 w. Dynamics of Atmospheres and Oceans 26(3), $133-158$.

Krauss, W. (1986). The north atlantic current. Journal of Geophysical Research: Oceans 91(C4), 5061-5074.

Larnicol, G., S. Guinehut, M. Rio, M. Drevillon, Y. Faugere, and G. Nicolas (2006). The global observed ocean products of the french mercator project. Proceedings of 15 Years of progress in Radar Altimetry Symposium.

Mann, C. (1967). The termination of the gulf stream and the beginning of the north atlantic current. Deep Sea Research and Oceanographic Abstracts 14(3), 337 - 359.

Mayer, D. A. and R. H. Weisberg (1993). A description of coads surface meteorological fields and the implied sverdrup transports for the atlantic ocean from $30 \mathrm{~s}$ to $60 \mathrm{n}$. Journal of Physical Oceanography 23(10), 2201-2221.

Miranda, A. P., B. Barnier, and W. K. Dewar (1999). On the dynamics of the zapiola anticyclone. Journal of Geophysical Research: Oceans 104(C9), 21137-21149.

Mulet, S., M.-H. Rio, A. Mignot, S. Guinehut, and R. Morrow (2012). A new estimate of the global 3d geostrophic ocean circulation based on satellite data and in-situ measurements. Deep Sea Research Part II: Topical Studies in Oceanography 77-80, 70 - 81. Satellite Oceanography and Climate Change.

Munk, W. H. (1950). On the wind-driven ocean circulation. Journal of meteorology 7(2), 80-93. 
Pinardi, N. and A. R. Robinson (1987). Dynamics of deep thermocline jets in the polymode region. Journal of Physical Oceanography 17(8), 1163-1188.

Richardson, P. L. (1983). Eddy kinetic energy in the north atlantic from surface drifters. Journal of Geophysical Research: Oceans 88(C7), 4355-4367.

Richardson, P. L. (2007). Agulhas leakage into the atlantic estimated with subsurface floats and surface drifters. Deep Sea Research Part I: Oceanographic Research Papers 54(8), $1361-1389$.

Rocha, C. B., I. C. A. Silveira, B. M. Castro, and J. A. M. Lima (2014). Vertical structure, energetics, and dynamics of the brazil current system at 22s-28s. Journal of Geophysical Research: Oceans 119(1), 52-69.

Rodrigues, R. R., M. Wimbush, D. R. Watts, L. M. Rothstein, and M. Ollitrault (2010). Journal of Marine Research 68(6), 819-850.

Rossby, T. (1996). The north atlantic current and surrounding waters: At the crossroads. Reviews of Geophysics 34(4), 463-481.

Schmid, C., G. Siedler, and W. Zenk (2000). Dynamics of intermediate water circulation in the subtropical south atlantic. Journal of Physical Oceanography 30(12), 3191-3211.

Scott, R. B., J. A. Goff, A. C. N. Garabato, and A. J. G. Nurser (2011). Global rate and spectral characteristics of internal gravity wave generation by geostrophic flow over topography. Journal of Geophysical Research: Oceans 116(C9).

Smith, K. S. (2007). The geography of linear baroclinic instability in earth's oceans. Journal of Marine Research 65(5), 655-683.

Stommel, H. (1948). The westward intensification of wind-driven ocean currents. Eos, Transactions American Geophysical Union 29(2), 202-206.

Stramma, L. (1992). The south indian ocean current. Journal of Physical Oceanography 22(4), 421-430.

Stramma, L. and R. G. Peterson (1990). The south atlantic current. Journal of Physical Oceanography 20(6), 846-859. 
Sverdrup, H. U. (1947). Wind-driven currents in a baroclinic ocean; with application to the equatorial currents of the eastern pacific. Proceedings of the National Academy of Sciences 33(11), 318-326.

Talley, L. D. (2011). Descriptive physical oceanography: an introduction. Academic press.

Tomczak, M. and J. S. Godfrey (2013). Regional oceanography: an introduction. Elsevier.

Tulloch, R., J. Marshall, C. Hill, and K. S. Smith (2011). Scales, growth rates, and spectral fluxes of baroclinic instability in the ocean. Journal of Physical Oceanography 41(6), 1057-1076.

Weijer, W., M. E. Maltrud, W. B. Homoky, K. L. Polzin, and L. R. Maas (2015). Eddy-driven sediment transport in the argentine basin: Is the height of the zapiola rise hydrodynamically controlled? Journal of Geophysical Research: Oceans 120(3), 2096-2111. 